\title{
Palinomorfos del Holoceno en la cuenca alta del Río Lerma, Estado de MéXICO, MÉXICO
}

\author{
BeAtriz Ludlow-Wiechers ${ }^{1}$, LuCía Almeida-LeÑero ${ }^{1}$ y Yoko Sugiura ${ }^{2}$ \\ ${ }^{1}$ Departamento de Ecología y Recursos Naturales, Facultad de Ciencias, Universidad Nacional Autónoma de \\ México, Ciudad Universitaria, México 04510, D.F. Tel 5622-4920. Fax 5622-4828, correo-e: \\ blw@hp.fciencias.unam.mx, lal1@hp.fciencias.unam.mx \\ ${ }^{2}$ Instituto de Investigaciones Antropológicas, Universidad Nacional Autónoma de México, Ciudad Universitaria, \\ México 04510, D.F. Tel. 5622-9509. Fax 5665-2959, correo-e: yokos@servidor.unam.mx
}

\begin{abstract}
Resumen: En los sedimentos de la laguna de Chignahuapan, Estado de México, México, se identificaron 96 palinomorfos. Se encontraron 8 taxa correspondientes a algas, un género y una familia tanto para Equisetopsida como para Lycopodiopsida, y 6 familias con 10 géneros para Polypodiopsida. Las Pinophyta estuvieron representadas por tres familias con tres géneros, las Liliopsida por 10 familias y 13 géneros, y las Magnoliopsida por 44 familias con 50 géneros. En los bosques templados cercanos a la Laguna de Chignahuapan sobresalen los siguientes taxa: Abies, Alnus, Pinus, Quercus y Salix. Entre los elementos de la vegetación acuática y subacuática se presentan: Cyperus, Luzula, Myriophyllum, Typha y Schoenoplectus. La actividad del hombre se infiere por la presencia de Zea mays y Cucurbitaceae.
\end{abstract}

Palabras clave: paleoecología, Holoceno, laguna, cuenca del río Lerma, México.

\begin{abstract}
In sediments from Chignahuapan Lake, State of Mexico, Mexico, 96 palynomorphs were identified. Eight taxa were found for algae, one family with one genus both for Equisetopsida and Lycopodiopsida, and 6 families with 10 genera for Polypodiopsida. Pinophyta were represented by 3 families and 3 genera, Liliopsida by 10 families and 13 genera, and Magnoliopsida by 44 families and 50 genera. The temperate forest surrounding Chignahuapan lake included components such as Abies, Alnus, Pinus, Quercus and Salix; aquatic and subaquatic vegetation components such as Cyperus, Luzula, Myriophyllum, Typha and Schoenoplectus were also present. Human activity was inferred from the occurrence of Zea mays and Cucurbitaceae.
\end{abstract}

Key words: paleoecology, Holocene, Lake, Lerma Basin, Mexico.

$\mathbf{L}$ as investigaciones palinológicas permiten reconocer la evolución, la adaptación, la migración y la extinción de las especies vegetales, así como su biodiversidad actual y pasada, eventos estrechamente relacionados con los cambios climáticos (Van der Hammen, 1995). En México, este tipo de estudios se han realizado fundamentalmente en el Eje Volcánico Transmexicano (EVT) y en el sureste de México; éste último, junto con Centroamérica, conforman la región Caribe.

Los estudios paleoambientales en el EVT se inician con Bradbury (1970, 1971) y continúan con Heine (1973), Ohngemach y Straka (1978), González-Quintero y FuentesMata (1980), González-Quintero (1981, 1986) y Watts y Bradbury (1982), y más adelante con los de Bradbury (1986), Flores-Díaz (1986), Straka y Ohngemach (1989), XelhuantziLópez (1989, 1994, 1995), Metcalfe et al. (1991), LozanoGarcía et al. (1993), Lozano-García y Ortega-Guerrero (1994), Almeida-Leñero (1997) y Goman y Byrne (1998).
Entre los estudios paleoambientales en el sureste de México cabe destacar los de Hodell et al. (1995), de Curtis et al. (1996) y de Islebe et al. (1996).

Las ciénegas y lagos han constituido el medio insustituible para el desarrollo de poblaciones humanas. Los asentamientos más antiguos en las zonas lacustres para la cuenca de México están fechados con una antigüedad de 24,000 años AP (Mirambell, 1985). La cuenca alta del río Lerma (CAL) se caracteriza por la presencia de lagunas, actualmente desecadas o convertidas en ciénegas. La importancia de esta área fue advertida desde los tiempos de los cronistas (García-Quintana y López-Austin, 1989). Sugiura y McClung-de Tapia (1988) detectaron asentamientos antiguos para la zona de Metepec y Santa Cruz Azcapotzaltongo, del período Formativo, afirmando que la CAL fue la antigua morada de los Matlatzincas, Otomíes, Mazahuas y Mexicas.

Esta zona, que en otra época estaba cubierta de bosques y pantanos, actualmente asienta a la ciudad de Toluca. Las obras 
de captación del agua potable de manantiales y del subsuelo de las lagunas para abastecer a la ciudad de México han provocado que el área se haya convertido en un conjunto de ciénegas unidas por un canal o colector general del río Lerma (Sugiura et al., 1994).

El objetivo de esta investigación es identificar los palinomorfos presentes en los sedimentos del lago de Chignahuapan, Estado de México, para determinar los taxa que componían la vegetación en los bosques circundantes, en la zona lacustre, así como las plantas que han sido utilizadas por el hombre.

\section{Área de estudio}

Localización. El área de estudio forma parte de la cuenca del Alto Lerma, Estado de México. Se encuentra en la porción central de la República Mexicana, como parte del EVT (Macías et al., 1997). La zona estudiada (figura 1) ocupa una pequeña porción en el extremo sur de la cuenca del río LermaChapala-Santiago, Región Hidrológica 12, dentro de la subcuenca Almoloya-Otzolotepec y comprende la ciénega de Almoloya, la cual se encuentra en la mitad oriental de la subcuenca del mismo nombre (Secretaría de Programación y Presupuesto, 1983).

Geología. Forma parte de un arco continental andesítico cuyo origen se remonta al Terciario. Se compone de grandes estratos volcánicos entre los que destacan el Nevado de Toluca y otros pequeños volcanes monogenéticos, con lavas de edades entre 8,390 a 40,000 años AP (Bloomfield, 1975).

El volcán Nevado de Toluca tuvo una erupción hace ca. 24,000 años AP; posteriormente, hacia 11,600 años AP sobrevino una segunda erupción violenta que produjo gran cantidad de pómez dacítica conocida como la Tripartita de grano fino o Pómez Toluca Superior (PTS) que probablemente se extendió hacia la Cuenca de México (Bloomfield y Valastro, 1977). Esta capa es la misma encontrada en Tlapacoya con una fecha de 9,920 años AP (Flores-Díaz, 1986).

Arriba de la tripartita se encuentran suelos lacustres y la tefra de Tres Cruces con una fecha de 8,500 años AP (Newton y Metcalfe, 1999); a los 3,300 años AP se presenta otra tefra (Newton y Metcalfe, 1999).

Hidrología. La Cuenca del Lerma es el vaso lacustre más alto del ETV. El río Lerma nace en Almoloya del Río, atravesando el lecho de la planicie lacustre hacia el norte. El volumen y el caudal son de tal magnitud que el cauce es insuficiente para contenerlo, inundando las zonas cercanas y propiciando la formación de extensas zonas pantanosas y niveles freáticos someros que se filtran hacia la superficie. Éste es el origen de las tres lagunas o ciénegas que se extienden desde Texcalyacac al sur, hasta Tarasquillo al norte (Romero-Quiroz, 1987).

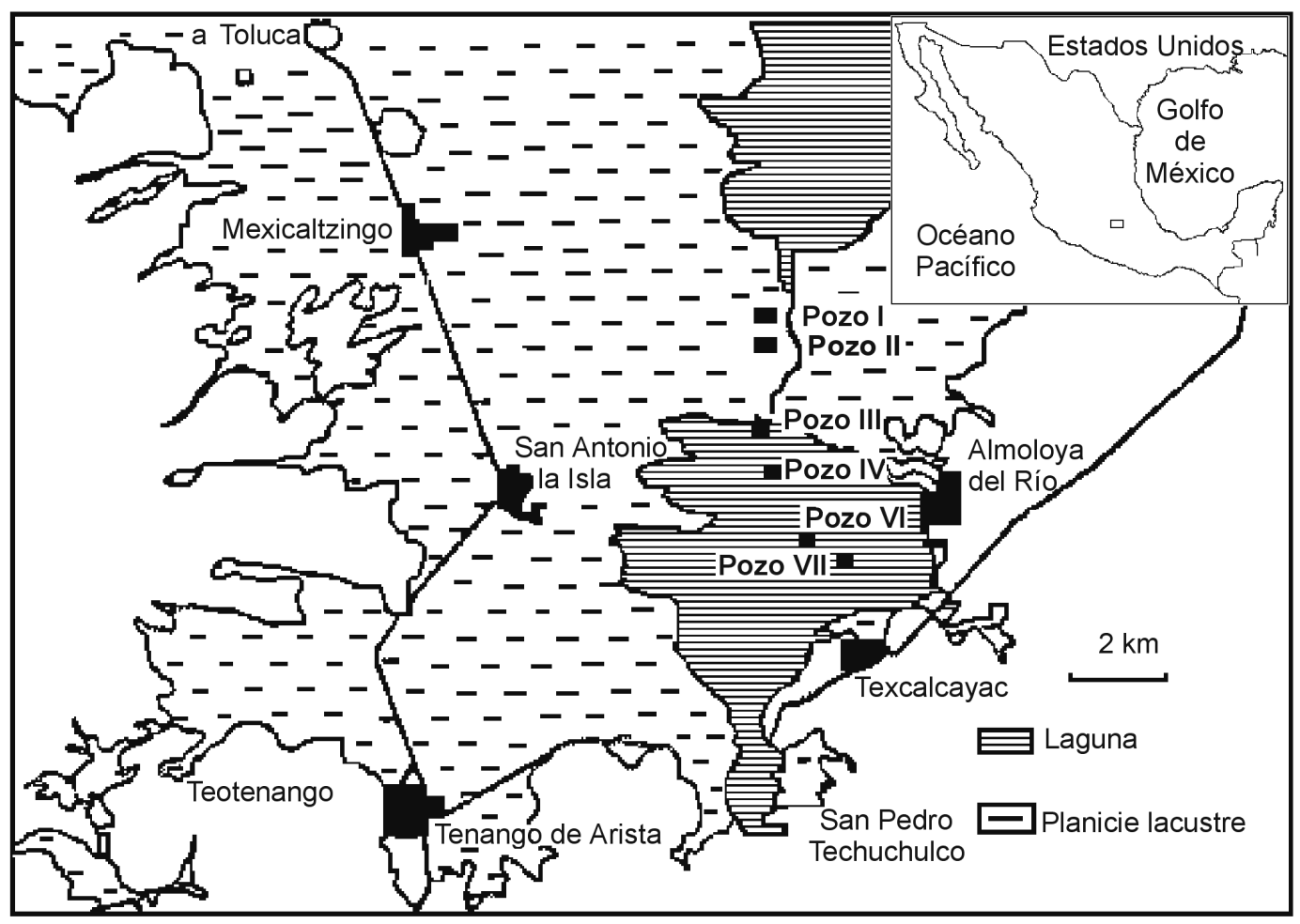

Figura 1. Localización del área de estudio. 
La laguna de Chignahuapan tiene $50 \mathrm{~km}^{2}$ de superficie; se extiende de Texcalyacac hasta Atenco, Edo. de México. Esta laguna era la más alta de las tres, que en escalones sucesivos descendían hacia el norte; las otras corresponden a las lagunas de Lerma y de Tarasquillo (Romero-Quiroz, 1987).

Climatología. La región de estudio se encuentra cercana a las estaciones climatológicas de Almoloya del Río y Atenco. La primera de ellas se localiza a los $19^{\circ} 10^{\prime}$ lat. $\mathrm{N}$ y $99^{\circ} 28^{\prime}$ long. $\mathrm{O}$, y a una altitud de $2,600 \mathrm{~m}$ s.n.m. Tiene un clima templado subhúmedo, con lluvias en verano $\mathrm{Cb}\left(\mathrm{w}_{2}\right)(\mathrm{w})\left(\mathrm{i}^{\prime}\right)$. La temperatura media anual es de $12^{\circ} \mathrm{C}$, fluctuando entre 8.4 y $14.4^{\circ} \mathrm{C}$. La precipitación pluvial anual es de $879.3 \mathrm{~mm}$.

La estación Atenco está localizada a los $19^{\circ} 11^{\prime}$ lat. N y $99^{\circ} 31^{\prime}$ long. O, a una altitud de 2,600 m s.n.m. Tiene un clima templado subhúmedo, $\mathrm{Cb}\left(\mathrm{w}_{0}\right)(\mathrm{w})\left(\mathrm{i}^{\prime}\right) \mathrm{g}$. La temperatura media anual es de $15.1^{\circ} \mathrm{C}$, fluctuando entre 11.2 y $17.9^{\circ} \mathrm{C}$. La precipitación pluvial anual es de $595.9 \mathrm{~mm}$.

Vegetación. En el Estado de México, Martínez y Matuda (1979) realizaron de 1952 a 1957 exploraciones botánicas en todas las regiones del estado.

La vegetación natural en el sur, el sureste y el oeste de la CAL está restringida a formaciones montañosas, donde destacan por su fisonomía los bosques de Pinus, Abies, Quercus y Pinus-Quercus, y hacia la planicie lacustre se encuentran los pastizales y la vegetación acuática (RamosVentura, 1999).

Bosque de Quercus.- Se han registrado encinares puros con un intervalo altitudinal de 2,400 a 2,600 m s.n.m., especialmente con Quercus castanea y $Q$. laurina, que se desarrollan en la parte norte de la cuenca. Al sur y suroeste en la región de Amoloya persisten manchones de encinares que colindan con bosques de Pinus-Quercus. Cerca de Texcalyacac existe una mancha de $Q$. crassifolia y $Q$. laurina. En las faldas del Nevado de Toluca los bosques de Quercus se encuentran debajo de la línea de los pinares.

Bosque de Pinus-Quercus.- Se localizan manchones muy reducidos en el norte y el sur de la cuenca que sugieren una transición.

Bosque de Pinus.- Los pinares se localizan al noreste, centro y suroeste de la cuenca. Los más representativos son los del volcán Nevado de Toluca, entre los 2,600 y 2,800 m s.n.m. Estas comunidades están formadas por Pinus rudis, mezclándose esporádicamente con especies de los géneros Arbutus, Clethra y Quercus (Ramos-Ventura, 1999). De los 2,800 a los 3,200 m s.n.m. se encuentran Pinus pseudostrobus y $P$. ayacahuite. De los 3,000 a 3,200 m s.n.m. predomina Pinus montezumae, que puede estar asociado a $P$. pseudostrobus (Sandoval-Basso, 1987). De los 3,500 a los 4,000 m s.n.m. dominan comunidades de Pinus hartwegii, que alcanzan el límite inferior de la vegetación alpina (VelaGálvez et al., 1976).
Bosque de Abies.- Se encuentra en las regiones montañosas del Nevado de Toluca; entre 3,000 y 3,500 m s.n.m. (VelaGálvez et al., 1976; Ramos-Ventura, 1999). En algunas zonas las masas puras están reducidas a manchones, principalmente en las laderas norte, oeste y sur.

Vegetación alpina.- Se localiza en el Nevado de Toluca y está formada por dos pisos altitudinales. El primero está presente en todas las vertientes con Calamagrostis tolucensis entre 4,000 y hasta 4,300 m s.n.m.; el segundo está formado por asociaciones de líquenes y comprende de 4,400 hasta 4,500 m s.n.m. en las laderas norte y sur (Villalpando-Barriga, 1968; González-Trapaga, 1986; Almeida-Leñero, 1997).

Pastizales.- Se desarrollan desde los 2,250 hasta los 4,300 m s.n.m. Los pastizales naturales están constituidos por los géneros Aristida, Bouteloua, Eragrostis, Hilaria, Lycurus, Muhlenbergia, Setaria, Sporobolus y Stipa. En zonas muy perturbadas se presentan pastizales secundarios o inducidos con Agrostis, Bouteloua, Briza, Buchloe, Cynodon, Mulhenbergia y Stipa (Ramos-Ventura, 1999).

Vegetación acuática.- Los trabajos más antiguos para la región son los de Herrera (1951), Rioja y Herrera (1951) y RamírezCantú y Herrera (1954); en ellos se identifican las plantas que componen la vegetación acuática y subacuática, clasificándola en: acuática, litoral, pradera húmeda y ruderal; además, mencionan como componentes desde las algas hasta las fanerógamas, incluyendo especies cultivadas.

La vegetación acuática vascular de la CAL fue estudiada para los diversos cuerpos de agua por Ramos-Ventura (1999); con base en el reconocimiento de formas de vida, este autor registra un total de 90 especies distribuidas en 45 géneros y 31 familias. Las familias con mayor representación son: Cyperaceae, Lemnaceae, Juncaceae, Poaceae y Potamogetonaceae.

Las plantas que más se han cultivado en la planicie lacustre son: Zea mays L. (maíz), Phaseolus vulgaris L. (frijol) y Vicia faba L. (haba introducida); además, se siembran: Lactuca sativa L. (lechuga), Daucus carota L. (zanahoria), Allium cepa L. (cebolla), Brassica oleracea var. botrytis L. (coliflor), Beta vulgaris var. rapa Dum. (betabel), Solanum tuberosum L. (papa), Coriandrum sativum L. (cilantro), Medicago sativa $\mathrm{L}$. (alfalfa), Cucurbita pepo L. (calabaza), Avena fatua spp. sativa (L.) Tell (avena). Como hierbas favorecidas por el hombre están Amaranthus hybridus L., Portulaca oleraceae L. y Brassica campestris L. (Rodríguez-Jiménez, 1967).

\section{Materiales y métodos}

Trabajo de campo. Para hacer un reconocimiento de la zona se realizaron recorridos de campo durante noviembre y diciembre de 1993 y enero y abril de 1994. Se definió una línea con dirección noroeste-sureste y noreste-suroeste de aproximadamente $10.5 \mathrm{~km}$ de longitud, a lo largo del cual se excavaron seis pozos, iniciando en el litoral norte y terminando en la parte central de la laguna de Chignahuapan 
Cuadro 1. Localización geográfica de los pozos estudiados en la Laguna de Chignahuapan, Edo. de México.

\begin{tabular}{|c|c|c|c|c|c|c|}
\hline $\begin{array}{c}\text { Número de pozo } \\
\text { y nombre }\end{array}$ & Latitud norte & Longitud oeste & Municipio & Localización & $\begin{array}{l}\text { Distancia entre } \\
\text { pozos }(\mathrm{km})\end{array}$ & Orientación \\
\hline Chign. I. Tejocote & $19^{\circ} 11^{\prime} 30^{\prime \prime}$ & $99^{\circ} 31^{\prime} 35^{\prime \prime}$ & $\begin{array}{c}\text { Santiago } \\
\text { Tianguistenco }\end{array}$ & $\begin{array}{l}\text { planicie } \\
\text { lacustre }\end{array}$ & & NS \\
\hline Chign. II. Bañito & $19^{\circ} 11^{\prime} 06^{\prime \prime}$ & $99^{\circ} 31^{\prime} 40^{\prime \prime}$ & $\begin{array}{l}\text { Santa Cruz } \\
\text { Atizapán }\end{array}$ & $\begin{array}{l}\text { planicie } \\
\text { lacustre }\end{array}$ & 0.75 & NS \\
\hline Chign. III. Tiradero & $19^{\circ} 10^{\prime} 15^{\prime \prime}$ & $99^{\circ} 31^{\prime} 45^{\prime \prime}$ & $\begin{array}{l}\text { Santa Cruz } \\
\text { Atizapán }\end{array}$ & $\begin{array}{l}\text { orilla de } \\
\text { laguna }\end{array}$ & 3.7 & NO-SE \\
\hline Chign. IV. Santa Cruz & $19^{\circ} 09^{\prime} 57^{\prime \prime}$ & $99^{\circ} 31^{\prime} 30^{\prime \prime}$ & $\begin{array}{l}\text { Santa Cruz } \\
\text { Atizapán }\end{array}$ & $\begin{array}{l}\text { dentro de } \\
\text { laguna }\end{array}$ & 1.4 & NO-SE \\
\hline $\begin{array}{l}\text { Chign. VI. Cabeza } \\
\text { de negro }\end{array}$ & $19^{\circ} 09^{\prime} 08^{\prime \prime}$ & $99^{\circ} 30^{\prime} 45^{\prime \prime}$ & $\begin{array}{l}\text { Santa Cruz } \\
\text { Atizapán }\end{array}$ & $\begin{array}{l}\text { dentro de } \\
\text { laguna }\end{array}$ & 4.0 & NO-SE \\
\hline Chign. VII. Musaraña & $19^{\circ} 08^{\prime} 36^{\prime \prime}$ & $99^{\circ} 31^{\prime} 15^{\prime \prime}$ & $\begin{array}{l}\text { Santa Cruz } \\
\text { Atizapán }\end{array}$ & $\begin{array}{l}\text { dentro de } \\
\text { laguna }\end{array}$ & 2.1 & NE-SO \\
\hline
\end{tabular}

Para el análisis palinológico se tomaron muestras de suelos sobre las paredes de los seis pozos estratigráficos que presentan profundidades variables de 100 a $250 \mathrm{~cm}$ aproximadamente; desde los estratos más modernos, hasta encontrar la capa de piedra pómez, conocida como la Tripartita, depositada hace 11,600 años AP (Bloomfield y Valastro, 1977).

En todos los pozos se empezaron a tomar las muestras a partir de los $20 \mathrm{~cm}$, considerando que estas áreas son actualmente zonas de cultivo, por lo que el suelo está removido. Las muestras se colectaron cada $5 \mathrm{~cm}$, se numeraron por profundidad y fueron guardadas en recipientes de plástico estériles, enjuagados con agua destilada. Se organizaron siguiendo la numeración de la colección de palinología depositada en la Facultad de Ciencias, Universidad Nacional Autónoma de México.

Preparación de las muestras. Para el procesamiento de las muestras se tomaron $20 \mathrm{~g}$ de sedimento; se agregó ácido clorhídrico al $10 \%$ por espacio de 12 a 18 horas para eliminar carbonatos y posteriormente la muestra fue lavada hasta obtener un $\mathrm{pH}$ neutro. Para eliminar los silicatos se agregó ácido fluorhídrico al 35\% entre 12 y 72 horas. Una vez disueltos los silicatos, se decantó la solución y se agregó agua destilada varias veces hasta neutralizar la muestra. Se agregó $\mathrm{KOH}$ al 5\% durante 40 min para eliminar ácidos húmicos. El material se lavó varias veces con agua destilada, se centrifugó a 1,500 RPM durante 3 min, se dejó decantar, enseguida se deshidrató dos veces con ácido acético glacial, siempre centrifugando a la misma velocidad y tiempo. Se acetolizaron las muestras con la técnica convencional de Erdtman (1960) y se elaboraron laminillas permanentes mediante el montaje del material en gelatina glicerinada con dimetilsulfóxido.
Identificación de los palinomorfos. Se analizaron 11 transectos en cada laminilla. En cada una de éstas se describieron e identificaron todos los palinomorfos mediante la comparación con la colección palinológica de referencia de la Facultad de Ciencias y con base en trabajos bibliográficos (Punt, 1976; Morbelli, 1977; Nilsson et al., 1977; Bassett et al., 1979; Clarke y Jones, 1980a, 1980b; Engel, 1980; Punt y Monna-Brands, 1980; Cronk y Clarke, 1981; Jones y Clarke, 1981; Punt y Reumer, 1981, SánchezMartínez, 1982; Tryon y Tryon, 1982; Ludlow-Wiechers $e t$ al., 1983; Blackmore, 1984; Blackmore y Heath, 1984 a, b; Hooghiemstra, 1984; Punt, 1984; Van Benthem et al., 1984; Christensen y Blackmore, 1988; Culhane y Blackmore, 1988; Furness, 1988; Punt y Langewis, 1988; Van Leeuwen et al., 1988; Boss y Punt, 1991, Clarke et al., 1991; Palacios-Chávez et al., 1991; Stafford, 1991; Arreguín et al., 1996; PalaciosChávez et al., 1996; Olvera, 1997; Arreguín et al., 2001; Ludlow-Wiechers y Palacios-Chávez, 2001).

Para la clasificación de las algas se siguió el criterio de Van den Hoek et al. (1995); para Equisetopsida, Lycopodiopsida y Polypodiopsida se siguieron los criterios propuestos para la Flora Mesoamericana por Moran y Riba (1995) y para angiospermas se siguieron los criterios de Cronquist (1981) y Dahlgren et al. (1985), respectivamente.

Los palinomorfos fueron fotografiados con un microscopio Olympus CH2E con cámara automática, empleando película Plus X pan; el revelado se hizo con HC-110, y se imprimieron en papel Kodabromide F-3.

Fechamiento de las muestras. Las muestras para datación se tomaron de sedimentos provenientes de las paredes de los pozos, escogiéndose las capas donde se observaba mayor contenido de materia orgánica. Los sedimentos fueron 
fechados en el Laboratorio de Prehistoria del INAH, determinándose la actividad de ${ }^{14} \mathrm{C}$ por medio de un espectómetro de centelleo líquido, de donde se obtuvieron fechas en años radiocarbono. De esta manera se encontró que las muestras más antiguas estuvieron en el Pozo Chign. IV, con un fechamiento de $9,788 \pm 146$ años AP a la profundidad de $142.5-137.5 \mathrm{~cm}$.

\section{Descripciones palinológicas}

\section{CHRYSOPHYTA/HETEROKONTOPHYTA} CHRYSOPHYCEAE

- Chrysophyceae (Lámina I, figura 1)

Estatocistos de $17 \mu \mathrm{m}$ de diámetro. Pared de $1 \mu \mathrm{m}$ de grosor; ornamentación granulada de $2 \mu \mathrm{m}$ de altura y $2 \mu \mathrm{m}$ de base (Pozo VII, muestra 19).

\section{EUGLENOPHYTA}

\section{EUGLENALES}

- Trachelomonas sp. (Lámina I, figura 2)

Tecas de hemicelulosa. Abertura con cuello (Pozo VII, muestra 19).

\section{CHLOROPHYTA}

\section{CHLOROPHYCEAE}

CHLOROCOCCALES

- Botryococcus sp. (Lámina I, figuras 3 y 4)

Colonias de $25 \mu \mathrm{m}$ de diámetro. Células ovoides con abundante gelatina, formando tetradas (Pozo VII, muestra 38; Pozo IV, muestra 19).

- Coelastrum 1 (Lámina I, figura 5)

Cenobios de células esféricas, $<10 \mu \mathrm{m}$. La pared presenta proyecciones polares. Pared $<1 \mu \mathrm{m}$; ornamentación psilada (Pozo VII, muestra 12).

- Coelastrum 2 (Lámina I, figura 6)

Cenobios de individuos de $15 \mu \mathrm{m}$ de diámetro. El cenobio compuesto por 16 células, dispuestas en la periferia, con proyecciones de la pared que las unen entre sí. También presentan proyecciones polares (Pozo VII, muestra 27).

- Oocystis sp. (Lámina I, figura 7)

Colonias maternas de individuos de $10 \mu \mathrm{m}$ de diámetro.

Se observa una pared materna común a las células.

\section{ZYGNEMATALES}

- Pediastrum sp.

Colonias de 18 células centrales y 16 periféricas, de $105 \mu \mathrm{m}$ de diámetro aproximadamente. Células isodiamétricas, de $20 \mu \mathrm{m}$ de diámetro aproximadamente, las periféricas con proyecciones apiculadas (Pozo VII, muestra 36).

Nota: No existe registro fotográfico.

- Spyrogira sp. (Lámina I, figura 8)

Esporas, eje mayor de 85 a $90 \mu \mathrm{m}$, eje menor de $42 \mu \mathrm{m}$. Pared de $1.5 \mu \mathrm{m}$ de grosor; ornamentación lisa (Pozo VII, muestra 17).
- Chlorophyceae/Xantophyceae/Cyanophyceae (¿?) (Lámina I, figura 9)

Colonias mucilaginosas, células dispersas sin orden. Vaina común con pigmento. Vaina individual en cada célula (Pozo II, muestra 4).

\section{EQUISETOPSIDA}

EQUISETACEAE

- Equisetum 1 (Lámina II, figura 10)

Esporas elípticas a triangulares, con el eje ecuatorial mayor de $50 \mu \mathrm{m}$ y el eje ecuatorial menor de $42 \mu \mathrm{m}$. Exina de $3 \mathrm{a}$ $4 \mu \mathrm{m}$ de grosor, sexina de $3 \mu \mathrm{m}$ y nexina de $1 \mu \mathrm{m}$ de espesor; ornamentación puntitegilada. Diporado, los poros en el polo proximal de $6 \mu \mathrm{m}$ de diámetro con anillo de $3 \mu \mathrm{m}$ de ancho (Pozo VI, muestra 46).

- Equisetum 2 (Lámina II, figura 11)

Esporas esferoidales, con los ejes de 50 a $55 \mu \mathrm{m}$. Exina de 2 a $3 \mu \mathrm{m}$ de grosor; ornamentación levemente verrugada. No se observa abertura (Pozo VII, muestra 32).

\section{LYCOPODIOPSIDA}

\section{SELAGINELLACEAE}

- Selaginella hoffmannii Hieron. (Lámina II, figuras 12 y 13) Microsporas triangulares circulares, eje ecuatorial de $20 \mu \mathrm{m}$, eje polar $22 \mu \mathrm{m}$, sin contar las espinas. Exina de 2 a $3 \mu \mathrm{m}$ de grosor; ornamentación equinada, espinas de 4 a $5 \mu \mathrm{m}$ de altura y 2 a $3 \mu \mathrm{m}$ de base, muy afiladas. Trilete (Pozo VII, muestra 19).

- Selaginella rupincola Underw. (Lámina II, figuras 14 y 15) Microsporas triangulares lobadas, eje ecuatorial de $27 \mu \mathrm{m}$ de diámetro. Exina de $1 \mu \mathrm{m}$ de grosor; ornamentación rugulada. Trilete, rayos de la abertura casi tan larga como la cara proximal (Pozo VII, muestra 31).

- Selaginella sp. (Lámina II, figuras 16 y 17)

Microsporas triangulares circulares, eje ecuatorial de $57 \mu \mathrm{m}$. Exina de 5 a $6 \mu \mathrm{m}$ de grosor; ornamentación equinada, espinas de 4 a $5 \mu \mathrm{m}$ de altura y 2 a $3 \mu \mathrm{m}$ de base. Trilete con margo de $2 \mu \mathrm{m}$ de grosor, un rayo de $25 \mu \mathrm{m}$, los otros dos rayos de $15 \mu \mathrm{m}$ de longitud (Pozo VII, muestra 24).

\section{POLYPODIOPSIDA}

CYATHEACEAE

- Lophosoria quadripinnata (J.F.Gmel) C.Chr. (Lámina II, figuras 18 y 19)

Esporas triangulares, el eje ecuatorial mayor de $65 \mu \mathrm{m}$, el eje ecuatorial menor de $60 \mu \mathrm{m}$. Exina de 4 a $7 \mu \mathrm{m}$ de grosor; ornamentación con perforaciones de dos tamaños de 1 a $2 \mu \mathrm{m}$ y de 7 a $9 \mu \mathrm{m}$ de diámetro. Trilete, con los radios llegando al ecuador (Pozo VII, muestra 24).

DENNSTAEDTIACEAE

- Dennstaedtia sp. (Lámina II, figuras 20 y 21)

Esporas triangulares, eje ecuatorial de $40 \mu \mathrm{m}$, eje polar de $25 \mu \mathrm{m}$. Exina de 1 a $2 \mu \mathrm{m}$ de grosor; ornamentación clavada y equinada. Clavas $2 \mu \mathrm{m}$ de altura y $1 \mu \mathrm{m}$ de base y equinas 
de 1 a $2 \mu \mathrm{m}$ de altura y $1 \mu \mathrm{m}$ de base, muy afiladas. Trilete, rayos de la abertura llegando al ecuador (Pozo VI, muestra 46). DRYOPTERIDACEAE

- Ctenitis sp. (Lámina III, figuras 22 y 23)

Esporas elípticas, el eje ecuatorial mayor de $44 \mu \mathrm{m}$, el eje ecuatorial menor de $34 \mu \mathrm{m}$. Exina de 2 a $3 \mu \mathrm{m}$ de grosor; ornamentación equinada, espinas de 1 a $2.5 \mu \mathrm{m}$ de altura. Monolete (Pozo VII, muestra 29).

- Dryopteridaceae 1 (Lámina III, figuras 24 y 25)

Esporas elípticas. Eje mayor de 110 a $120 \mu \mathrm{m}$, eje menor de 65 a $70 \mu \mathrm{m}$. Exina de 2 a $3 \mu \mathrm{m}$ de grosor; ornamentación reticulada. Monolete (Pozo IV, muestra 23).

- Dryopteridaceae 2 (Lámina III, figuras 26 y 27)

Esporas elípticas, eje mayor de $45 \mu \mathrm{m}$, eje menor de $35 \mu \mathrm{m}$. Exina de $2 \mu \mathrm{m}$ de grosor. Perisporio muy desarrollado, de aspecto ondulado a verrugado. Monolete (Pozo VII, muestra 30; pozo II, muestra 3).

PLAGIOGYRIACEAE

- Plagiogyria semicordata (C.Presl.) H.Christ (Lámina III, figuras 28 y 29)

Esporas triangulares, el eje ecuatorial mayor de $55 \mu \mathrm{m}$, eje ecuatorial menor de $45 \mu \mathrm{m}$. Exina de $2 \mu \mathrm{m}$ de grosor; ornamentación con verrugas de 2 a $5 \mu \mathrm{m}$ de diámetro y 2 a $3 \mu \mathrm{m}$ de altura. Trilete, los rayos llegan al ecuador (Pozo VII, muestra 26).

POLYPODIACEAE

- Campyloneurum angustifolium (Sw.) Fée (Lámina IV, figuras 30 y 31 )

Esporas elípticas, eje mayor de $85 \mu \mathrm{m}$, eje menor de $65 \mu \mathrm{m}$. Exina de 7 a $9 \mu \mathrm{m}$ de grosor; ornamentación con verrugas de 5 a $8 \mu \mathrm{m}$ de diámetro y 2 a $5 \mu \mathrm{m}$ de altura. Monolete (Pozo VII, muestra 15).

- Phlebodium araneosum (M.Martens et Galeotti) Mickel et Beitel (Lámina IV, figura 32)

Esporas elípticas, eje mayor de $63 \mu \mathrm{m}$, eje menor de $50 \mu \mathrm{m}$. Exina de $6 \mu \mathrm{m}$ de grosor, sexina de $5 \mu \mathrm{m}$ y nexina menor de $1 \mu \mathrm{m}$ de grosor; ornamentación con verrugas irregulares de 5 a $10 \mu \mathrm{m}$ de diámetro y 3 a $5 \mu \mathrm{m}$ de altura. Monolete (Pozo VII, muestra 31).

- Polypodium 1 (Lámina IV, figuras 33 y 34)

Esporas elípticas, eje mayor de $43 \mu \mathrm{m}$, eje menor de $28 \mu \mathrm{m}$. Exina de 2 a $3 \mu \mathrm{m}$ de grosor; ornamentación con verrugas de tamaño variable de 1 a $3 \mu \mathrm{m}$ de diámetro y 1 a $2 \mu \mathrm{m}$ de altura. Monolete (Pozo IV, muestra 19).

- Polypodium 2 (Lámina IV, figura 35)

Esporas elípticas, el eje mayor y eje menor no se pudieron determinar porque estaba rota la espora. Exina de $4 \mu \mathrm{m}$ de grosor, sexina más gruesa que nexina; ornamentación levemente verrugada. Monolete (Pozo VII, muestra 32).

- Polypodium 3 (Lámina IV, figura 36)

Esporas elípticas, el eje ecuatorial mayor de $105 \mu \mathrm{m}$, el eje ecuatorial menor de $60 \mu \mathrm{m}$. Exina de $5 \mu \mathrm{m}$ de grosor; ornamentación levemente fosulada. Monolete (Pozo VI, muestra 46).

\section{PTERIDACEAE}

- Cheilanthes farinosa (Forssk.) Kaulf. (Lámina V, figura 37) Esporas esféricas, el eje ecuatorial de $40 \mu \mathrm{m}$. Exina de $4 \mu \mathrm{m}$ de grosor. Perisporio muy desarrollado, de ornamentación rugulada-gemada. Trilete (Pozo VII, muestra 29).

- Cheilanthes sinuata (Lag. ex Sw.) Domin (Lámina V, figuras 38 y 39 )

Esporas triangulares, en vista polar el eje ecuatorial de $56 \mu \mathrm{m}$. Exina de 3 a $4 \mu \mathrm{m}$ de grosor; ornamentación microequinada, espinas de $2 \mu \mathrm{m}$ de altura y $1 \mu \mathrm{m}$ en la base. Trilete, con labio, de $10 \mu \mathrm{m}$ de ancho en la parte central y angostándose en los extremos, hasta hacerse ampuliforme (Pozo II, muestra 3).

\section{INDETERMINADAS}

- Espora 1 (Lámina V, figura 40)

Espora elíptica, el eje ecuatorial mayor de $60 \mu \mathrm{m}$, el eje ecuatorial menor de $45 \mu \mathrm{m}$. Exina de $1 \mu \mathrm{m}$ de grosor; ornamentación levemente areolada. No se observa abertura (Pozo VII, muestra 19).

- Espora monolete 1 (Lámina V, figura 41)

Espora elíptica, el eje ecuatorial mayor de $59 \mu \mathrm{m}$, el eje ecuatorial menor de $33 \mu \mathrm{m}$. Exina de $2.5 \mu \mathrm{m}$ de grosor; ornamentación levemente areolada, con escasas granulaciones. Monolete, labio de 1 a $2 \mu \mathrm{m}$ de grosor (Pozo VII, muestra 30).

- Espora monolete 2 (Lámina V, figuras 42 y 43) Espora elíptica, el eje ecuatorial mayor de $32 \mu \mathrm{m}$, el eje ecuatorial menor de $20 \mu \mathrm{m}$. Exina de $1 \mu \mathrm{m}$ de grosor; ornamentación verrugada. Monolete (Pozo II, muestra 8).

- Espora monolete 3 (Lámina V, figuras 44 y 45)

Espora elíptica, el eje ecuatorial mayor de $25 \mu \mathrm{m}$, el eje ecuatorial menor de $15 \mu \mathrm{m}$. Exina de 1.5 a $2 \mu \mathrm{m}$ de grosor; ornamentación microrrugulada. Perisporio de 3 a $4 \mu \mathrm{m}$ de espesor. Monolete (Pozo VI, muestra 46).

- Espora monolete 4 (Lámina V, figuras 46 y 47)

Espora elíptica, el eje ecuatorial mayor de $65 \mu \mathrm{m}$, el eje ecuatorial menor de $34 \mu \mathrm{m}$. Exina de $2 \mu \mathrm{m}$ de grosor. Perisporio equinado, espinas romas. Monolete (Pozo II, muestra 3).

- Espora trilete 1 (Lámina VI, figuras 48 y 49)

Esporas triangulares de $15 \mu \mathrm{m}$ de diámetro. Exina menor a $1 \mu \mathrm{m}$ de grosor. Perisporio de $3 \mu \mathrm{m}$ de espesor. Trilete, rayos de la abertura llegando al ecuador (Pozo VI, muestra 46).

- Espora trilete 2 (Lámina VI, figuras 50 y 51)

Esporas elípticas, eje ecuatorial mayor de $25 \mu \mathrm{m}$, eje ecuatorial menor de $20 \mu \mathrm{m}$. Exina de $2 \mu \mathrm{m}$ de grosor; ornamentación levemente microreticulada. Trilete, uno de los radios de la abertura más largo que los otros dos (Pozo II, muestra 7).

- Espora trilete 3 (Lámina VI, figura 52) Esporas triangulares, eje ecuatorial mayor de $60 \mu \mathrm{m}$, eje ecuatorial menor de $50 \mu \mathrm{m}$. Exina de 2 a $3 \mu \mathrm{m}$ de grosor; ornamentación perforada. Perforaciones de 1 a $3 \mu \mathrm{m}$ de 
espesor. Trilete (Pozo VII, muestra 4).

Nota: probablemente se puede asignar a Lycopodium.

- Espora trilete 4 (Lámina VI, figura 53)

Esporas triangulares, el eje ecuatorial 45 a $55 \mu \mathrm{m}$. Exina de $2 \mu \mathrm{m}$ de grosor; ornamentación microrreticulada. Trilete, con labio, de $1 \mu \mathrm{m}$ de ancho, los rayos llegan al ecuador (Pozo VII, muestra 29).

Nota: L. Quiroz (com. pers.) sugiere que es un grano de polen sincolpado; por otra parte, R. Villanueva (com. pers.) la considera como una probable Sapindaceae.

- Espora trilete 5 (Lámina VI, figura 54)

Esporas elípticas, el eje ecuatorial mayor de $75 \mu \mathrm{m}$, el eje ecuatorial menor de $60 \mu \mathrm{m}$. Exina de $2 \mu \mathrm{m}$ de grosor; ornamentación levemente verrugada, verrugas de 2 a $5 \mu \mathrm{m}$ en la base y 2 a $5 \mu \mathrm{m}$ de altura. Trilete (Pozo VII, muestra 17).

- Espora trilete 6 (Lámina VI, figura 55)

Esporas triangulares, el eje ecuatorial mayor de $65 \mu \mathrm{m}$, el eje ecuatorial menor de $60 \mu \mathrm{m}$. Exina de $5 \mu \mathrm{m}$ de grosor; ornamentación psilada. Trilete con labio de $2 \mu \mathrm{m}$ de ancho, los radios llegan al ecuador (Pozo VII, muestra 30 ).

\section{PINOPHYTA}

\section{ABIETACEAE}

- Abies sp. (Lámina VII, figuras 56 y 57)

Granos de polen disacados, generalmente con una constricción entre el cuerpo y los sacos. El cuerpo del grano de $140 \mu \mathrm{m}$ de largo y $100 \mu \mathrm{m}$ de ancho. Los sacos aéreos de $80 \times 110-110 \mu \mathrm{m}$. Exina en la zona dorsal del cuerpo $10 \mu \mathrm{m}$, en los extremos $5 \mu \mathrm{m}$; ornamentación escrobiculada en el cuerpo, perreticulada en los sacos aéreos. Monosulcado (Pozo VII, muestra 25).

CUPRESSACEAE/TAXODIACEAE

- CuTaJu (Lámina VII, figura 58)

Granos de polen esféricos, de 27-45 × 22-37 um de diámetro. Exina de 1 a1.5 $\mu \mathrm{m}$ de grosor. No se distingue estratificación de la exina; ornamentación psilada con pequeñas microverrugas aisladas. ¿Inaperturado o monoporado? (Pozo VII, muestra 26).

\section{PINACEAE}

- Pinus sp. (Lámina VII, figuras 59, 60 y 61)

Granos de polen disacados, generalmente con una constricción ente el cuerpo y los sacos. El cuerpo del grano de $61 \mu \mathrm{m}$ de altura y $70 \mu \mathrm{m}$ de longitud. Los sacos aéreos de $60 \times 56 \mu \mathrm{m}$ de diámetro. Exina en la zona dorsal del cuerpo de $3 \mu \mathrm{m}$ de grosor; sexina de $2 \mu \mathrm{m}$ y nexina de $1 \mu \mathrm{m}$ de ancho; ornamentación escrobiculada en el cuerpo, perreticulada en los sacos aéreos. Monosulcado (Pozo VII, muestras 20 y 36 ).

\section{MAGNOLIOPHYTA \\ LILIOPSIDA}

ALISMATACEAE

- Sagittaria sp. (Lámina VIII, figuras 62 y 63)

Granos de polen esféricos, de 35 a $45 \mu \mathrm{m}$ de diámetro.
Exina de $3 \mu \mathrm{m}$ de grosor; ornamentación equinada, espinas de 1 a $1.5 \mu \mathrm{m}$ de altura y $0.8 \mu \mathrm{m}$ de ancho. No se observaron aberturas (Pozo VII, muestra 22).

\section{BROMELIACEAE}

- Bromeliaceae 1 (Lámina VIII, figuras 64 y 65) Granos de polen elipsoides, 52-60 × 32-40 $\mu \mathrm{m}$. Exina de $3 \mu \mathrm{m}$ de grosor, sexina $2 \mu \mathrm{m}$, nexina $1 \mu \mathrm{m}$; ornamentación perreticulada, columelas en el retículo, lúmenes de 1 a $3 \mu \mathrm{m}$ y muros de $1 \mathrm{a} 2 \mu \mathrm{m}$; heterobrocado. Monosulcado (Pozo VI, muestra 46).

- Bromeliaceae 2 (Lámina VIII, figuras 66 y 67)

Granos de polen elipsoidales, 75-80 × $32 \mu \mathrm{m}$. Exina de $3 \mu \mathrm{m}$ de grosor, sexina más gruesa que la nexina; ornamentación perreticulada, lúmenes de 1 a $3 \mu \mathrm{m}$ de diámetro y muros de $1 \mu \mathrm{m}$ de ancho, columelas libres en los lúmenes. Monosulcado (Pozo IV, muestra 17).

\section{COMMELINACEAE}

- Commelinaceae (Lámina X, figuras 80 y 81). Granos de polen elípticos, de 35-42 × $25 \mu \mathrm{m}$. Exina de 3 a $4 \mu \mathrm{m}$ de grosor, sexina de 2 a $3 \mu \mathrm{m}$ y nexina de $1 \mu \mathrm{m}$; intectada pilada, pilas de $2 \mu \mathrm{m}$ de altura y $2 \mu \mathrm{m}$ de ancho en la base. Monosulcado, abertura tan larga como el eje ecuatorial mayor (Pozo IV, muestras 20 y 22).

\section{CYPERACEAE}

- Cyperus 1 (Lámina IX, figuras 68, 69 y 70) Granos de polen esféricos a piriformes, 30-40 x 30-40 $\mu \mathrm{m}$. Exina de 1 a $2 \mu \mathrm{m}$ de grosor; ornamentación puntitegilada a areolada. Periporado, poros mal definidos de $¿ 5$ a 6 poros? Otras veces aberturas lagunares, en número de cuatro (Pozo IV, muestra 47; Pozo VI, muestra 42).

Nota: se observaron varios tipos morfológicos con variaciones en las aberturas, algunas poradas, otras lagunares, por lo que algunos son parecidos a Carex, otros a Cyperus, pero se prefirió agruparlos en el morfotipo de Cyperus, por ser el más semejante.

- Cyperus 2 (Lámina IX, figuras 71, 72, 73 y 74)

Granos de polen esféricos a cuadrangulares, 40-50 x 40$50 \mu \mathrm{m}$. Exina de 1 a $3 \mu \mathrm{m}$ de grosor; ornamentación ligeramente verrugada a fuertemente verrugada, otras veces tectada puntitegilada. Monoporado, con tres lagunas muy difíciles de observar, a veces sólo se observan las cuatro lagunas sin poro (Pozo II, muestra 2; Pozo VII, muestra 19).

Nota: se observaron varios tipos morfológicos, algunas poradas, otros lagunares, algunos parecidos a Eleocharis, otros a Cyperus, pero se prefirió agruparlos en el morfotipo de Cyperus por ser el más semejante.

- Schoenoplectus 1 (Lámina IX, figuras 75 y 76) Granos de polen esféricos a cuadrangulares, 60-70 x 40$50 \mu \mathrm{m}$. Exina de 1 a $2 \mu \mathrm{m}$ de grosor; ornamentación ligeramente verrugada a fuertemente verrugada, algunas veces escrobiculada. Monoporado, con tres lagunas muy difíciles de observar, a veces sólo se observan las cuatro lagunas o más, sin poro. Otras veces se observa un poro mal definido (Pozo VII, muestras 19 y 21). 
- Schoenoplectus 2 (Lámina X, figuras 77, 78 y 79) Granos de polen piriformes, de 65-75 x 44-48 $\mu$ m. Exina de $2 \mu \mathrm{m}$ de grosor; ornamentación escrobiculada. Monoporado, con tres a cuatro lagunas, el poro con gemas de $1 \mu \mathrm{m}$ de diámetro (Pozo VII, muestra 22; pozo II, muestra 2).

\section{ERIOCAULACEAE}

- Eriocaulon sp. (Lámina X, figuras 82 y 83)

Granos de polen, elípticos, de 25-35 x 22-27 $\mu$ m. Exina de $2 \mu \mathrm{m}$ de grosor, sexina más gruesa que nexina; tectada equinada, espinas triangulares, iguales o menores a $1 \mu \mathrm{m}$ de altura y $1 \mu \mathrm{m}$ de base. Abertura espiralada (Pozo VII, muestras 17 y18).

JUNCACEAE

- aff. Luzula sp. (Lámina X, figura 84)

Granos de polen agrupados en tétradas tetrahédricas, de 50 x $40 \mu \mathrm{m}$ de diámetro. Exina de 1 a $2 \mu \mathrm{m}$ de grosor, no se diferencia sexina de la nexina; ornamentación puntitegilada. No se observan aberturas (Pozo VII, muestra 16).

- aff. Juncaceae 1 (Lámina X, figura 85) Granos de polen agrupados en tétradas; no se diferencían claramente las monadas, tétradas esferoidales de 30-37 x 30-35 $\mu \mathrm{m}$ de diámetro. Exina de $2 \mu \mathrm{m}$ de grosor, sexina de igual espesor que la nexina; ornamentación puntitegilada. No se observan aberturas, con líneas de dehiscencia (Pozo VII, muestra 17).

- aff. Juncaceae 2 (Lámina X, figura 86)

Granos de polen agrupados en tétradas, no hay diferencia clara entre las monadas, tétradas elípticas a esferoidales de $50 \times 48 \mu \mathrm{m}$ de diámetro. Exina de $1.5 \mu \mathrm{m}$ de grosor, sexina y nexina de igual espesor; ornamentación de psilada a ligeramente puntitegilada. No se observan aberturas, con líneas de dehiscencia (Pozo VI, muestra 24).

LILIACEAE

- Liliaceae 1 (Lámina XI, figura 87)

Granos de polen elípticos, eje ecuatorial mayor de 40 a $45 \mu \mathrm{m}$, eje ecuatorial menor de 25 a $30 \mu \mathrm{m}$ en vista polar. Exina de $3 \mu \mathrm{m}$ de grosor, sexina de $2 \mu \mathrm{m}$, nexina de $1 \mu \mathrm{m}$; ornamentación microrreticulada. Monosulcado (Pozo VII, muestra 27).

- Liliaceae 2 (Lámina XI, figuras 88 y 89)

Granos de polen elípticos, eje ecuatorial mayor de $35 \mu \mathrm{m}$, eje ecuatorial menor de $26 \mu \mathrm{m}$ en vista polar. Exina de $2 \mu \mathrm{m}$ de grosor, sexina más gruesa que la nexina; tectada verrugada. Monosulcado (Pozo VII, muestra 14).

\section{POACEAE}

- Poaceae 1 (Lámina XI, figura 90)

Granos de polen esferoidales, de 23 x 25-28 um de diámetro. Exina de $2 \mu \mathrm{m}$ de grosor, sexina más gruesa que la nexina; tectada ligeramente areolada. Monoporado, poro de $2 \mu \mathrm{m}$ de diámetro, con anillo de $2 \mu \mathrm{m}$ de ancho (Pozo VI, muestra 46).

- Poaceae 2 (Lámina XI, figura 91)

Granos de polen esferoidales, de $30 \mu \mathrm{m}$ de diámetro. Exina de $2 \mu \mathrm{m}$ de grosor, sexina más gruesa que la nexina; tectada ligeramente areolada. Monoporado, poro de $2 \mu \mathrm{m}$ de diámetro, con anillo de 2 a $5 \mu \mathrm{m}$ de ancho (Pozo VII, muestra 18).

- Poaceae 3 (Lámina XI, figura 92)

Granos de polen esferoidales, de $40 \mu \mathrm{m}$ de diámetro. Exina de $2 \mu \mathrm{m}$ de grosor, sexina más gruesa que la nexina; tectada ligeramente areolada. Monoporado, poro de 4 a $5 \mu \mathrm{m}$ de diámetro, con anillo de 2 a $5 \mu \mathrm{m}$ de ancho (Pozo VII, muestra 32).

- Poaceae 4 (Lámina XI, figura 93)

Granos de polen esferoidales, de $50 \mu \mathrm{m}$ de diámetro. Exina de $2 \mu \mathrm{m}$ de grosor, sexina más gruesa que la nexina; tectada ligeramente areolada. Monoporado, poro de $4 \mu \mathrm{m}$ de diámetro, con anillo de 3 a $4 \mu \mathrm{m}$ de ancho (Pozo VII, muestra 18).

- Poaceae 5 (Lámina XI, figura 94)

Granos de polen esferoidales, de $60 \mu \mathrm{m}$ de diámetro. Exina de $2 \mu \mathrm{m}$ de grosor, sexina más gruesa que la nexina; tectada ligeramente escabrada. Monoporado, poro de 4 a $5 \mu \mathrm{m}$ de diámetro, con anillo de 4 a $6 \mu \mathrm{m}$ de ancho (Pozo VII, muestra 17).

- Poaceae 6 (Lámina XI, figura 95)

Granos de polen esferoidales, de $80 \mu \mathrm{m}$ de diámetro. Exina de $2 \mu \mathrm{m}$ de grosor, sexina más gruesa que la nexina; tectada psilada a ligeramente escabrada. Monoporado, poro de 5 a $6 \mu \mathrm{m}$ de diámetro, con anillo de 3 a $6 \mu \mathrm{m}$ de ancho (Pozo VII, muestra 17).

- Zea mays L. (Lámina XI, figuras 96 y 97)

Granos de polen esferoidales, de 100 × $90 \mu \mathrm{m}$ de diámetro. Exina de $2 \mu \mathrm{m}$ de grosor, sexina más gruesa que la nexina; tectada ligeramente escabrada. Monoporado, poro muy difícil de observar (Pozo II, muestra 3).

\section{PONTEDERIACEAE}

- Heteranthera 1 (Lámina XII, figura 98)

Granos de polen esféricos, eje ecuatorial mayor de 100 a $120 \mu \mathrm{m}$, eje ecuatorial menor de 50 a $72 \mu \mathrm{m}$ en vista ecuatorial lateral. Exina de 5 a $6 \mu \mathrm{m}$ de grosor, sexina de 4 a $5 \mu \mathrm{m}$ y nexina de 1 a $2 \mu \mathrm{m}$ de espesor; ornamentación intectada verrugada, verrrugas de 3 a $10 \mu \mathrm{m}$ de diámetro, de forma irregular. ¿Disulcado? (Pozo VII, muestra 18).

- Heteranthera 2 (Lámina XII, figura 99)

Granos de polen elípticos a elíptico cóncavo-convexos, eje ecuatorial mayor de $50 \mu \mathrm{m}$, eje ecuatorial menor de $32 \mu \mathrm{m}$ en vista polar. Exina de $2 \mu \mathrm{m}$ de grosor, sexina y nexina de igual espesor; fuertemente verrugada, verrugas de 1 a $3 \mu \mathrm{m}$ de diámetro y $1 \mu \mathrm{m}$ de altura. Disulcado (Pozo VI, muestra 38).

- Heteranthera 3 (Lámina XII, figura 100)

Granos de polen elípticos a elíptico cóncavo-convexos, eje ecuatorial mayor de 36 a $40 \mu \mathrm{m}$, eje ecuatorial menor de $24 \mu \mathrm{m}$ en vista polar. Exina de $2 \mu \mathrm{m}$ de grosor, sexina y nexina de igual espesor; levemente verrugada. Disulcado (Pozo IV, muestra 19).

- Heteranthera 4 (Lámina XII, figura 101) Granos de polen elípticos a elíptico cóncavo-convexos. Eje 
ecuatorial mayor de $24 \mu \mathrm{m}$, eje ecuatorial menor de $15 \mu \mathrm{m}$. Exina de $1 \mu \mathrm{m}$ de grosor; clavada, clavas de $1 \mu \mathrm{m}$ de altura y $1 \mu \mathrm{m}$ de base. Disulcado (Pozo VI, muestra 42).

\section{POTAMOGETONACEAE}

- Potamogeton sp. (Lámina XII, figuras 102 y 103)

Granos de polen, esféricos, 25-30 x $30 \mu \mathrm{m}$ de diámetro. Exina de $2 \mu \mathrm{m}$ de grosor, sexina y nexina de igual espesor; reticulada, muros menores a $1 \mu \mathrm{m}$, lúmenes mayores de $1 \mu \mathrm{m}$. Inaperturado (Pozo VII, muestra 26).

\section{THYPHACEAE}

- Thypha sp. (Lámina XII, figuras 104 y 105)

Granos de polen agrupados en tétradas tetrahédricas y ¿tetragonales o cuadrangulares? Se encontraron mónadas de diferente tamaño, $25 \times 25 \mu \mathrm{m}$ y $50 \times 55 \mu \mathrm{m}$ de diámetro. Exina de 2 a $4 \mu \mathrm{m}$ de grosor, sexina más gruesa que la nexina; ornamentación reticulada, muros de $1 \mu \mathrm{m}$ de ancho y lúmenes de $1 \mu \mathrm{m}$ de diámetro. Monoporado, poro de $3 \mathrm{a}$ $4 \mu \mathrm{m}$ de diámetro (Pozo VII, muestras 23 y 32).

Nota: Se presentan dos especies de Typha que se pueden diferenciar por al tamaño de las mónadas.

\section{MAGNOLIOPSIDA}

\section{ACANTHACEAE}

- Acanthaceae (Lámina XIII, figura 106) Granos de polen subprolatos, eje polar de $30 \mu \mathrm{m}$, eje ecuatorial de $25 \mu \mathrm{m}$ en vista ecuatorial. $\mathrm{P} / \mathrm{E}=1.2$. Exina de $1 \mu \mathrm{m}$ de grosor, no se distinguen sexina y nexina; tectada puntitegilada, superficialmente dividida en bandas separadas por una fisura de más o menos $1 \mu \mathrm{m}$. Tricolporado, con margo bandeado de $5 \mu \mathrm{m}$ de ancho, psilado, llegando hasta los polos; membrana del colpo longitudinal lisa, la endoabertura cubierta por gránulos (Pozo VII, muestra 19).

\section{AMARANTHACEAE}

- Althernantera sp.

Granos de polen esferoidales, eje polar de $20 \mu \mathrm{m}$, eje ecuatorial de $22 \mu \mathrm{m}$ en vista ecuatorial. $\mathrm{P} / \mathrm{E}=0.9$. Exina de 0.5 a $2 \mu \mathrm{m}$ de grosor, no se distinguen sexina y nexina; tectada microequinada, lofado polihédrico, las bandas de $3 \mu \mathrm{m}$ de ancho. Periporado, aproximadamente 8 a 12 poros, restringidos a las lagunas (Pozo IV, muestra 6).

Nota: no existe registro fotográfico.

\section{APIACEAE}

\section{- Berula erecta (Lámina XIII, figuras 107 y 108)}

Granos de polen prolados, eje polar de $28 \mu \mathrm{m}$, eje ecuatorial de $15 \mu \mathrm{m}$ en vista ecuatorial. $\mathrm{P} / \mathrm{E}=1.9$. Exina de $3 \mu \mathrm{m}$ de grosor, sexina más gruesa que nexina; ligeramente microrreticulada a microestriada. Tricolporado, colpo longitudinal muy largo y angosto, con costa colpi. Endoabertura lalongada de 5 a $6 \mu \mathrm{m}$ de largo y $2 \mu \mathrm{m}$ de ancho (Pozo IV, muestra 17).

- Hydrocotyle sp. (Lámina XIII, figuras 109, 110 y 111) Granos de polen prolados, eje polar de $23 \mu \mathrm{m}$, eje ecuatorial de $16 \mu \mathrm{m}$ en vista ecuatorial. $\mathrm{P} / \mathrm{E}=1.4$. Exina de $3 \mu \mathrm{m}$ de grosor, sexina de $2.5 \mu \mathrm{m}$ y nexina de $0.5 \mu \mathrm{m}$; ornamentación microrreticulada. Tricolporado, endoabertura lalongada de $4 \mu \mathrm{m}$ de longitud y 1.5 a $2 \mu \mathrm{m}$ de ancho. Ectoabertura angosta (Pozo IV, muestra 20).

- Apiaceae 1 (Lámina XIII, figuras 112 y 113)

Granos de polen perprolatos, eje polar de $30 \mu \mathrm{m}$, eje polar de $14 \mu \mathrm{m}$ en vista ecuatorial. $\mathrm{P} / \mathrm{E}=2.2$. Exina de 1 a $1.5 \mu \mathrm{m}$ de grosor, sexina más gruesa que nexina; microrreticulada. Tricolporado, colpo longitudinal muy largo y ancho, con costa colpi. Endoabertura lalongada de 3 a $5 \mu \mathrm{m}$ de ancho (Pozo IV, muestra 17).

- Apiaceae 2 (Lámina XIII, figuras 114 y 115)

Granos de polen perprolatos, eje polar de $30 \mu \mathrm{m}$, eje ecuatorial de $14 \mu \mathrm{m}$ en vista ecuatorial. $\mathrm{P} / \mathrm{E}=2.2$. Exina de $1 \mathrm{a} 1.5 \mu \mathrm{m}$ de grosor, sexina más gruesa que nexina; tectada psilada. Tricolporado, colpo longitudinal muy largo y angosto, con costa colpi. Endoabertura de 3 a $5 \mu \mathrm{m}$ de largo y 5 a 7 de ancho (Pozo IV, muestra 20).

- Apiaceae 3 (Lámina XIII, figura 116)

Granos de polen prolados a perprolados, eje polar de 30 a $40 \mu \mathrm{m}$, eje ecuatorial de 18-20 $\mu \mathrm{m}$ en vista ecuatorial; P/ $\mathrm{E}=1.6$ a 2.2. Exina de 1 a $1.5 \mu \mathrm{m}$ de grosor, sexina más gruesa que nexina; tectada psilada. Tricolporado, colpo longitudinal muy largo y angosto, sin costa colpi. Endoabertura apiculada, difícil de delimitar (Pozo VII, muestra 26).

- Apiaceae 4 (Lámina XIII, figuras 117 y 118)

Granos de polen prolados, eje polar de $72 \mu \mathrm{m}$, eje ecuatorial de $40 \mu \mathrm{m}$ en vista ecuatorial; $\mathrm{P} / \mathrm{E}=1.8$. Exina de $2 \mu \mathrm{m}$ de grosor, sexina de $1.5 \mu \mathrm{m}$ y nexina de $0.5 \mu \mathrm{m}$ de espesor; levemente microrreticulada. Tricolporado, colpo longitudinal muy largo y ancho, sin costa colpi. Endoabertura apiculada, de 3 a $7 \mu \mathrm{m}$ de ancho (Pozo VII, muestra 32).

- Apiaceae 5 (Lámina XIII, figuras 119 y 120)

Granos de polen prolados, eje polar de $60 \mu \mathrm{m}$, eje ecuatorial de $32 \mu \mathrm{m}$ en vista ecuatorial; $\mathrm{P} / \mathrm{E}=1.9$. Exina de $2 \mu \mathrm{m}$ de grosor, sexina de $1.5 \mu \mathrm{m}$ y nexina de $0.5 \mu \mathrm{m}$ de espesor; levemente puntitegilada. Tricolporado, colpo longitudinal muy largo y angosto, con costa colpi (Pozo II, muestra 2).

- Apiaceae 6 (Lámina XIII, figuras 121 y 122)

Granos de polen prolatos, eje polar de $50 \mu \mathrm{m}$, eje ecuatorial de $30 \mu \mathrm{m} ; \mathrm{P} / \mathrm{E}=1.6$. Exina de $2 \mu \mathrm{m}$ de grosor, sexina más gruesa que nexina; ornamentación puntitegilada. Tricolporado, endoabertura de $15 \mu \mathrm{m}$ de longitud, $5 \mu \mathrm{m}$ de ancho en la parte media y $8 \mu \mathrm{m}$ en los extremos. Endoabertura angosto, con costa colpi (Pozo IV, muestra 17).

\section{ASTERACEAE}

- Ambrosia sp. (Lámina XIV, figuras 123 y 124) Granos de polen esferoidales, eje polar de $24 \mu \mathrm{m}$, eje ecuatorial de $25 \mu \mathrm{m}$ en vista ecuatorial. $\mathrm{P} / \mathrm{E}=0.96$. Exina de $3 \mu \mathrm{m}$ de grosor, sexina de $2.5 \mu \mathrm{m}$ y nexina de $0.5 \mu \mathrm{m}$ de grosor; tectada microequinada. Tricolporado (Pozo II, muestra 6; pozo III, muestra 19).

- Lactuceae (Lámina XIV, figuras 125 y 126) Granos de polen apolares, esferoidales de 25 a $30 \mu \mathrm{m}$ de 
diámetro. Exina de $6 \mu \mathrm{m}$ de grosor, sexina de $5 \mu \mathrm{m}$ y nexina de 2 a $3 \mu \mathrm{m}$ de espesor, equinolofado, bandas de 4 a $5 \mu \mathrm{m}$ de ancho, lagunas de $7 \mu \mathrm{m}$ de diámetro; espinas de 1 a $1.5 \mu \mathrm{m}$ de altura y $0.5 \mu \mathrm{m}$ en la bases, largas y afiladas. Porado (Pozo II, muestra 5).

- Asteraceae 1 (Lámina XIV, figura 127)

Granos de polen suboblatos, eje polar de 20 a $25 \mu \mathrm{m}$, eje ecuatorial de 27 a $30 \mu \mathrm{m}$ de diámetro; $\mathrm{P} / \mathrm{E}=0.78$. Exina de $4 \mu \mathrm{m}$ de grosor, sexina y nexina de igual espesor; tectada equinada, espinas de 3 a $4 \mu \mathrm{m}$ de altura y $3 \mu \mathrm{m}$ en la base. Tricolporado (Pozo VII, muestra 18).

- Asteraceae 2 (Lámina XIV, figuras 128 y 129)

Granos de polen esferoidales, de 30 a $35 \mu \mathrm{m}$ de diámetro en vista polar. Exina de 4 a $5 \mu \mathrm{m}$ de grosor, sexina de 3 a $4 \mu \mathrm{m}$ y nexina de $1 \mu \mathrm{m}$ de grosor; tectada equinada, espinas de $2 \mu \mathrm{m}$ de altura y $5 \mu \mathrm{m}$ en la base. Tricolporado (Pozo VII, muestra 27).

- Asteraceae 3 (Lámina XIV, figuras 130 y 131) Granos de polen esféricos, eje polar de $30 \mu \mathrm{m}$, eje ecuatorial de $30 \mu \mathrm{m}$ en vista ecuatorial; $\mathrm{P} / \mathrm{E}=1$. Exina de $3 \mu \mathrm{m}$ de grosor, sexina más gruesa que la nexina; tectada equinada, espinas de $6 \mu \mathrm{m}$ de altura y $4 \mu \mathrm{m}$ en la base, largas y afiladas. Tricolporado (Pozo VII, muestra 30).

Nota: Los granos de polen se parecen a los del género Cosmos. aff. BATIDACEAE

- aff. Batis maritima L. (Lámina XIV, figuras 132 y 133) Granos de polen prolados, eje polar de 27 a $30 \mu \mathrm{m}$, eje ecuatorial de $20 \mu \mathrm{m}$ en vista ecuatorial; $\mathrm{P} / \mathrm{E}=1.4$ a 1.5. Exina de $1.5 \mu \mathrm{m}$ de espesor, sexina y nexina de igual espesor; tectada psilada. Tricolporoidado (Pozo VII, muestra 17).

BERBERIDACEAE

- Berberis sp. (Lámina XIV, figura 134)

Granos de polen apolares, de forma esferoidal a subesferoidal, de $37 \times 44 \mu \mathrm{m}$ de diámetro. Exina de $3 \mu \mathrm{m}$ de grosor, no se distinguen la sexina y la nexina; tectada psilada. Colpado, el colpo espiralado; difícil de definir si son varios colpos unidos o uno solo (Pozo IV, muestra 22).

BETULACEAE

- Alnus 1 (Lámina XV, figura 135)

Granos de polen pentagonales, de $25 \times 27 \mu \mathrm{m}$ de diámetro en vista polar. Exina de $2 \mu \mathrm{m}$ de grosor, sexina y nexina de igual espesor; tectada psilada a levemente rugulada. Arcos presentes. Pentaporado (algunas veces cuatro poros), poro de 2 a $3 \mu \mathrm{m}$ de diámetro, con anillo de 2 a $2.5 \mu \mathrm{m}$ de ancho (Pozo V, muestra 46).

- Alnus 2 (Lámina XV, figura 136)

Granos de polen pentagonales, de 35 × $40 \mu \mathrm{m}$ de diámetro en vista ecuatorial. Exina de $2 \mu \mathrm{m}$ de grosor, sexina y nexina de igual espesor; tectada psilada a levemente rugulada. Arcos presentes. Pentaporado (algunas veces cuatro poros), poro de 2 a $3 \mu \mathrm{m}$ de diámetro, con anillo de 2 a $2.5 \mu \mathrm{m}$ de ancho (Pozo VII, muestra 17).

- Alnus 3 (Lámina XV, figura 137)

Granos de polen triangulares, de $30 \times 33 \mu \mathrm{m}$ de diámetro en vista polar. Exina de $3 \mu \mathrm{m}$ de grosor, sexina y nexina de igual espesor; tectada psilada a levemente rugulada. Arcos presentes. Triporado, poro de $4 \mu \mathrm{m}$ de diámetro, con anillo de 2 a $2.5 \mu \mathrm{m}$ de ancho (Pozo VII, muestra 32).

\section{BORAGINACEAE}

- Lithospermum sp. (Lámina XV, figuras 138 y 139) Granos de polen esferoidales, de $10 \times 12 \mu \mathrm{m}$ de diámetro en vista polar. Exina de $1 \mu \mathrm{m}$ de espesor, sexina y nexina no se diferencian; tectada psilada. Tricolporoidado (Pozo VII, muestra 17).

\section{BRASSICACEAE}

- Rorippa sp. (Lámina XV, figuras 140, 141, 142, 143 y 144) Granos de polen oblados a suboblados, eje polar de 20 a $25 \mu \mathrm{m}$, eje ecuatorial de 30 a $32 \mu \mathrm{m}$ en vista ecuatorial; $\mathrm{P} / \mathrm{E}=0.66$ a 0.8 . Vista polar circular, de $20 \mu \mathrm{m}$ de diámetro. Exina de 2.5 a $4 \mu \mathrm{m}$ de grosor, sexina de 2 a $3 \mu \mathrm{m}$ y nexina de 0.5 a $1 \mu \mathrm{m}$ de espesor; semitectada, reticulada, muros y lúmenes de $1 \mu \mathrm{m}$ aproximadamente. Tricolpado (Pozo VII, muestras 26 y 30 ).

\section{BURSERACEAE}

- Bursera sp. (Lámina XV, figuras 145 y 146) Granos de polen circulares, de $33 \mu \mathrm{m}$ de diámetro en vista polar. Exina de $2 \mu \mathrm{m}$ de grosor, sexina más gruesa que nexina; ornamentación estriada reticulada. Triporado, poros aspidados, áspide de 2 a $4 \mu \mathrm{m}$ de altura (Pozo VI, muestra 24).

\section{CACTACEAE}

- Heliocereus sp. (Lámina XVI, figuras 147, 148 y 149) Granos de polen cuadrangulares, de $43 \times 42 \mu \mathrm{m}$. Exina de $2 \mu \mathrm{m}$ de grosor, sexina más gruesa que nexina; ornamentación microequinada o puntitegilada. Pericolpado, probablemente ocho colpos arreglados geométricamente (Pozo VII, muestra 19).

\section{CARYOPHYLLACEAE}

- Arenaria sp. (Lámina XVI, figura 150) Granos de polen apolares, esferoidales, de $35 \mu \mathrm{m}$ de diámetro. Exina de $3 \mu \mathrm{m}$ de grosor, sexina más gruesa que nexina; microreticulada. Periporado, de cuatro a seis poros en vista superficial, aproximadamente 12 poros en total; poros de 4 a $5 \mu \mathrm{m}$ de diámetro (Pozo VII, muestra 29).

\section{CUCURBITACEAE}

- Cucurbita 1 (Lámina XVI, figura 151)

Granos de polen, apolares, esferoidales, de $80 \times 70-75 \mu \mathrm{m}$ de diámetro. Exina de $2 \mu \mathrm{m}$ de grosor, no se diferencian la sexina y la nexina; ¿intectada?, equinada, también equinulado; espinas de 5 a $7 \mu \mathrm{m}$ de altura y $3 \mu \mathrm{m}$ en la base, algunas ligeramente constreñidas en la base o insertas en el tectum. Terminaciones romas. No se observaron aberturas (Pozo II, muestra 4).

\section{- Cucurbita 2 (Lámina XVI, figura 152)}

Granos de polen apolares, esferoidales a triangulares, de $75 \times 65 \mu \mathrm{m}$ de diámetro. Exina de 2 a $3 \mu \mathrm{m}$ de grosor, sexina y nexina de igual espesor; ¿intectada?, equinada, también equinulada; espinas de 2 a $3 \mu \mathrm{m}$ de altura y $2 \mu \mathrm{m}$ 
de ancho, terminaciones romas; espinas caedizas. No se observaron aberturas (Pozo II, muestra 3).

CHENOPODIACEAE-AMARANTHACEAE

- Cheno-Am 1 (Lámina XVI, figura 153)

Granos de polen apolares, esferoidales, de $25 \mu \mathrm{m}$ de diámetro. Exina de $2 \mu \mathrm{m}$ de grosor, sexina y nexina de igual espesor; puntitegilada. Periporado, 20 a 30 poros en vista superficial, en total 40 a 60 poros. Poros aproximadamente de 2 a $3 \mu \mathrm{m}$ de diámetro (Pozo VII, muestra 30).

- Cheno-Am 2 (Lámina XVI, figura 154)

Granos de polen apolares, esferoidales, de $40 \mu \mathrm{m}$ de diámetro. Exina de $2 \mu \mathrm{m}$ de grosor, sexina más gruesa que nexina; puntitegilada. Periporado, 40 a 50 poros en vista superficial, en total 80 a 100 poros. Poros aproximadamente de 2 a $3 \mu \mathrm{m}$ de diámetro (Pozo VII, muestra 32).

CONVOLVULACEAE

- Convolvulaceae (Lámina XVII, figuras 155 y 156)

Granos de polen esferoidales, de 50 a $54 \mu \mathrm{m}$ de diámetro. Exina de $2 \mu \mathrm{m}$ de grosor, sexina y nexina de igual espesor; tectada, verrugada. Tricolpado o estefanocolpado. Colpos angostos, de 25 a $30 \mu \mathrm{m}$ de longitud (Pozo VII, muestra 23).

\section{FAGACEAE}

- Quercus sp. (Lámina XVII, figuras 157, 158 y 159) Granos de polen suboblados a esferoidales, eje polar de 27 a 36, eje ecuatorial de 37 a $40 \mu \mathrm{m}$ en vista ecuatorial; $\mathrm{P} / \mathrm{E}=0.72$ a 0.9 . Vista polar de $30-32 \mu \mathrm{m}$ de diámetro, circular. Exina de 2 a $4 \mu \mathrm{m}$ de grosor, sexina y nexina de igual espesor; tectada verrugada a fuertemente verrugada. Tricolpado o tricolporoidado (Pozo VII, muestra 17).

Nota: Probablemente se incluyan varias especies de Quercus que no fue posible separar.

HALORAGACEAE

- Myriophyllum 1 (Lámina XVII, figuras 160, 161 y 162) Granos de polen suboblados, eje polar de 27 a $30 \mu \mathrm{m}$, eje ecuatorial de 33 de $37 \mu \mathrm{m}$ en vista ecuatorial; $\mathrm{P} / \mathrm{E}=0.8$. Exina de $2 \mu \mathrm{m}$ de grosor, sexina y nexina de igual espesor; tectada psilada a ligeramente puntitegilada. Periporado, con número variable de poros de 4 a 7 , no distribuidos regularmente sobre el ecuador, algunas veces, alguno de ellos ligeramente desplazado hacia los polos; poro de 2 a $5 \mu \mathrm{m}$ de diámetro con anillo de 2 a $4 \mu \mathrm{m}$ de ancho; poro aspidado, protudente de 4 a $5 \mu \mathrm{m}$ de altura (Pozo VII, muestra 24).

- Myriophyllum 2 (Lámina XVII, figura 163)

Granos de polen suboblados, eje polar de $40 \mu \mathrm{m}$, eje ecuatorial de $46 \mu \mathrm{m}$ en vista ecuatorial; $\mathrm{P} / \mathrm{E}=0.8$. Exina de $2 \mu \mathrm{m}$ de grosor, sexina y nexina de igual espesor; tectada psilada a ligeramente puntitegilada. Periporado, con número variable de poros de 4 a 7 , no distribuidos regularmente sobre el ecuador, algunas veces, alguno de ellos ligeramente desplazado hacia los polos. Poro de 3 a $5 \mu \mathrm{m}$ de diámetro con anillo de 3 a $4 \mu \mathrm{m}$ de ancho. Poro aspidado, protudente de 4 a $5 \mathrm{~m}$ de altura (Pozo VII, muestra 16).

\section{HAMAMELIDACEAE}

- Liquidambar sp. (Lámina XVII, figura 164)

Granos de polen apolares, esferoidales, de 25-27 $\mu \mathrm{m}$ de diámetro. Exina de $2 \mu \mathrm{m}$ de grosor, sexina y nexina de igual espesor; tectada, puntitegilada. Periporado, de 5 a 6 poros en vista superficial, aproximadamente 10 a 12 poros en total; poros de 4 a $5 \mu \mathrm{m}$ de diámetro; poros semicirculares, con fisuras y escabras (Pozo VII, muestra 27).

\section{JUGLANDACEAE}

- aff. Carya sp. (Lámina XVII, figuras 165 y 166)

Granos de polen subisopolares, suboblados a esferoidales, eje polar de 35 a $40 \mu \mathrm{m}$, eje ecuatorial de 35 a $47 \mu \mathrm{m}$ de diámetro; $\mathrm{P} / \mathrm{E}=0.8$ a 1 . Exina de $1 \mu \mathrm{m}$ de grosor, no se distinguen la sexina y la exina; tectada, psilada a ligeramente escrobiculada. Triporado, poros de 3 a $4 \mu \mathrm{m}$ de diámetro, desplazados hacia uno de los polos (Pozo IV, muestra 25).

- Juglans sp. (Lámina XVIII, figuras 167, 168 y 169) Granos de polen apolares, de 40 a $45 \mu \mathrm{m}$ de diámetro. Exina de $2 \mu \mathrm{m}$ de grosor, nexina ligeramente más gruesa que la sexina; tectada ligeramente escrobiculada. Periporado, 10 poros en vista superficial, probablemente 20 en total, ligeramente aspidados; poros de $2 \mu \mathrm{m}$ de diámetro, con anillo de $2 \mu \mathrm{m}$ de ancho (Pozo VII, muestra 15).

\section{LAMIACEAE}

- Lamiaceae (Lámina XVIII, figuras 170 y 171) Granos de polen lobados, de $17 \mu \mathrm{m}$ de diámetro en vista polar. Exina de $1.5 \mu \mathrm{m}$ de grosor, sexina de $1 \mu \mathrm{m}$ y nexina de $0.5 \mu \mathrm{m}$ de espesor; microrreticulada. Hexacolpado (Pozo IV, muestra 19).

LEGUMINOSAE

- Cassia 1 (Lámina XVIII, figuras 172 y 173)

Granos de polen prolados, eje polar de $27 \mu \mathrm{m}$, eje ecuatorial de $20 \mu \mathrm{m}$ en vista ecuatorial. $\mathrm{P} / \mathrm{E}=1.35$. Exina de $2 \mu \mathrm{m}$, sexina y nexina no se distinguen; tectada perforada. Tricolpado (Pozo IV, muestra 20).

- Cassia 2 (Lámina XVIII, figuras 174 y 175)

Granos de polen prolados, eje polar de $45 \mu \mathrm{m}$, eje ecuatorial de $30 \mu \mathrm{m}$ en vista ecuatorial; $\mathrm{P} / \mathrm{E}=1.5$. Exina de $2 \mu \mathrm{m}$, sexina más gruesa que nexina; microrreticulada. Tricolpado, con margo de 1 a $2 \mu \mathrm{m}$ de ancho (Pozo IV, muestra 20).

- Mimosa sp. (Lámina XVIII, figura 176)

Poliadas de ocho granos de polen, unidas en dos pares de tetradas rotadas. Mónadas de $10 \mu \mathrm{m}$ de longitud y $5 \mu \mathrm{m}$ de ancho. Exina $1 \mu \mathrm{m}$ de espesor, no se distinguen sexina y nexina; tectada, psilada. No se observan aberturas (Pozo IV, muestra 19).

\section{LENTIBULARIACEAE}

- aff. Utricularia 1 (Lámina XVIII, figura 177) Granos de polen prolados, eje polar de $29 \mu \mathrm{m}$, eje ecuatorial de $20 \mu \mathrm{m}$ en vista ecuatorial; $\mathrm{P} / \mathrm{E}=1.5$. Exina $1 \mu \mathrm{m}$ de espesor, no se distinguen sexina y nexina; ¿microgemada o puntitegilada? Heptacolpado (probablemente con una endoabertura incipiente) (Pozo II, muestra 2). 


\section{- Utricularia 2}

Granos de polen prolados, eje polar de $50 \mu \mathrm{m}$, eje ecuatorial de $33 \mu \mathrm{m}$ en vista ecuatorial; $\mathrm{P} / \mathrm{E}=1.5$. Exina $3.5 \mu \mathrm{m}$ de espesor, sexina de $2.5 \mu \mathrm{m}$ y nexina de $1 \mu \mathrm{m}$ de espesor; microrreticulada. Colporado, 10 a 12 colpos en el ecuador. Endoabertura $5 \mu \mathrm{m}$ de altura (Pozo IV, muestra 13).

Nota: no hay registro fotográfico.

\section{LORANTHACEAE}

- Arceuthobium sp. (Lámina XVIII, figuras 178 y 179) Granos de polen circulares. Vista polar, el eje ecuatorial de 25 a $30 \mu \mathrm{m}$. Exina de 1 a $2 \mu \mathrm{m}$ de grosor, sexina y nexina no se distinguen; tectada equinada, espinas de $5 \mu \mathrm{m}$ de altura y 2 a $3 \mu \mathrm{m}$ en la base, afiladas. Tricolpado, con pseudocolpos alternando con los colpos (Pozo VII, muestra 24).

MALPIGHIACEAE

- Malpighiaceae (Lámina XIX, figuras 180 y 181)

Granos de polen apolares, esféricos de $40 \mu \mathrm{m}$ de diámetro. Exina de 2 a $3 \mu \mathrm{m}$ de grosor, sexina más gruesa que nexina; ornamentación escrobiculada. Pericolporado, colpos vestigiales, muy delgados, probablemente fusionándose entre sí; sólo se observa un poro en vista superficial de $4 \mu \mathrm{m}$ de diámetro (Pozo VII, muestra 26).

\section{MALVACEAE}

- Malvaceae 1 (Lámina XIX, figuras 182, 183, 184 y 185) Granos de polen subesferoidales a esféricos, eje polar de 42 a $50 \mu \mathrm{m}$, eje ecuatorial de 45 a $50 \mu \mathrm{m}$ de diámetro en vista ecuatorial, sin contar las espinas; $\mathrm{P} / \mathrm{E}=0.9$ a 1 . Exina de 4 a $5 \mu \mathrm{m}$, sexina de 3 a $4 \mu \mathrm{m}$ y nexina de $1 \mu \mathrm{m}$ de espesor; tectada equinada, puntitegilada. Espinas de 4 a $7 \mu \mathrm{m}$ de altura y 5 a $8 \mu \mathrm{m}$ de base, terminaciones de las espinas romas. Tricolpado (Pozo VII, muestras 16 y 26).

- Malvaceae 2 (Lámina XIX, figuras 186 y 187)

Granos de polen subprolatos, eje polar de $41 \mu \mathrm{m}$, eje ecuatorial de $34 \mu \mathrm{m}$ en vista ecuatorial. $\mathrm{P} / \mathrm{E}=1.2$. Exina de $2.5 \mu \mathrm{m}$ de grosor, sexina de $2 \mu \mathrm{m}$ y nexina de $0.5 \mu \mathrm{m}$ de espesor, sin contar las espinas; tectada equinada, espinas de 3 a $5 \mu \mathrm{m}$ de altura y $3 \mu \mathrm{m}$ en la base. Tricolpado (Pozo IV, muestra 23).

\section{MENYANTHACEAE}

- Nymphoides fallax Ornduff (Lámina XX, figura 188) Granos de polen triangulares, de 40 a $47 \mu \mathrm{m}$ de diámetro en vista polar. Exina de $2 \mu \mathrm{m}$ de grosor, sexina y nexina de igual espesor; tectada microgemada. Parasincolpado (Pozo VII, muestra 26).

\section{MYRICACEAE}

\section{- Myrica sp. (Lámina XX, figura 189)}

Granos de polen semiangulares, de 15 a $17 \mu \mathrm{m}$ de diámetro en vista polar. Exina de $2 \mu \mathrm{m}$ de grosor, sexina y nexina de igual espesor; ornamentación psilada. Triporado, poro de $3 \mu \mathrm{m}$ de diámetro, ligeramente aspidado (Pozo VI, muestra 46).

\section{NYMPHAEACEAE}

- Nuphar sp. (Lámina XX, figuras 190 y 191)

Granos de polen elípticos, el eje ecuatorial mayor de 38 a $55 \mu \mathrm{m}$, el eje ecuatorial menor de 20 a $38 \mu \mathrm{m}$ en vista polar, sin contar las espinas. Exina de $3 \mu \mathrm{m}$ de grosor, sexina de $2 \mu \mathrm{m}$, nexina de $1 \mu \mathrm{m}$ de espesor; intectada equinada, espinas de $5 \mu \mathrm{m}$ de altura, y $2 \mu \mathrm{m}$ de base, algunas de terminaciones romas y otras afiladas. Espinas caedizas. Monosulcado, sulco tan largo como el eje ecuatorial mayor (Pozo VII, muestras 17 y 29).

- Nymphaea ampla (Salisb.) DC. (Lámina XX, figuras 192, 193 y 194)

Granos de polen elípticos, eje ecuatorial mayor de 55 a $62 \mu \mathrm{m}$, eje ecuatorial menor de 27 a $54 \mu \mathrm{m}$ en vista polar. Exina de $2 \mu \mathrm{m}$ de grosor, sexina y nexina de igual espesor; tectada levemente fosulada a ligeramente verrugada. Zonisulcado. Algunas veces los granos de polen se rompen y se abren por la abertura quedando dos partes (Pozo VI, muestra 46; pozo VII, muestra 23).

- aff. Nymphaea mexicana Zucc. (Lámina XX, figura 195) Granos de polen elípticos, eje ecuatorial mayor de 50 a $55 \mu \mathrm{m}$, eje ecuatorial menor de 45 a $50 \mu \mathrm{m}$ en vista polar. Exina de $2 \mu \mathrm{m}$ de grosor, sexina y nexina de igual espesor; intectada, gemada equinada, gemas de tamaño variable, espinas de $4 \mu \mathrm{m}$ de altura y $1 \mu \mathrm{m}$ en la base. Zonisulcado (Pozo II, muestra 5).

\section{OLEACEAE}

- Fraxinus sp. (Lámina XX, figuras 196 y 197) Granos de polen esferoidales, de 25-27 x 25-30 $\mu$ m en vista ecuatorial lateral. Exina de $2 \mu \mathrm{m}$ de grosor, sexina y nexina de igual espesor; microrreticulada. Tetracolpado. Distancia entre los colpos de 15 a $17 \mu \mathrm{m}$ (Pozo VII, muestra 23).

\section{ONAGRACEAE}

- Ludwigia sp. (Lámina XX, figura 198)

Tetradas tetrahédricas de $80 \times 100 \mu \mathrm{m}$. Mónadas de 40 $x 50 \mu \mathrm{m}$. Exina de $3 \mu \mathrm{m}$ de ancho, sexina y nexina de igual espesor; tectada escabrosa. Triporado, poros aspidados, de 4 a $5 \mu \mathrm{m}$ de altura y $10 \mu \mathrm{m}$ de ancho (Pozo VI, muestra 24).

\section{PLANTAGINACEAE}

- Plantago sp. (Lámina XXI, figuras 199 y 200)

Granos de polen apolares, esferoidales, de $22 \mu \mathrm{m}$ diámetro. Exina de $2 \mu \mathrm{m}$ de grosor, sexina más gruesa que la nexina; tectada puntitegilada. Periporado, de seis a ocho poros, poros de $5 \mu \mathrm{m}$ de diámetro (Pozo IV, muestra 17).

\section{POLYGONACEAE}

- Polygonum 1 (Lámina XXI, figuras 201 y 202)

Granos de polen apolares, esferoidales, de 30 a $35 \mu \mathrm{m}$ de diámetro. Exina de 4 a $5 \mu \mathrm{m}$ de grosor, sexina de 3 a $4 \mu \mathrm{m}$ y nexina de $1 \mu \mathrm{m}$ de espesor; semitectada, reticulada. Muros de 1 a $2 \mu \mathrm{m}$ de ancho y lúmenes de $4 \mu \mathrm{m}$ de diámetro. Periporado, no se pudieron observar todas las aberturas (Pozo VII, muestra 17).

- Polygonum 2 (Lámina XXI, figura 203)

Granos de polen apolares, esferoidales, de 55 a $60 \mu \mathrm{m}$ de diámetro. Exina de 5 a $6 \mu \mathrm{m}$ de grosor, sexina de 4 a $5 \mu \mathrm{m}$ y nexina de $1 \mu \mathrm{m}$ de espesor; semitectada, reticulada. Muros de 2 a $3 \mu \mathrm{m}$ de ancho y lúmenes de 6 a $8 \mu \mathrm{m}$ de diámetro. 
Periporado, aproximadamente ocho poros (Pozo VII, muestra 32).

- Polygonaceae (Lámina XXI, figura 204) Granos de polen esferoidales, eje polar de $45 \mu \mathrm{m}$, eje ecuatorial de $40 \mu \mathrm{m}$ en vista ecuatorial; $\mathrm{P} / \mathrm{E}=1.12$. Exina de $2 \mu \mathrm{m}$ de grosor, sexina más gruesa que nexina; semitectada, perreticulada, lúmenes y muros de $1 \mu \mathrm{m}$ de ancho. Tricolpado (Pozo IV, muestra 21).

RANUNCULACEAE

- Ranunculus sp. (Lámina XXI, figura 205)

Granos de polen esferoidales, eje polar de $40 \mu \mathrm{m}$, eje ecuatorial de $35 \mu \mathrm{m}$ en vista ecuatorial; $\mathrm{P} / \mathrm{E}=1.14$. Exina de 2 a $3 \mu \mathrm{m}$ de grosor, sexina y nexina de igual espesor; tectada puntitegilada, equinada, espinas de $1 \mu \mathrm{m}$ de altura y $1 \mu \mathrm{m}$ en la base. Tricolpado (Pozo VII, muestra 14).

\section{RHAMNACEAE}

- Rhamnus sp. (Lámina XXI, figuras 206 y 207)

Granos de polen triangulares. En vista polar de $25 \mu \mathrm{m}$ de diámetro. Exina de 1 a $1.5 \mu \mathrm{m}$ de grosor, no se distinguen la sexina de la nexina; tectada psilada. Tricolpado. Distancia entre los colpos de $3 \mu \mathrm{m}$ (Pozo VII, muestra 18).

\section{ROSACEAE}

- Prunus sp. (Lámina XXI, figuras 208 y 209)

Granos de polen prolados, eje polar de $42 \mu \mathrm{m}$, eje ecuatorial de $30 \mu \mathrm{m}$ en vista ecuatorial; $\mathrm{P} / \mathrm{E}=1.4$. Exina de $2 \mu \mathrm{m}$ de grosor, sexina y nexina de igual espesor; ornamentación microrreticulada. Tricolporoidado (Pozo VII, muestra 17).

- Rosaceae (Lámina XXII, figura 210)

Granos de polen subprolados, eje polar de $60 \mu \mathrm{m}$, en vista polar $48 \mu \mathrm{m}$ en vista ecuatorial; $\mathrm{P} / \mathrm{E}=1.2$. Exina de $5 \mu \mathrm{m}$, sexina de $2 \mu \mathrm{m}$ y nexina de $3 \mu \mathrm{m}$ de espesor; tectada puntitegilada. Tricolpado (Pozo VII, muestra 23).

RUBIACEAE

- aff. Asemnantha sp. (Lámina XXII, figuras 211 y 212)

Granos de polen semitriangulares, de $30 \mu \mathrm{m}$ de diámetro en vista polar. Exina de $2 \mu \mathrm{m}$ de grosor, sexina más gruesa que la nexina; tectada escabrada, nexina fosulada. Tricolporado, colpo longitudinal con margo de $8 \mu \mathrm{m}$ de ancho en el ecuador y de 4 a $5 \mu \mathrm{m}$ en los polos. Los margos se unen dando un aspecto sincolpado. Distancia entre los colpos $7 \mu \mathrm{m}$ (Pozo VII, muestra 19).

- Rubiaceae 1 (Lámina XXII, figuras 213 y 214) Granos de polen semicirculares, de 30 a $40 \mu \mathrm{m}$ en vista polar lateral. Exina de $3 \mu \mathrm{m}$ de grosor, sexina de $2 \mu \mathrm{m}$ y nexina de $1 \mu \mathrm{m}$ de espesor; microreticulada. Triporado, poros de 7 a $9 \mu \mathrm{m}$ de diámetro, con anillo de $5 \mu \mathrm{m}$ de ancho, ligeramente aspidado (Pozo VII, muestra 27).

- Rubiaceae 2 (Lámina XXII, figuras 215 y 216)

Granos de polen esferoidales, eje polar de $32 \mu \mathrm{m}$, eje ecuatorial de $35 \mu \mathrm{m}$ en vista ecuatorial; $\mathrm{P} / \mathrm{E}=0.9$. Exina de $1.5 \mu \mathrm{m}$ de grosor, sexina más gruesa que la nexina; microrreticulada, simplibaculada. Tetracolpado, colpos angostos y cortos, de 6 a $7 \mu \mathrm{m}$ de largo (Pozo VII, muestra 27).
- Rubiaceae 3 (Lámina XXII, figura 217)

Granos de polen esferoidales, eje polar de $33 \mu \mathrm{m}$, eje ecuatorial de $36 \mu \mathrm{m}$ en vista ecuatorial; $\mathrm{P} / \mathrm{E}=0.9$. Exina de 1.5 a $2 \mu \mathrm{m}$ de grosor, sexina y nexina de igual espesor; ornamentación psilada. Pentacolpado, colpos largos con membranas, margo poco evidente de 1 a $2 \mu \mathrm{m}$ de grosor, exina en la zona de la abertura de $3 \mu \mathrm{m}$ de grosor. Distancia entre los colpos de $20 \mu \mathrm{m}$ (Pozo VII, muestra 31).

- Rubiaceae 4 (Lámina XXII, figuras 218 y 219)

Granos de polen suboblados, eje polar de $42 \mu \mathrm{m}$, eje ecuatorial de $48 \mu \mathrm{m}$ en vista ecuatorial; $\mathrm{P} / \mathrm{E}=0.8$. Exina de 3 a $4 \mu \mathrm{m}$ de grosor, sexina del mismo espesor que la nexina; ornamentación reticulada, lúmenes y muros de $1 \mu \mathrm{m}$ de ancho. Hexacolpado, colpos angostos y cortos de 6 a $7 \mu \mathrm{m}$ de largo (Pozo VII, muestra 23).

\section{SALICACEAE}

- Populus 1 (Lámina XXIII, figura 220)

Granos de polen apolares, esferoidales, de $65 \times 55 \mu \mathrm{m}$ de diámetro. Exina de 1 a $1.5 \mu \mathrm{m}$ de grosor; intectada escabrosa. Inaperturado (Pozo VII, muestra 32).

- Populus 2

Granos de polen apolares, esferoidales, de $55 \times 40 \mu \mathrm{m}$ de diámetro. Exina de 1 a $1.5 \mu \mathrm{m}$ de grosor; intectada escabrosa. Inaperturado (Pozo VI, muestra 46).

Nota: no existe registro fotográfico.

- Populus 3 (Lámina XXIII, figura 221) Granos de polen apolares, esferoidales, de $48 \mu \mathrm{m}$ de diámetro. Exina de $2 \mu \mathrm{m}$, sexina más gruesa que la nexina; intectada escabrosa. Inaperturado (Pozo IV, muestra 22).

- Salix 1 (Lámina XXIII, figura 222)

Granos de polen suprolatos, eje polar de $20 \mu \mathrm{m}$, eje ecuatorial de $17 \mu \mathrm{m}$ en vista ecuatorial; $\mathrm{P} / \mathrm{E}=1.18$. En vista polar de $22 \mu \mathrm{m}$ de diámetro. Exina de $2 \mu \mathrm{m}$ de grosor, sexina y nexina de igual espesor; semitectada, perreticulada, lúmenes de 1 a $2 \mu \mathrm{m}$ de diámetro, muros menores a $1 \mu \mathrm{m}$. Tricolporado. Distancia entre los colpos $7 \mu \mathrm{m}$ (Pozo VII, muestra 26).

- Salix 2 (Lámina XXIII, figura 223)

Granos de polen esferoidales, eje polar de $20 \mu \mathrm{m}$, eje ecuatorial de $22 \mu \mathrm{m}$ en vista ecuatorial; $\mathrm{P} / \mathrm{E}=0.9$. En vista polar de $22 \mu \mathrm{m}$ de diámetro. Exina de $3 \mu \mathrm{m}$ de grosor, sexina más gruesa que nexina; semitectada, perreticulada, lúmenes de 1 a $2 \mu \mathrm{m}$ de diámetro, muros menores a $1 \mu \mathrm{m}$. Tricolporado (Pozo IV, muestra 17).

- Salix 3 (Lámina XXIII, figura 224)

Granos de polen prolados, eje polar de $35 \mu \mathrm{m}$, eje ecuatorial de $25 \mu \mathrm{m}$ en vista ecuatorial; $\mathrm{P} / \mathrm{E}=1.4$. Exina de $1.5 \mu \mathrm{m}$, sexina más gruesa que nexina; semitectada, simplibaculada, heterobrocada, lúmenes de 1 a $4 \mu \mathrm{m}$ de diámetro, muros menores a $1 \mu \mathrm{m}$. Tricolpado (Pozo VII, muestra 24).

- Salix 4 (Lámina XXIII, figura 225)

Granos de polen prolados, eje polar de $38 \mu \mathrm{m}$, eje ecuatorial de $25 \mu \mathrm{m}$ en vista ecuatorial; $\mathrm{P} / \mathrm{E}=1.5$. Exina de $2.5 \mu \mathrm{m}$, sexina de $2 \mu \mathrm{m}$ y nexina de $0.5 \mu \mathrm{m}$ de espesor; semitectada, 
simplibaculada, heterobrocada, lúmenes y muros de $1 \mu \mathrm{m}$ de ancho. Tricolpado (Pozo II, muestra 2).

SCROPHULARIACEAE

- aff. Scrophulariaceae 1 (Lámina XXIII, figura 226) Granos de polen esferoidales, eje polar de $46 \mu \mathrm{m}$, eje ecuatorial de $40 \mu \mathrm{m}$ en vista ecuatorial; $\mathrm{P} / \mathrm{E}=1.15$. Exina de 1.5 a $2 \mu \mathrm{m}$ de grosor, sexina más gruesa que nexina; tectada psilada a levemente puntitegilada. Tricolpado ¿oroidado? (Pozo VII, muestra 32).

- aff. Scrophulariaceae 2 (Lámina XXIII, figura 227) Granos de polen esferoidales, de $35 \mu \mathrm{m}$ en vista polar. Exina de 1.5 a $2 \mu \mathrm{m}$ de grosor, sexina de igual grosor que la nexina; tectada, levemente escabrada. Tricolpado. Distancia entre colpos $5 \mu \mathrm{m}$ (Pozo VII, muestra 30).

\section{SOLANACEAE}

- Datura sp. (Lámina XXIII, figuras 228)

Granos de polen esferoidales, eje polar de $30 \mu \mathrm{m}$, eje ecuatorial de $32 \mu \mathrm{m}$ en vista ecuatorial; $\mathrm{P} / \mathrm{E}=0.9$. Exina de $3 \mu \mathrm{m}$ de grosor, sexina de $2 \mu \mathrm{m}$ y nexina de $1 \mu \mathrm{m}$ de espesor; tectada microestriada. Estrías ligeramente puntibaculadas. Estrías menores de $1 \mu \mathrm{m}$ de ancho, liras menores de $1 \mu \mathrm{m}$ de ancho. Tricolporado, endoabertura de 4 a $5 \mu \mathrm{m}$ de largo y 3 a $4 \mu \mathrm{m}$ de altura (Pozo VII, muestra 17).

- Solanum sp. (Lámina XXIV, figura 229)

Granos de polen esféricos a esferoidales, eje polar de 32 a $35 \mu \mathrm{m}$, eje ecuatorial de $32 \mu \mathrm{m}$ en vista ecuatorial; $\mathrm{P} / \mathrm{E}=1$ a 1.12. Exina de $3 \mu \mathrm{m}$ de grosor, sexina de $2 \mu \mathrm{m}$ y nexina de $1 \mu \mathrm{m}$ de espesor; tectada psilada. Tricolporado, endoabertura $8 \mu \mathrm{m}$ de largo y 4 a $5 \mu \mathrm{m}$ de altura (Pozo IV, muestra 19).

- Solanaceae 1 (Lámina XXIV, figura 230)

Granos de polen esferoidales, eje polar de $27 \mu \mathrm{m}$, eje ecuatorial de $25 \mu \mathrm{m}$ en vista ecuatorial; $\mathrm{P} / \mathrm{E}=1.08$. Exina de $3 \mu \mathrm{m}$ de grosor, sexina de $2 \mu \mathrm{m}$ y nexina de $1 \mu \mathrm{m}$ de espesor; tectada puntitegilada a microrreticulada. Tricolporado, endoabertura lalongada de $10 \mu \mathrm{m}$ de largo y $5 \mu \mathrm{m}$ de ancho (Pozo IV, muestra 20).

- Solanaceae 2 (Lámina XXIV, figura 231)

Granos de polen esféricos, eje polar de $40 \mu \mathrm{m}$, eje ecuatorial de $40 \mu \mathrm{m}$ en vista ecuatorial; $\mathrm{P} / \mathrm{E}=1$. Exina de $2 \mu \mathrm{m}$ de grosor, sexina de igual espesor que la nexina; tectada puntitegilada. Tricolporado (Pozo VII, muestra 17).

\section{TILIACEAE}

- Heliocarpus sp. (Lámina XXIV, figuras 232 y 233) Granos de polen prolados, eje polar de $45 \mu \mathrm{m}$, eje ecuatorial de $25 \mu \mathrm{m}$ en vista ecuatorial; $\mathrm{P} / \mathrm{E}=1.8$. Exina de $2 \mu \mathrm{m}$ de grosor, sexina más gruesa que nexina; tectada suprarreticulada, lúmenes de 1 a $3 \mu \mathrm{m}$ y muros de $1 \mu \mathrm{m}$; simplibaculada, columelas presentes en los lúmenes. Tricolporado. En la zona cercana a las aberturas la ornamentación es microrreticulada (Pozo II, muestra 2).

- Tiliaceae 1 (Lámina XXIV, figura 234)

Granos de polen prolados, eje polar de $52 \mu \mathrm{m}$, eje ecuatorial de $32 \mu \mathrm{m}$ en vista ecuatorial; $\mathrm{P} / \mathrm{E}=1.6$. Exina de $3 \mu \mathrm{m}$ de grosor, sexina de $2 \mu \mathrm{m}$ y nexina de $1 \mu \mathrm{m}$; microrreticulada. Tricolporado, endoabertura de 10 a $15 \mu \mathrm{m}$ de largo y 1 a $2 \mu \mathrm{m}$ de ancho (Pozo IV, muestra 18).

\section{ULMACEAE}

- aff. Celtis sp. (Lámina XXIV, figura 235)

Granos de polen circulares, de $25 \mu \mathrm{m}$ de diámetro en vista polar. Exina de $2 \mu \mathrm{m}$ de grosor, sexina y nexina de igual espesor; ornamentación psilada. Triporado, poro de $3 \mu \mathrm{m}$ de diámetro, con anillo de $2 \mu \mathrm{m}$ de ancho (Pozo VI, muestra 46). URTICACEAE

- Urtica sp. (Lámina XXIV, figuras 236 y 237)

Granos de polen isopolares, esferoidales, de $20 \mu \mathrm{m}$ de diámetro. Exina de $2 \mu \mathrm{m}$ de grosor, sexina y nexina de igual espesor; tectada puntitegilada. Triporado, poros de 3 a $5 \mu \mathrm{m}$ de diámetro (Pozo VII, muestra 14).

\section{VALERIANACEAE}

- Valeriana sp. (Lámina XXIV, figuras 238 y 239)

Granos de polen prolados, eje polar de $58 \mu \mathrm{m}$, el eje ecuatorial de $40 \mu \mathrm{m}$, en vista ecuatorial; $\mathrm{P} / \mathrm{E}=1.45$. Exina de $5 \mu \mathrm{m}$ de grosor, sexina de $4 \mu \mathrm{m}$ y nexina de $1 \mu \mathrm{m}$ de espesor; tectada equinada, espinas de $1 \mu \mathrm{m}$ de altura y $1 \mu \mathrm{m}$ en la base. Tricolpado (Pozo IV, muestra 16).

VERBENACEAE

- Lantana sp. (Lámina XXIV, figuras 240, 241 y 242) Granos de polen prolados, eje polar de $47 \mu \mathrm{m}$, eje ecuatorial de $35 \mu \mathrm{m}$ en vista ecuatorial; $\mathrm{P} / \mathrm{E}=1.3$. Exina de $2 \mu \mathrm{m}$ de grosor, sexina y nexina de igual espesor; tectada psilada. Tricolporado, colpo longitudinal, delgado, mal definido. Ectoabertura de $12 \mu \mathrm{m}$ de largo y $7 \mu \mathrm{m}$ de altura en los extremos y $5 \mu \mathrm{m}$ de altura en la parte central (Pozo IV, muestra 17).

- Lippia sp. (Lámina XXIV, figura 243)

Granos de polen esferoidales, de $25 \mu \mathrm{m}$ de diámetro en vista ecuatorial lateral. Exina de $1 \mu \mathrm{m}$ de grosor; ornamentación escrobiculada. Tricolporado (Pozo VII, muestra 14).

\section{INDETERMINADAS}

- Inaperturado 1 (Lámina XXV, figura 244)

Granos de polen apolares, de $45 \mu \mathrm{m}$ de diámetro. Exina de $3 \mu \mathrm{m}$, sexina de $2 \mu \mathrm{m}$ y nexina de $1 \mu \mathrm{m}$ de espesor; ornamentación equinada verrugada, espinas largas de punta roma, de 1 a $2 \mu \mathrm{m}$ de altura. Inaperturado (Pozo VII, muestra 30).

- Inaperturado 2 (Lámina XXV, figura 245)

Granos de polen apolares, elípticos a semicirculares, de $50 \times 40 \mu \mathrm{m}$ de diámetro. Exina de 3 a $4 \mu \mathrm{m}$, sexina más gruesa que la nexina; ornamentación escabrada. Inaperturado (Pozo VII, muestra 3).

- Monosulcado 1 (Lámina XXV, figura 246) Granos de polen elípticos, eje ecuatorial mayor de $62 \mu \mathrm{m}$, eje ecuatorial menor de $40 \mu \mathrm{m}$ en vista polar. Exina de 2 a $3 \mu \mathrm{m}$ de grosor, sexina y nexina de igual espesor; tectada escabrada. Monosulcado, sulco amplio, tan largo como el eje ecuatorial mayor (Pozo VII, muestra 32). 
- Monosulcado 2 (Lámina XXV, figura 247)

Granos de polen esferoidales, eje ecuatorial mayor de $40 \mu \mathrm{m}$, eje ecuatorial menor de $40 \mu \mathrm{m}$ en vista polar. Exina de $1 \mu \mathrm{m}$ de grosor, sexina y nexina no se diferencían; tectada escabrada. Monosulcado, sulco angosto (Pozo VII, muestra 17).

- Monosulcado 3 (Lámina XXV, figura 248)

Granos de polen elípticos, eje ecuatorial mayor de $51 \mu \mathrm{m}$, eje ecuatorial menor de $40 \mu \mathrm{m}$ en vista polar. Exina de $3 \mu \mathrm{m}$ de grosor, sexina de $2 \mu \mathrm{m}$ y nexina de $1 \mu \mathrm{m}$ de espesor; tectada con verrugas de $5 \mu \mathrm{m}$ de diámetro. Monosulcado, sulco de 30 a $35 \mu \mathrm{m}$ de largo (Pozo VII, muestra 19).

Nota: R. Villanueva (com. pers.) sugiere que se trata de una Bromeliaceae.

- Monosulcado 4 (Lámina XXV, figuras 249 y 250)

Granos de polen elípticos, eje ecuatorial mayor de $45 \mu \mathrm{m}$, eje ecuatorial menor de $25 \mu \mathrm{m}$ en vista polar. Exina de $2 \mu \mathrm{m}$ de grosor, sexina más gruesa que nexina; ornamentación con verrugas menores de $1 \mu \mathrm{m}$ de altura y en la base. Monosulcado, sulco muy amplio, tan largo como el eje ecuatorial mayor (Pozo VII, muestra 24).

- Monosulcado 5 (Lámina XXV, figura 251)

Granos de polen elípticos, eje ecuatorial mayor de $45 \mu \mathrm{m}$, eje ecuatorial menor de $25 \mu \mathrm{m}$ en vista polar. Exina de $1 \mu \mathrm{m}$ de grosor, sexina más gruesa que nexina; ornamentación intectada gemada, gemas de $1 \mu \mathrm{m}$ de grosor. Monosulcado, sulco tan largo como el eje ecuatorial mayor (Pozo IV, muestra 14).

- Monosulcado 6 (Lámina XXV, figura 252)

Granos de polen elípticos, eje ecuatorial mayor de $34 \mu \mathrm{m}$, eje ecuatorial menor de $25 \mu \mathrm{m}$ en vista polar. Exina de $1 \mu \mathrm{m}$ de grosor, sexina y nexina de igual espesor; ornamentación verrugada-gemada, verrugas y gemas menores de $1 \mu \mathrm{m}$ de grosor. Monosulcado (Pozo IV, muestra 19).

- Monosulcado 7 (Lámina XXVI, figura 253)

Granos de polen esféricos, de $32 \mu \mathrm{m}$ de diámetro. Exina de $2 \mu \mathrm{m}$ de grosor, sexina y nexina de igual espesor; ornamentación verrugada-gemada, verrugas y gemas menores de $1 \mu \mathrm{m}$ de grosor. Monosulcado (Pozo IV, muestra 19).

- Monosulcado 8 (Lámina XXVI, figura 254)

Granos de polen prolados, eje ecuatorial mayor de $86 \mu \mathrm{m}$, eje ecuatorial menor de $40 \mu \mathrm{m}$ en vista polar. Exina de $3 \mu \mathrm{m}$ de grosor, sexina de $2 \mu \mathrm{m}$ y nexina de $1 \mu \mathrm{m}$ de espesor; tectada puntitegilada a ligeramente estriada en la zona de la abertura. Monosulcado, sulco largo (Pozo IV, muestra 22).

- Tricolpado 1 (Lámina XXVI, figura 255)

Granos de polen prolados, eje polar de $34 \mu \mathrm{m}$, eje ecuatorial de $25 \mu \mathrm{m}$ en vista ecuatorial. $\mathrm{P} / \mathrm{E}=1.4$. Exina de $2.5 \mu \mathrm{m}$, sexina de $2 \mu \mathrm{m}$ y nexina de $0.5 \mu \mathrm{m}$ de espesor; intectada clavada, clavas de $1.5 \mu \mathrm{m}$ de ancho a $0.5 \mu \mathrm{m}$ de base. Tricolpado, membrana del colpo lisa (Pozo VI, muestra 46).
Nota: R. Villanueva (com. pers.) sugiere que se trata de una Rubiaceae.

- Tricolpado 2 (Lámina XXVI, figura 256)

Granos de polen subprolados, eje polar de $26 \mu \mathrm{m}$, eje ecuatorial de $21 \mu \mathrm{m}$ en vista ecuatorial. $\mathrm{P} / \mathrm{E}=1.2$. Exina de $2 \mu \mathrm{m}$, sexina más gruesa que nexina; microrreticulada, simplibaculada. Tricolpado (Pozo IV, muestra 20).

- Tricolpado 3 (Lámina XXVI, figura 257)

Granos de polen prolados, eje polar de $38 \mu \mathrm{m}$, en vista polar $28 \mu \mathrm{m}$ en vista ecuatorial; $\mathrm{P} / \mathrm{E}=1.4$. Exina de $2 \mu \mathrm{m}$, sexina más gruesa que nexina; semitectada, muros y lúmenes de $1 \mu \mathrm{m}$ de diámetro. Tricolpado (Pozo VI, muestra 46).

- Tricolpado 4 (Lámina XXVI, figura 258)

Granos de polen subprolados, eje polar de $47 \mu \mathrm{m}$, eje ecuatorial de $37 \mu \mathrm{m}$ en vista ecuatorial; $\mathrm{P} / \mathrm{E}=1.2$. Exina de $6 \mu \mathrm{m}$ de grosor, sexina de $5 \mu \mathrm{m}$ y nexina de $1 \mu \mathrm{m}$ de espesor; semitectada, simplibaculada, heterobrocada, lúmenes y muros de $1 \mu \mathrm{m}$ de ancho. Tricolpado (Pozo IV, muestra 22).

- Tricolpado 5 (Lámina XXVI, figura 259)

Granos de polen esféricos, eje polar de $38 \mu \mathrm{m}$, eje ecuatorial de $38 \mu \mathrm{m}$ en vista ecuatorial; $P / E=1$. Exina de 2 a $3 \mu \mathrm{m}$ de grosor, sexina y nexina de igual espesor; semitectada, lúmenes y muros de $1 \mu \mathrm{m}$ de ancho. Tricolpado (Pozo VII, muestra 24).

- Tricolpado 6 (Lámina XXVI, figura 260)

Granos de polen prolados, eje polar de $42 \mu \mathrm{m}$, el eje ecuatorial de $31 \mu \mathrm{m}$ en vista ecuatorial; $\mathrm{P} / \mathrm{E}=1.4$. Exina de $1.5 \mu \mathrm{m}$ de grosor, sexina más gruesa que nexina; semitectada, lúmenes de $2 \mu \mathrm{m}$ aproximadamente con una verruga dentro del lumen, muros menores de $1 \mu \mathrm{m}$ de ancho. Tricolpado (Pozo VII, muestra 24).

- Tricolpado 7 (Lámina XXVI, figura 261)

Granos de polen esféricos, de $37 \mu \mathrm{m}$ de diámetro en vista polar lateral. Exina de $1 \mu \mathrm{m}$ de grosor, sexina más gruesa que nexina; intectada escabrada. Tricolpado. Distancia entre los colpos de 8 a $10 \mu \mathrm{m}$ (Pozo IV, muestra 24).

- Tricolpado 8 (Lámina XXVII, figura 262)

Granos de polen circulares, de 30 a $36 \mu \mathrm{m}$ diámetro en vista polar. Exina de 3 a $4 \mu \mathrm{m}$ de grosor, sexina más gruesa que la nexina; tectada equinada, espinas $<1 \mu \mathrm{m}$. Tricolpado (Pozo VII, muestra 32).

- Tricolpado 9 (Lámina XXVII, figura 263) Granos de polen circulares. En vista polar de $45 \mu \mathrm{m}$ diámetro. Exina de $1.5 \mu \mathrm{m}$ de grosor, sexina más gruesa que la nexina; microrreticulada. Tricolpado, distancia entre los colpos $10 \mu \mathrm{m}$ (Pozo VII, muestra 26).

Nota: Villanueva (com. pers.) sugiere que se trata de una Leguminosae.

- Tetracolpado (Lámina XXVII, figuras 264 y 265) Granos de polen circulares, de $50 \mu \mathrm{m}$ diámetro en vista polar. Exina de $2 \mu \mathrm{m}$ de grosor, sexina de igual grosor que la nexina; microrreticulada. Tetracolpado, distancia entre los colpos $13 \mu \mathrm{m}$ (Pozo VII, muestra 24). 
- Tricolpado/tricolporoidado (Lámina XXVII, figuras 266 y 267)

Granos de polen subprolados, eje polar de $22 \mu \mathrm{m}$, eje ecuatorial de $20 \mu \mathrm{m}$ en vista ecuatorial; $\mathrm{P} / \mathrm{E}=1.1$. Exina de $2 \mu \mathrm{m}$ de grosor, sexina y nexina del mismo espesor; tectada con verrugas de $1 \mu \mathrm{m}$ de altura y $1 \mu \mathrm{m}$ de ancho. Tricolpado o tricolporoidado (Pozo VII, muestra 38).

- Tricolporado 1 (Lámina XXVII, figuras 268 y 269) Granos de polen esféricos a esferoidales, eje polar de 18 a $20 \mu \mathrm{m}$, eje ecuatorial de $18 \mu \mathrm{m}$ en vista ecuatorial; $\mathrm{P} / \mathrm{E}=1$. a 1.1. Exina de $2 \mu \mathrm{m}$, sexina del mismo grosor que la nexina; tectada psilada. Tricolporado, endoabertura de $8 \mu \mathrm{m}$ de largo y 1.5 a $2 \mu \mathrm{m}$ de ancho, afilada en los extremos. Ectoabertura de $8 \mu \mathrm{m}$ de longitud, con los extremos afilados (Pozo IV, muestra 20).

- Tricolporado 2 (Lámina XXVII, figuras 270, 271 y 272) Granos de polen prolados, eje polar de 18 a $24 \mu \mathrm{m}$, eje ecuatorial de 12 a $15 \mu \mathrm{m}$ en vista ecuatorial; $\mathrm{P} / \mathrm{E}=1.5 \mathrm{a}$ 1.6. Exina de $2.5 \mu \mathrm{m}$ de grosor, sexina y nexina de igual espesor; tectada perforada. Tricolporado, endoabertura de 4 a $5 \mu \mathrm{m}$ de longitud y $1 \mu \mathrm{m}$ de ancho. Ectoabertura tan larga como el eje polar (Pozo IV, muestra 19).

- Tricolporado 3 (Lámina XXVII, figuras 273 y 274) Granos de polen subprolados, eje polar de $26 \mu \mathrm{m}$, eje ecuatorial de $22 \mu \mathrm{m}$ en vista ecuatorial; $\mathrm{P} / \mathrm{E}=1.18$. Exina de $3 \mu \mathrm{m}$ de grosor, sexina de $2 \mu \mathrm{m}$ y nexina de $1 \mu \mathrm{m}$; tectada puntitegilada. Tricolporado, endoabertura de $7 \mu \mathrm{m}$ de longitud y 3 a $4 \mu \mathrm{m}$ de ancho. Ectoabertura angosta (Pozo IV, muestra 22).

Nota: R. Villanueva (com. pers.) sugiere que se trata de una Apiaceae.

- Tricolporado 4 (Lámina XXVIII, figuras 275, 276 y 277) Granos de polen subprolatos, eje polar de $25 \mu \mathrm{m}$, eje ecuatorial de $20 \mu \mathrm{m}$ en vista ecuatorial; $\mathrm{P} / \mathrm{E}=1.25$. Exina de $2 \mu \mathrm{m}$ de grosor, sexina de $1.5 \mu \mathrm{m}$ y nexina de $0.5 \mu \mathrm{m}$; ornamentación foveolada, falso patrón reticulado. Tricolporado, endoabertura circular, de 3 a $4 \mu \mathrm{m}$ de longitud y 2 a $3 \mu \mathrm{m}$ de ancho. Ectoabertura angosta (Pozo IV, muestra 19).

- Tricolporado 5 (Lámina XXVIII, figuras 278 y 279)

Granos de polen esferoidales, eje polar de $32 \mu \mathrm{m}$, eje ecuatorial de $34 \mu \mathrm{m}$ en vista ecuatorial; $\mathrm{P} / \mathrm{E}=0.9$. Exina de $3 \mu \mathrm{m}$ de grosor, sexina de $2.5 \mu \mathrm{m}$ y nexina de $0.5 \mu \mathrm{m}$; ornamentación puntitegilada. Tricolporado, endoabertura circular, de $8 \mu \mathrm{m}$ de diámetro. Ectoabertura angosta (Pozo IV, muestra 18).

- Pentacolporado (Lámina XXVIII, figuras 280, 281 y 282) Granos de polen de forma irregular, con prolongaciones apiculadas, eje de 23 a $25 \mu \mathrm{m}$ de diámetro. Exina de $2 \mu \mathrm{m}$ de grosor, sexina más gruesa que la nexina; ornamentación microrreticulada. Pentacolporado, las aberturas dispuestas irregularmente, tres en un eje y dos en el eje opuesto (Pozo IV, muestra 17).

Nota: El polen está muy deformado.
- Pentaporado (Lámina XXVIII, figura 283)

Granos de polen oblados, eje polar de $26 \mu \mathrm{m}$, eje ecuatorial de $35 \mu \mathrm{m}$ en vista ecuatorial; $\mathrm{P} / \mathrm{E}=0.74$. Exina de $2 \mu \mathrm{m}$ de grosor, sexina y nexina de igual espesor; ornamentación psilada. Pentaporado, poro de 2 a $4 \mu \mathrm{m}$ de diámetro, con anillo de 2 a $3 \mu \mathrm{m}$ de ancho (Pozo IV, muestra 23).

- Tetraporado/pentaporado (Lámina XXVIII, figura 284 y 285)

Granos de polen esferoidales, eje polar de $30 \mu \mathrm{m}$, eje ecuatorial de $30 \mu \mathrm{m}$ en vista ecuatorial; $\mathrm{P} / \mathrm{E}=1$. Exina de $2 \mu \mathrm{m}$ de grosor, sexina y nexina de igual espesor; ornamentación psilada. Tetraporado o pentaporado, poro de 2 a $4 \mu \mathrm{m}$ de diámetro, con anillo de $2 \mu \mathrm{m}$ de ancho (Pozo IV, muestra 23).

- Tétrada (Lámina XXVIII, figuras 286 y 287)

Tétradas cuadrangulares, de 34 × $20 \mu \mathrm{m}$. Monadas elípticas. Exina de $2 \mu \mathrm{m}$ de grosor, no se distinguen la sexina y la nexina; ornamentación escrobiculada. Probablemente monosulcado (Pozo II, muestra 8).

\section{Discusión}

En los sedimentos de la laguna de Chignahuapan se identificaron 96 palinomorfos presentes en los últimos 10,000 años AP. Éstos indican la presencia de bosques templados, como los de Abies, Pinus, Quercus, y de bosques húmedos. Los componentes de los bosques húmedos fueron Alnus, Carya, Fraxinus, Celtis, CuTaJu, Juglans, Liquidambar, Myrica, Populus, Prunus, Rosaceae, Salix y Heliocarpus.

En la orilla de la laguna se desarrollaron pastizales conformados por Asteraceae (incluye Lactuceae y Ambrosia, entre otras compuestas), varias especies de Poaceae y Amarantaceae/Chenopodiaceace.

Siguiendo el criterio de Bonilla-Barbosa y Novelo-Retana (1995) y Ramos-Ventura (1999), la vegetación acuática estuvo representada por los elementos locales. Entre éstos destacan los de la pradera inundable con Arenaria y Malvaceae; las subacuáticas se encuentran representadas por Ranunculaceae, Polygonum, Eriocaulon, Luzula y varias especies de Cyperus y Juncaceae; mientras que las acuáticas estrictas están representadas por Berula, Hydrocotyle, Ludwigia, Datura, Sagittaria, Potamogeton, Typha, Myriophyllum, Utricularia, Nymphoides, Nuphar y varias especies de Nymphaea, Schoenoplectus y Heteranthera.

Otras plantas presentes son Equisetum y Selaginella; entre las algas se encontraron Pediastrum y varias Chlorococcales, incluyendo Botryococcus.

Se encontraron diferentes tipos de polen de Heteranthera, Schoenoplectus, Populus, Salix y Quercus que no pudieron ser relacionadas con especies actuales. Por último, cabe agregar que se encontraron granos de polen de Bursera, Heliocereus y Asemnantha, cuya presencia no es posible explicar. Entre las especies cultivadas aparecen Cucurbitaceae y Zea mays. 
Los bosques que circundaban la laguna ofrecían material para leña, instrumentos, construcción de casas, etc., así como árboles frutales, entre los que se pueden mencionar a Prunus, Juglans y Carya. El bosque de Quercus probablemente fue explotado para carbón hace aproximadamente 3,000 años AP, ya que diminuye gradualmente, a la vez que aumentan las malezas y las arvenses. Las plantas acuáticas han sido utilizadas tradicionalmente como comestibles, medicinales y elaboración de artesanías (Novelo-Retana y Gallegos, 1988; Ramos-Ventura y Novelo-Retana, 1993; Bonilla-Barbosa y Novelo-Retana, 1995). Para la cuenca Alta del Río Lerma fueron identificadas con usos potenciales a Cyperus, Schoenoplectus, Luzula, Juncaceae, Typha, Berula, Datura, Sagittaria y varias Asteraceae.

\section{Agradecimientos}

Deseamos agradecer al Dr. Rodolfo Palacios-Chávez $\dagger$, la M. en C. María de la Luz Arreguín, la M. en C. Leonor Quiroz, el Dr. Rogel Villanueva y el Dr. Gerald Islebe, por su ayuda en la identificación de ciertos grupos de palinomorfos. Al Dr. Eberto Novelo la identificación de los grupos de algas. A los Srs. Jorge y Lourdes Olivera en la realización del trabajo fotográfico. A la Biól. Verónica Aguilar su apoyo técnico. Este trabajo se realizó con apoyo del CONACYT, Proyecto 13377-H.

\section{Literatura citada}

Almeida-Leñero L. 1997. Vegetación, fitogeografía y paleoecología del zacatonal alpino y bosques montanos de la región central de México. Tesis Doctoral, Universidad de Amsterdam, Amsterdam, 255 pp.

Arreguín M.L., Fernández R., Palacios-Chávez R. y Quiroz D.L. 1996. Morfología de las esporas de pteridófitas isospóreas del estado de Querétaro, México. Polibotánica 2:10-60.

Arreguín M.L., Palacios-Chávez R. y Quiroz D.L. 2001. Morfología de las esporas del género Selaginella en el estado de Querétaro, México y distribución de megasporangios y microesporangios en los estróbilos. Revista da Universidade de Guarulhos 9:84-128.

Bassett Y.J., Crompton C.W. y Parmelee J.A. 1979. An Atlas of Airbone Pollen Grains and Common Fungus Spores of Canada. Research Branch. Canada Department of Agriculture. Monograph No. 18. Ottawa, Canadá.

Blackmore S. 1984. Compositae-Lactuceae. En: Punt W. y Clarke G.C.S. Eds. The Northwest European Pollen Flora IV, pp. 4585, Elsevier, Amsterdam.

Blackmore S. y Heath G.L.A. 1984a. Berberidaceae. En: Punt W. y Clarke G.C.S. Eds. The Northwest European Pollen Flora IV, pp. 7-21, Elsevier, Amsterdam.

Blackmore S. y Heath G.L.A. 1984b. Menyanthaceae. En: Punt W. y Clarke G.C.S. Eds. The Northwest European Pollen Flora IV, pp. 121-132, Elsevier, Amsterdam.

Bloomfield K. 1975. A late-Quaternary monogenetic volcano field in Central Mexico. Geological Rundschau 64:476-497.
Bloomfield K. y Valastro S. 1977. Late Quaternary tephrochronology of Nevado de Toluca volcano, Central Mexico. Overseas Geology and Mineral Resources 46:1-15.

Bonilla-Barbosa J. y Novelo-Retana A. 1995. Manual de Identificación de Plantas Acuáticas del Parque Nacional Lagunas de Zempoala. Cuadernos del Instituto de Biología No. 26, Universidad Nacional Autónoma de México, México D.F.

Boss J.A.A. y Punt W. 1991. Juglandaceae. En: Punt W. y Blackmore S. Eds. The Northwest European Pollen Flora VI, pp. 79-95, Elsevier, Amsterdam.

Bradbury J. 1970. Diatoms from the Pleistocene sediments of Lake Texcoco, Mexico. Revue de Geographie Physique et de Geologie Dinamique 12:151-168.

Bradbury J. 1971. Paleolimnology of Lake Texcoco. Mexico. Limnology/Oceanography 16:180-200.

Bradbury J. 1986. Paleolimnología del lago de Chalco, México. El medio ambiente litoral. En: Lorenzo J.L. y Mirambell L. Eds. Tlapacoya: 35,000 Años de Historia del Lago de Chalco, pp. 167-172, Instituto Nacional de Antroplogía e Historia, México, D.F.

Christensen P.B. y Blackmore S. 1988. Tiliaceae. En: Punt W. Blackmore S. y Clarke G.C.S. Eds. The Northwest European Pollen Flora V, pp. 33-43, Elsevier, Amsterdam.

Clarke G.C.S. y Jones M.R. 1980a. Plantaginaceae. En: Punt W. y Clarke G.C.S. Eds. The Northwest European Pollen Flora II, pp. 29-154, Elsevier, Amsterdam.

Clarke G.C.S. y Jones M.R. 1980b. Valerianaceae. En: Punt W. y Clarke G.C.S. Eds. The Northwest European Pollen Flora II, pp. 155-198, Elsevier, Amsterdam.

Clarke G.C.S., Punt W. y Hoen P.P. 1991. Ranunculaceae. En: Punt W. y Blackmore S. Eds. The Northwest European Pollen Flora VI, pp. 117-271, Elsevier, Amsterdam.

Cronk Q.C.B. y Clarke G.C.S. 1981. Convolvulaceae. En: Punt W. y Clarke G.C.S. Eds. The Northwest European Pollen Flora III, pp. 117-135, Elsevier, Amsterdam.

Cronquist A. 1981. An Integrated System of Classification of Flowering Plants. Columbia University Press, Nueva York.

Culhane K.J. y Blackmore S. 1988. Malvaceae. En: Punt W., Blackmore S. y Clarke G.C.S. Eds. The Northwest European Pollen Flora V, pp. 45-74, Elsevier, Amsterdam.

Curtis J., Hodell D. y Brenner M. 1996. Climate variability on the Yucatan Peninsula (Mexico) during the past 3500 years, and implications for Maya cultural evolution. Quaternary Research 46:37-47.

Dahlgren R.M., Clifford H.T. y Yeo P.F. 1985. The families of the Monocotyledons, Structure, Evolution and Taxonomy. SpringerVerlag, Berlín.

Engel M.S. 1980. Haloragaceae. En: Punt W. y Clarke G.C.S. The Northwest European Pollen Flora II, pp. 209-260, Elsevier, Amsterdam.

Erdtman G. 1960. The acetolysis method: A revised description. Svensk Botanisk Tidskrift 54:561-564.

Flores-Díaz A. 1986. Fluctuaciones del lago de Chalco, desde hace 35 mil años al presente. En: Lorenzo J.L. y Mirambell L. Eds. Tlapacoya: 35,000 Años de Historia del Lago de Chalco, pp. 109-156, Instituto Nacional de Antropología e Historia, México, D.F.

Furness C.A. 1988. Eriocaulaceae. En: Punt W., Blackmore S. y Clarke G.C.S. Eds. The Northwest European Pollen Flora V, pp. 27-32, Elsevier, Amsterdam. 
García-Quintana J. y López-Austin A. 1989. Historia General de las Cosas de la Nueva España. Fray Bernardino de Sahagún. Tomos I y II. Consejo Nacional para la Cultura y las Artes de México, D.F.

Goman M. y Byrne R. 1998. A 5000-year record of agriculture and tropical forest clearance in the Tuxtlas, Veracruz, Mexico. The Holocene 8:83-89.

González-Quintero L. 1981. Análisis polínico en la porción austral de la Cuenca de México. II. Tlaltenco. Cuicuilco 2:12-15.

González-Quintero L. 1986. Análisis polínicos de los sedimentos. En: Lorenzo J.L. y Mirambell L. Eds. Tlapacoya: 35,000 Años de Historia del Lago de Chalco, pp. 157-166, Instituto Nacional de Antropología e Historia, México, D.F.

González-Quintero L. y Fuentes-Mata M. 1980. El Holoceno de la porción central de la cuenca del Valle de México. En: Sánchez F. Coord. Memorias III Coloquio sobre Paleobotánica y Palinología. SEP/INAH., México. 86:113-132.

González-Trapaga M.A. 1986. Descripción y aspectos fitogeográficos de la vegetación alpina del Nevado de Toluca, Edo. de México. Tesis de Licenciatura, Facultad de Ciencias, Universidad Nacional Autónoma de México, México, D.F., 63 pp.

Heine K. 1973. Variaciones más importantes del clima en los últimos 40,000 años en México. Comunicaciones 7:551-558.

Herrera T. 1951. Algunos datos ecológicos sobre la vegetación de Lerma. Boletín de la Sociedad Botánica de México 13:1-3.

Hodell D., Curtis J. y Brenner M. 1995. Possible role of climate in the collapse of classic Maya civilization. Nature 375:391-394.

Hooghiemstra H. 1984. Vegetational and climatic history of the high plain of Bogota, Colombia: A continuous record of the last 3.5 million years. Dissertationes Botanicae 79:1-368.

Islebe G.A., Hooghiemstra H., Brenner M., Curtis J.H. y Hodell D.A. 1996. A Holocene vegetation history from lowland Guatemala (Lake Peten-Itza). The Holocene 6:265-271.

Jones M.R. y Clarke G.C.S. 1981. Nymphaeaceae. En: Punt W. y Clarke G.C.S. Eds. The Northwest European Pollen Flora III, pp. 57-67, Elsevier, Amsterdam.

Lozano-García S. y Ortega-Guerrero B. 1994. Palynological and magnetic susceptibility records at Lake Chalco, Central Mexico. Palaeogeography, Palaeoclimatology, Palaeoecology 109:177-191.

Lozano-García S., Ortega-Guerrero B., Caballero M. y Urrutia J. 1993. Late Pleistocene and Holocene paleoenvironments of Chalco Lake, Central Mexico. Quaternary Research 40:332-342.

Ludlow-Wiechers B., Alvarado J.L. y Aliphat M. 1983. Polen de Zea (maiz y teosinte); perspectivas para conocer su origen. Biótica 8:235-258.

Ludlow-Wiechers B. y Ayala-Nieto M. 1992. Polen de plantas utilizadas en Mesoamérica. En: Darwin S.P. y Welden. A.L. Eds. Biogeography of Mesoamerica, pp. 155-172, Tulane University, Nueva Orleans.

Ludlow-Wiechers B. y Palacios-Chávez R. 2001. Palinología de los géneros encontrados en los sedimentos del lago de Chalco, Centro de México. Anales de la Escuela Nacional de Ciencias Biológicas 47:(en prensa).

Macías J.L., García A., Arce J.L., Siebe C., Espíndola J.M., Komorowski J.C. y Scott K. 1997. Late Pleistocene-Holocene cataclysmic eruptions at Nevado de Toluca and Jocotitlán Volcanoes, Central Mexico. I.A.V.C.E.I. Plenary Assembly, Puerto Vallarta, Jalisco, México. Excursion No. 14. Field Guide, México, D.F.
Martínez M. y Matuda E. 1979. Flora del Estado de México. Edición facsimilar de los fascículos publicados en los años 1953 a 1972. Biblioteca Enciclopédica del Estado de México. Tomos I, II y III. Toluca, Edo. de Méx.

Metcalfe S., Street-Perrott F.A., Perrott R.A. y Harkness D.D. 1991. Palaeolimnology of the Upper Lerma Basin, Central Mexico: a record of climatic change and anthropogenic disturbance since 11,600 yr BP. Journal of Palaeolimnology 5:197-218.

Mirambell L. 1985. Restos culturales en horizontes pleistocénicos. En: Lorenzo J.L. y Mirambell L. Eds. Tlapacoya: 35,000 Años de Historia del Lago de Chalco, pp. 207-217, Instituto Nacional de Antropología e Historia, México, D.F.

Moran R.C. y Riba R. 1995. Psilotaceae a Salviniaceae. En: Davidse G., Sousa M. y Knapp S. Eds. Flora Mesoamericana. Instituto de Biología, Universidad Nacional Autónoma de México, Missouri Botanical Garden, The Natural History Museum (London), México, D.F.

Morbelli M. 1977. Esporas de las especies argentinas de Selaginella (Selaginellaceae-Pterydophyta). Revista de la Universidad de La Plata 3:121-150.

Newton A. y Metcalfe S. 1999. Tephrochronology of the Toluca Basin, Central Mexico. Quaternary Science Reviews 18:10391059.

Nilsson S., Praglowski J. y NiIsson L. 1977. Atlas of Arborne Pollen Grains and Spores in Northern Europe. Natur och Kultur, Estocolmo.

Novelo-Retana A. y Gallegos M.M. 1988. Estudio de la flora y vegetación acuática relacionada con el sistema de chinampas en el sureste del Valle de México. Biótica 13:121-139.

Ohngemach D. y Straka H. 1978. La historia de la vegetación en la región Puebla-Tlaxcala durante el Cuaternario tardío. Comunicaciones 15:189-196.

Olvera M. 1997. Menyanthaceae, Nymphaeaceae, Pontederiaceae y Typhaceae En: Ludlow-Wiechers B. y Hooghiemstra H. Eds. Flora Palinológica de Guerrero, No. 5, Facultad de Ciencias, Universidad Nacional Autónoma de México, Laboratorio Hugo De Vries, Universidad de Amsterdam, México, D.F.

Palacios-Chávez R., Ludlow-Wiechers B. y Villanueva R. 1991. Flora Palinológica de la Reserva de la Biósfera en Sian Ka'an, Quintana Roo, México. Centro de Investigaciones de Quintana Roo, Chetumal.

Palacios-Chávez R., Arreguín-Sánchez M.L. y Quiroz-García D.L. 1996. Morfología de los granos de polen de las familias Acanthaceae, Vitaceae y Violaceae del Valle de México. Acta Botanica Mexicana 34:1-24.

Punt W. 1976. Sparganiaceae y Typhaceae. En: Punt W. Ed. The Northwest European Pollen Flora I, pp. 75-88, Elsevier, Amsterdam.

Punt W. 1984. Umbelliferae. En: Punt W. y Clarke G.C.S. Eds. The Northwest European Pollen Flora IV, pp. 155-363, Elsevier, Amsterdam.

Punt W. y Monna-Brands M. 1980. Solanaceae. En: Punt W. y Clarke G.C.S. Eds. The Northwest European Pollen Flora II, pp. 1-30, Elsevier, Amsterdam.

Punt W. y Reumer J.W. 1981. Alismataceae. En: Punt W. y Clarke G.C.S. Eds. The Northwest European Pollen Flora III, pp. 2744, Elsevier, Amsterdam.

Punt W. y Langewis E.A. 1988. Verbenaceae. En: Punt W., Blackmore S. y Clarke G.C.S. Eds. The Northwest European Pollen Flora V, pp. 75-79, Elsevier, Amsterdam. 
Ramírez-Cantú D. y Herrera T. 1954. Contribución al conocimiento de la vegetación de Lerma y sus alrededores. Anales del Instituto de Biología, México 25:65-95.

Ramos-Ventura L.J. 1999. Estudio de la flora y la vegetación acuáticas vasculares de la cuenca alta del Río Lerma, en el Estado de México. Tesis de Maestría en Ciencias, Facultad de Ciencias, Universidad Nacional Autónoma de México, México, D.F. $151 \mathrm{pp}$.

Ramos-Ventura L.J. y Novelo-Retana A. 1993. Vegetación y flora acuática de la laguna de Yuriria, Guanajuato, México. Acta Botanica Mexicana 25:61-79.

Rioja E. y Herrera S.T. 1951. Ensayo ecológico sobre el limnobio de Lerma y sus alrededores. Anales del Instituto de Biología, México 22:565-591.

Rodríguez-Jiménez C. 1967. Estudio ecológico de las malas hierbas del Valle de Toluca, México. Tesis de Licenciatura, Facultad de Ciencias, Universidad Nacional Autónoma de México. México, D.F., 85 pp.

Romero-Quiroz R. 1987. Santiago Tianguistenco. Gobierno del Estado de México. Toluca, Edo. de Méx.

Sánchez-Martínez F. 1982. Morfología Polínica de Algunas Malvaceaes Mexicanas. Instituto Nacional de Antropología e Historia, México, D.F.

Sandoval-Basso A.J. 1987. Actualización y análisis cartográfico sobre usos del suelo y vegetación del Parque Nacional Nevado de Toluca, Estado de México. Tesis de Licenciatura, Facultad de Ciencias, Universidad Nacional Autónoma de México, México, D.F., 107 pp.

SPP (Secretaría de Programación y Presupuesto). 1983. Síntesis Geográfica, Nomenclator y Anexo Cartográfico del Estado de México. Instituto Nacional de Estadística, Geografía e Informática, México, D.F.

Stafford P.J. 1991. Selaginellaceae. En: Punt W. y Blackmore S. Eds. The Northwest European Pollen Flora VI, pp. 1-22, Elsevier, Amsterdam.

Straka H. y Ohngemach O. 1989. Late Quaternary vegetation history of the Mexican highland. Plant Systematics and Evolution 162:115-132.

Sugiura Y., Flores A., Ludlow-Wiechers B., Valadez F., Gold M. y Maillol J.M. 1994. El agua, la tierra, el bosque y el hombre en el Alto Lerma: un estudio multidisciplinario. Arqueología 1112:29-45.

Fecha de recepción: 8 de octubre de 2002

Versión corregida: 14 de abril de 2003

Aceptado: 15 de abril de 2003
Sugiura Y. y McClung de Tapia E. 1988. Algunas consideraciones sobre el uso prehispánico de recursos vegetales en la cuenca del Alto Lerma. Anales de Antropología 25:111-125.

Tryon R.M. y Tryon A.F. 1982. Ferns and Allied Plants, with Special Reference to Tropical America. Springer Verlag, Nueva York.

Van Benthem F., Clarke G.C.S. y Punt W. 1984. Fagaceae. En: Punt W. y Clarke G.C.S. Eds. The Northwest European Pollen Flora $I V$, pp. 87-110, Elsevier, Amsterdam.

Van den Hoek C., Mann D.G. y Jahns H.W. 1995. Algae. An introduction to Phycology. Cambridge University Press, Cambridge.

Van der Hammen T. 1995. Global change, biodiversity, and conservation of neotropical montane forests. En: Churchill S.T., Balslev H., Forero E. y Luteyn J.L. Eds. Biodiversity and Conservation of Neotropical Montane Forests, pp. 603-607, The New York Botanical Garden, Nueva York.

Van Leeuwen P., Punt W. y Hoen P.P. 1988. Polygonaceae. En: Punt W., Blackmore S. y Clarke G.C.S. Eds. The Northwest European Pollen Flora V, pp. 81-151, Elsevier, Amsterdam.

Vela-Gálvez L., Boyás-Delgado J., Hernández-Reyna A., ManceraOrozco A. y Rodríguez-Ángeles A. 1976. El Nevado de Toluca. Ciencia Forestal 1:53-61.

Villalpando-Barriga O.K. 1968. Algunos aspectos ecológicos del Volcán Nevado de Toluca. Tesis de Licenciatura, Facultad de Ciencias, Universidad Nacional Autónoma de México, México, D.F., 36 pp.

Watts W.A. y Bradbury J.P. 1982. Paleoecological studies at lake Patzcuaro on the West Central Mexican plateau and at Chalco in the basin of Mexico. Quaternary Research 17:56-70.

Xelhuantzi-López S. 1989. Estudios Polínicos sobre el Clima del Cuaternario en México. Instituto Nacional de Antropología e Historia, México, D.F.

Xelhuantzi-López S. 1994. Determinación palinológica del paleoambiente Holocénico en la parte norte del Estado de Michoacán. Boletín de la Sociedad Botánica de México 54:251265.

Xelhuantzi-López S. 1995. Palynologie et paléoenvironement du bassin de Zacapu, Michoacán. Mexique, depuis 8,000 ans. Geofísica Internacional 34:239-248. 


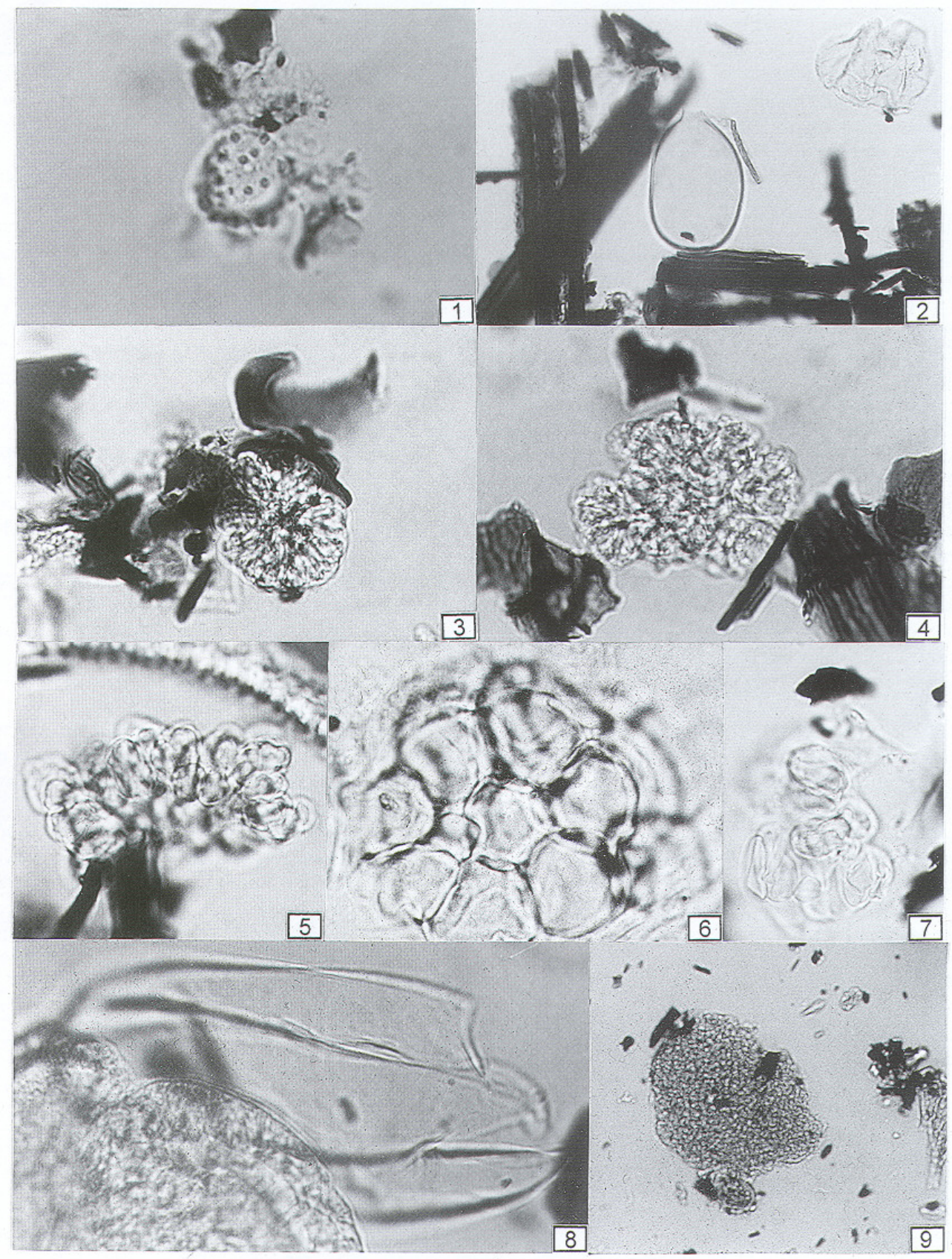

Lámina I. CHRYSOPHYTA/HETEROKONTOPHYTA. CHRYSOPHYCEAE. Figura 1: Chrysophyceae (VII, 19) (escala 1:1000). EUGLENOPHYTA. EUGLENALES. Figura 2: Trachelomonas (VII, 19) (escala 1:1000). CHLOROPHYTA. CHLOROCOCCALES. Figuras 3 y 4: Botryococcus sp. (VII, 38; IV, 19) (escala 1:1000). Figura 5: Coelastrum 1 (VII, 12) (escala 1:1000). Figura 6: Coelastrum 2 (VII, 27) (escala 1:1000). Figura 7: Oocystis sp. (escala 1:1000). Figura 8: Spyrogira sp. (VII, 17) (escala 1:1000). Figura 9: Chlorophyceae/ Xantophyceae/Cyanophyceae (II, 4) (escala 1:1000). 


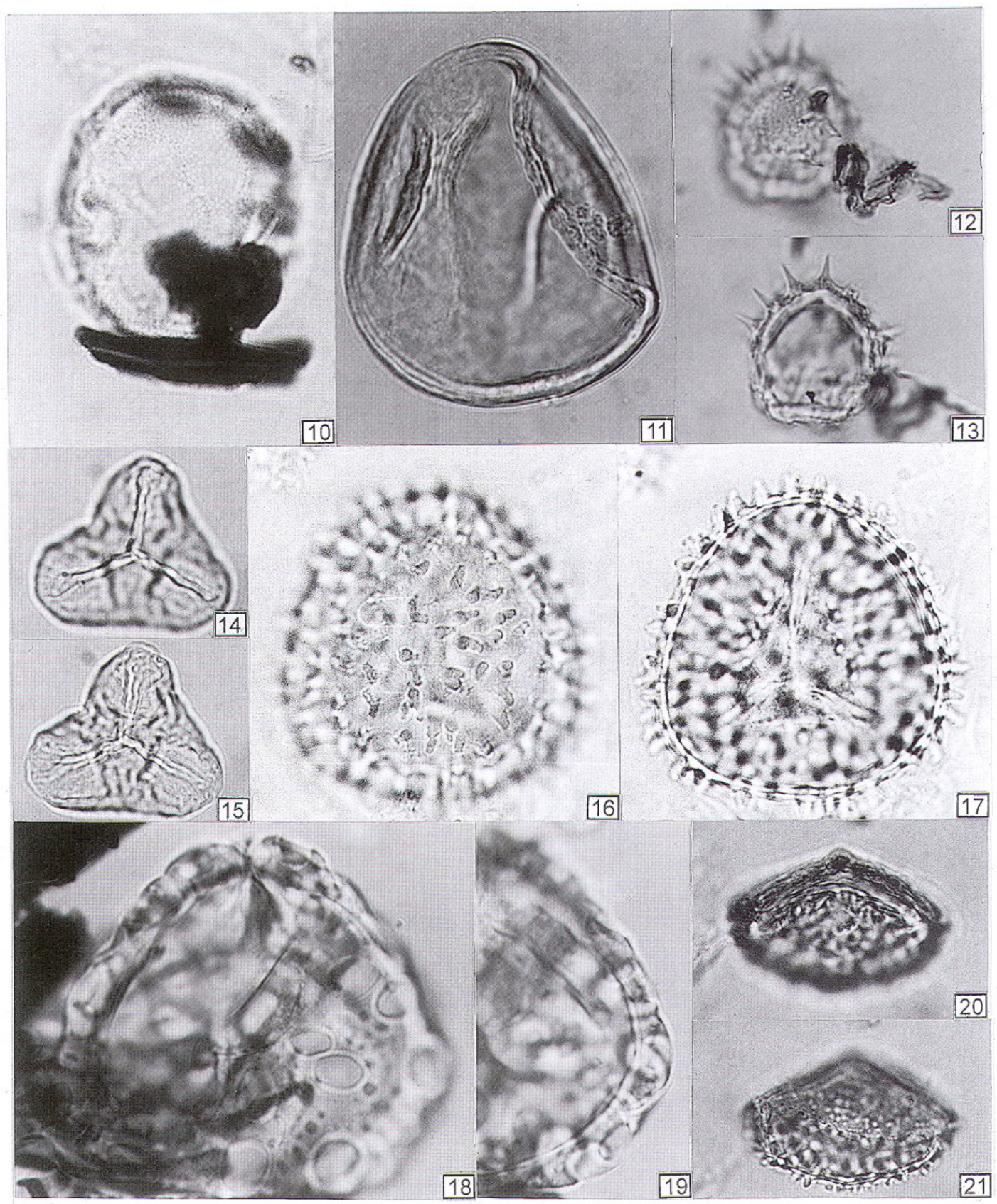

Lámina II. EQUISETOPSIDA. EQUISETACEAE. Figura 10: Equisetum 1 (VI, 46) (escala 1:1000). Figura 11: Equisetum 2 (VII, 32) (escala 1:1000). LYCOPODIOPSIDA. SELAGINELLACEAE. Figuras 12 y 13: Selaginella hoffmannii (VII, 19) (escala 1:1000). Figuras 14 y 15: Selaginella rupincola (VII, 31) (escala 1:1000). Figuras 16 y 17: Selaginella sp. (VII, 24) (escala 1:1000). POLYPODIOPSIDA. CYATHEACEAE. Figuras 18 y 19: Lophosoria quadripinnata (VII, 24) (escala 1:1000). DENNSTAEDTIACEAE. Figuras 20 y 21: Dennstaedtia sp. (VI, 46) (escala 1:1000). 


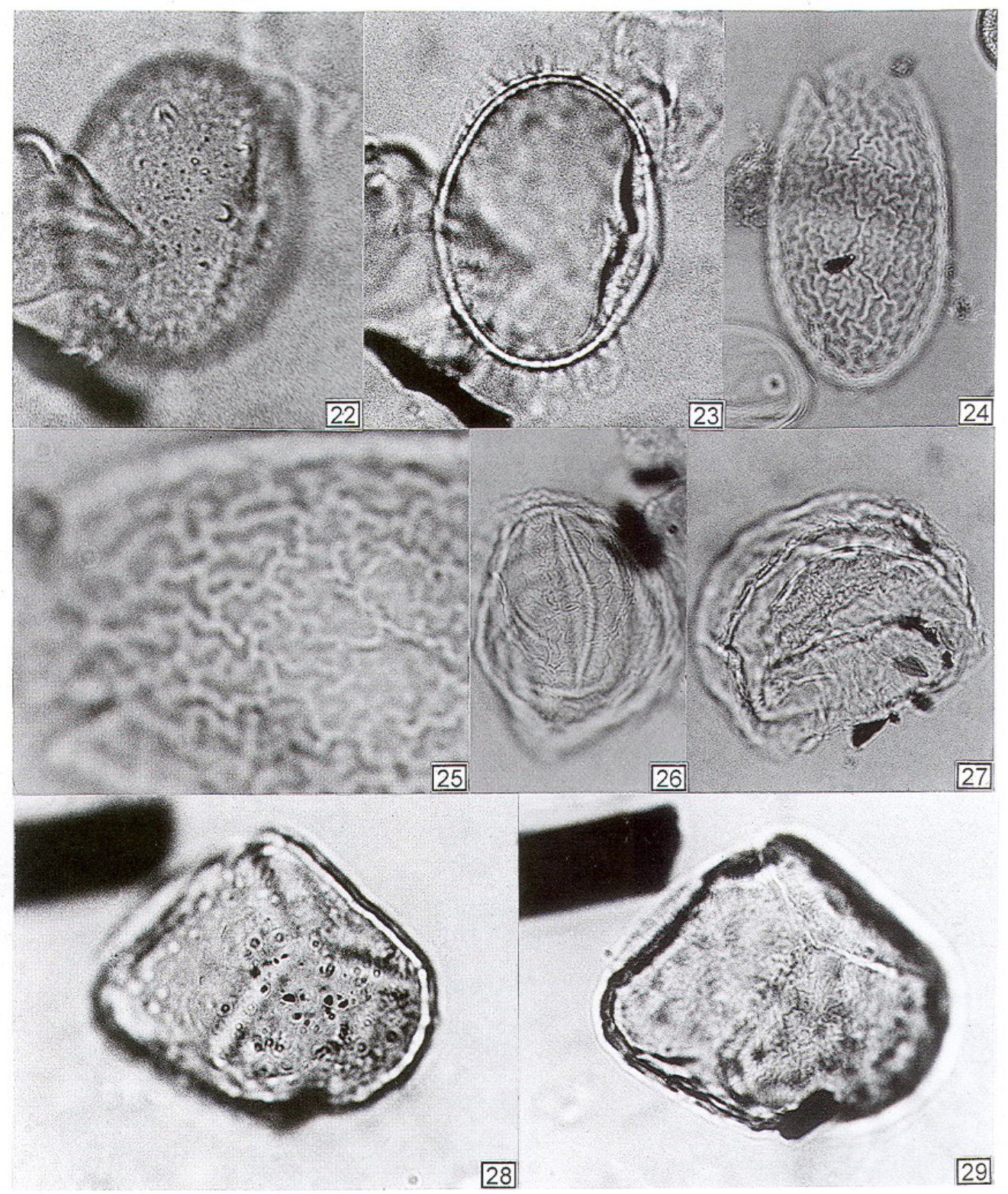

Lámina III. DRYOPTERIDACEAE. Figuras 22 y 23: Ctenitis sp. (VII, 29) (escala 1:1000). Figuras 24 y 25: Dryopteridaceae 1 (IV, 23 ) (24, escala 1:500; 25 escala 1:1000). Figuras 26 y 27: Dryopteridaceae 2 (VII, 30; II, 3) (escala 1:1000). PLAGIOGYRIACEAE. Figuras 28 y 29: Plagiogyria semicordata (VII, 26) (escala 1:1000). 

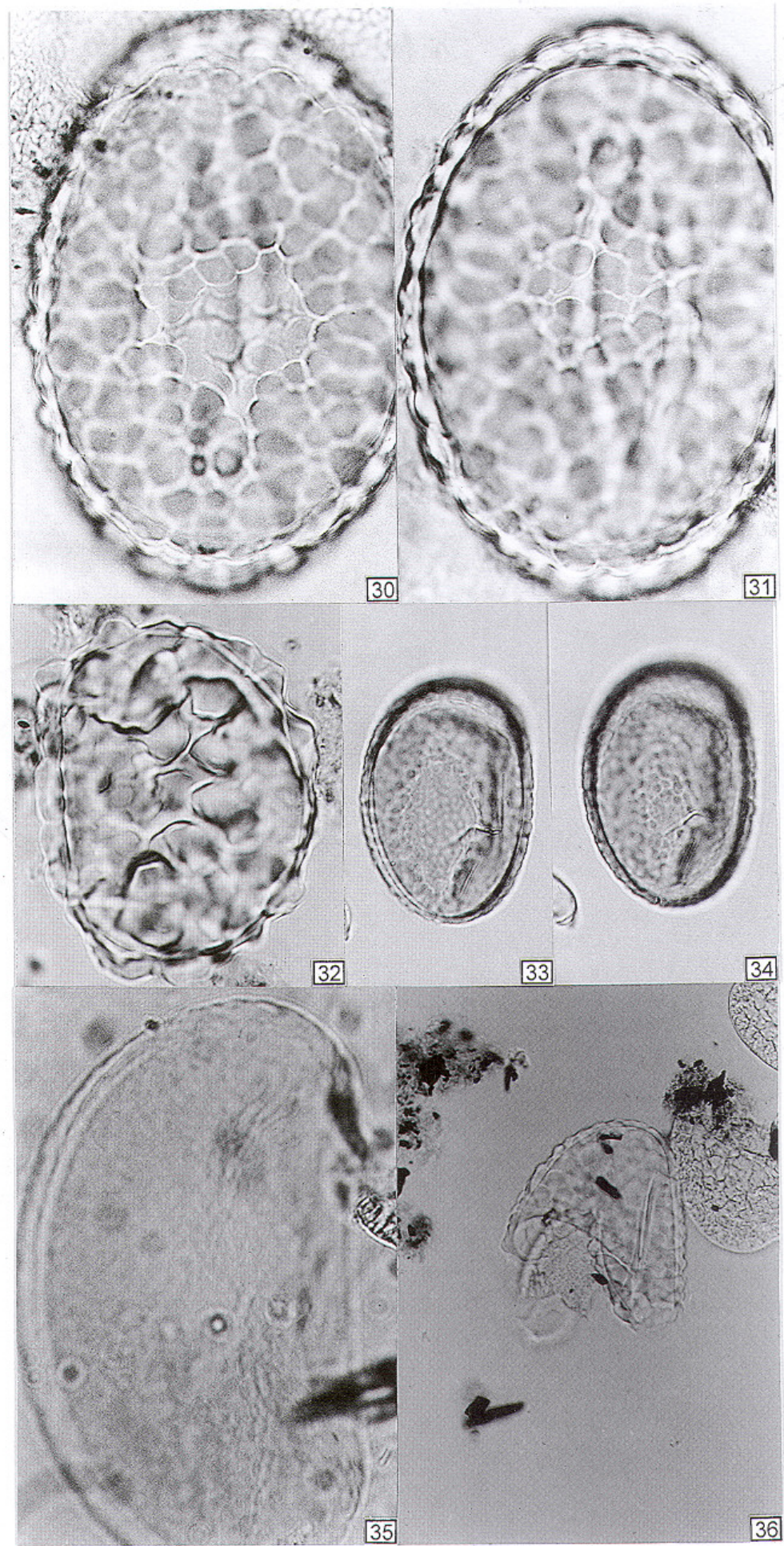

Lámina IV. POLYPODIACEAE. Figuras 30 y 31: Campylonerum angustifolium (VII, 15) (escala 1:1000). Figura 32: Phlebodium araneosum (VII, 31) (escala 1:1000). Figuras 33 y 34: Polypodium 1 (IV, 19) (escala 1:1000). Figura 35: Polypodium 2(VII, 32). Figura 36: Polypodium 3 (VI, 46) (escala 1:400). 
Beatriz Ludlow-Wiechers, Lucía Almeida-Leñero y YoKo Sugiura

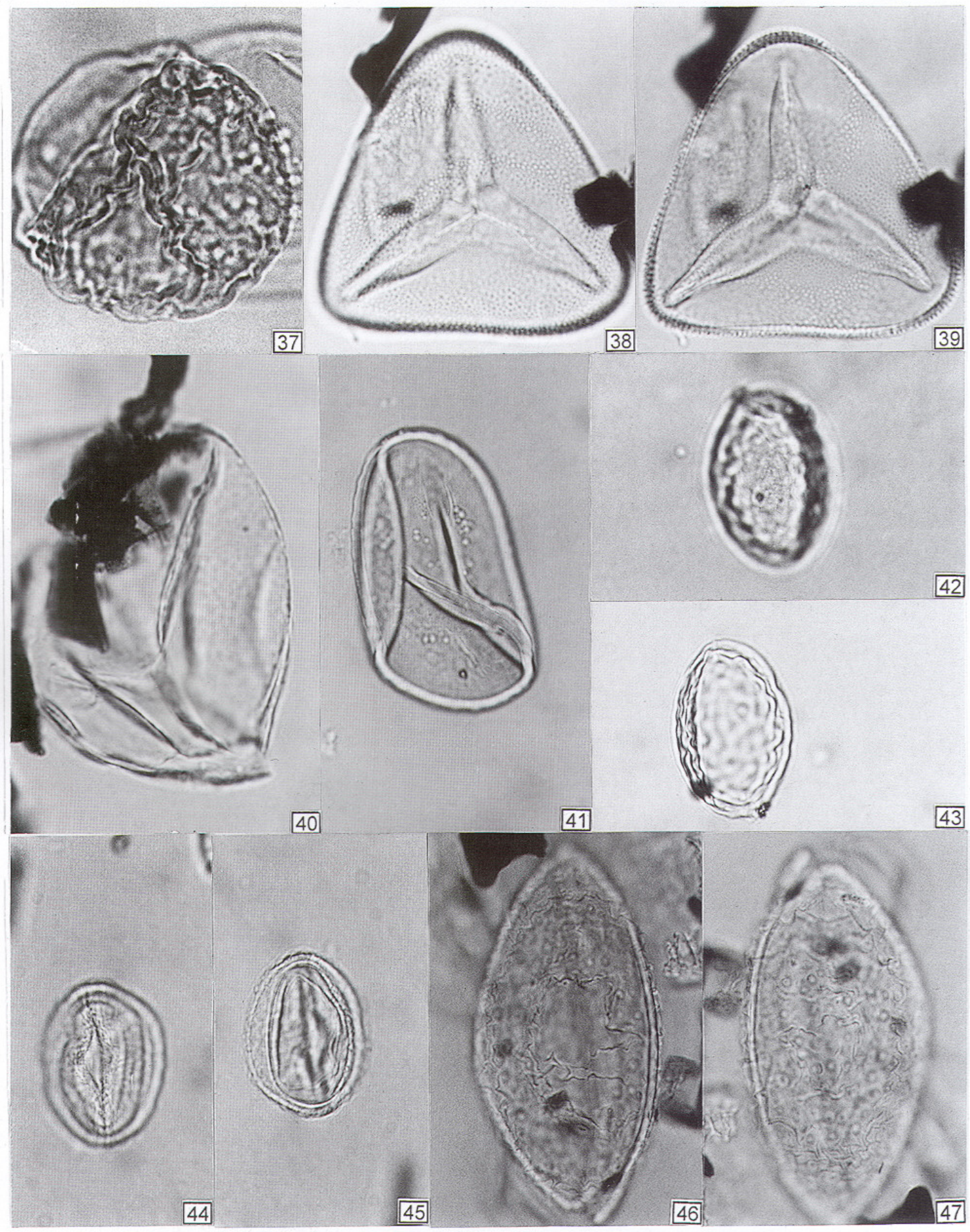

Lámina V. PTERIDACEAE. Figura 37: Cheilanthes farinosa (VII, 29) (escala 1:1000). Figuras 38 y 39: Cheilanthes sinuata (II, 3) (escala 1:1000). INDETERMINADAS. Figura 40: Espora 1 (VII, 19) (escala 1:1000). Figura 41: Espora monolete 1 (VII, 30) (escala 1:9000). Figuras 42 y 43: Espora monolete 2 (II, 8) (escala 1:1000). Figuras 44 y 45: Espora monolete 3 (VI, 46) (escala 1:1000). Figuras 46 y 47: Espora monolete 4 (II, 3) (escala 1:1000). 


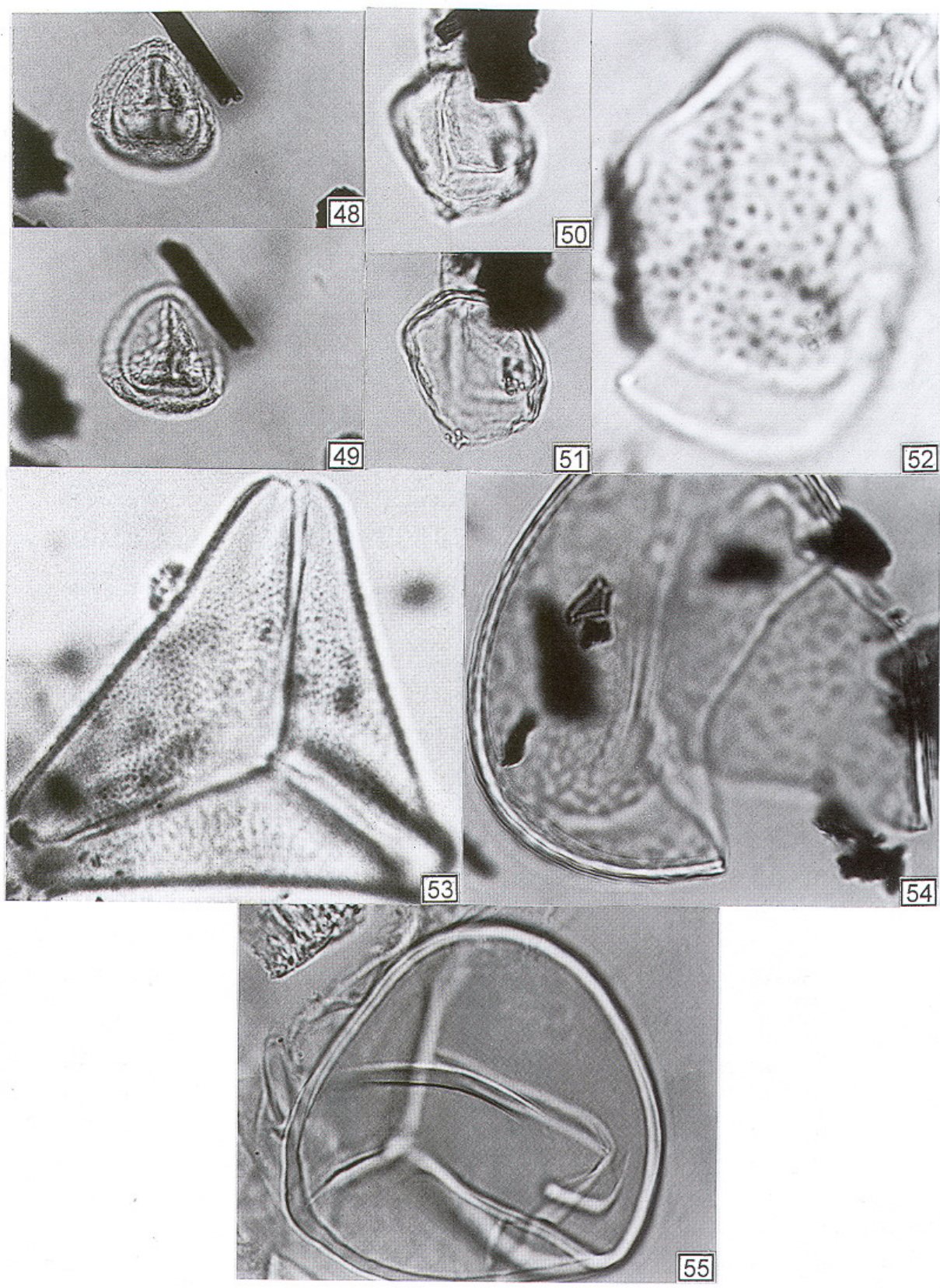

Lámina VI. Figuras 48 y 49: Espora trilete 1 (VI, 46) (escala 1:1000). Figuras 50 y 51: Espora trilete 2 (II, 7) (escala 1:1000). Figura 52: Espora trilete 3 (VII, 4) (escala 1:1000). Figura 53: Espora trilete 4 (probablemente Sapindaceae) (VII, 29) (escala 1:1000). Figura 54: Espora trilete 5 (VII, 17) (escala 1:1000). Figura 55: Espora trilete 6 (VII, 30) (escala 1:800). 
Beatriz Ludlow-Wiechers, Lucía Almeida-Leñero y Yoko Sugiura

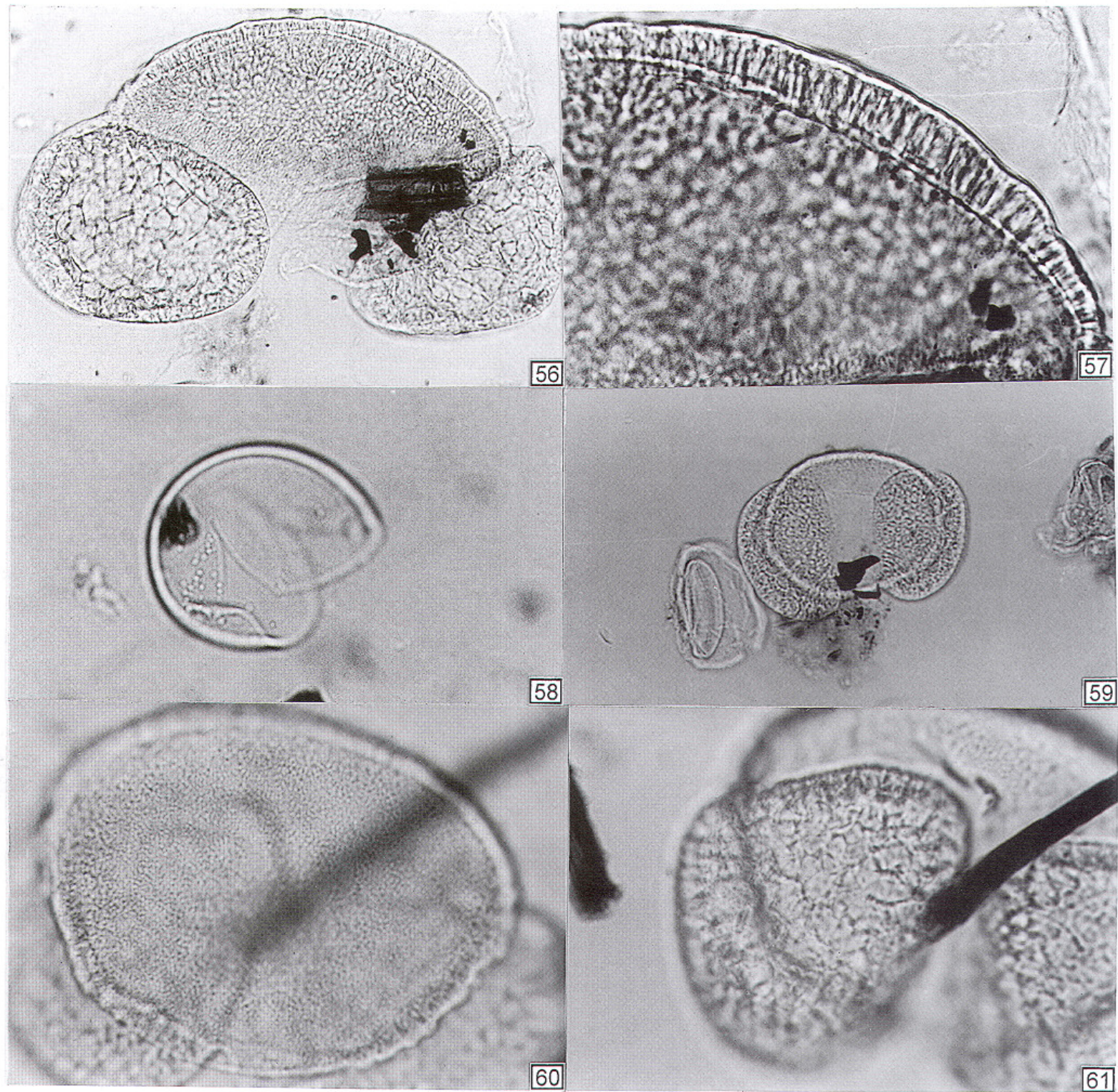

Lámina VII. PINOPHYTA. ABIETACEAE. Figuras 56 y 57: Abies sp. (VII, 25) (56, escala 1:450; 57, escala 1:1000). CUPRESSACEAE/ TAXODIACEAE. Figura 58: CuTaJu. (VII, 26) (escala 1:1000). PINACEAE. Figuras 59, 60 y 61: Pinus sp. (VII, 20 y 36) (59, escala $1: 500 ; 60$, escala $1: 1000 ; 61$, escala 1:900). 


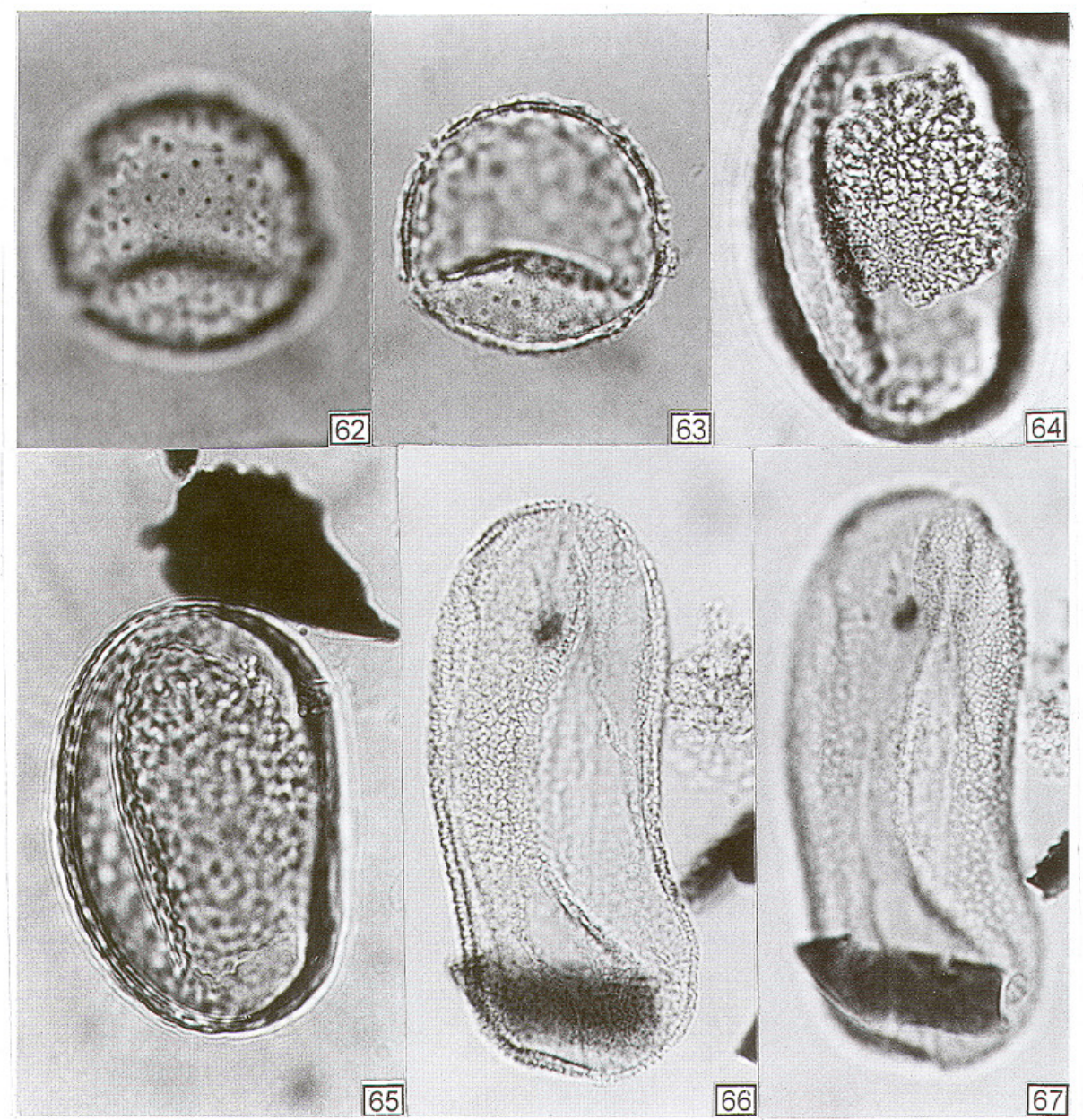

Lámina VIII. MAGNOLIOPHYTA. LILIOPSIDA. ALISMATACEAE. Figuras 62 y 63: Sagittaria sp. (VII, 22) (escala 1:1000). BROMELIACEAE. Figuras 64 y 65: Bromeliaceae 1 (VI, 46) (escala 1:1000). Figuras 66 y 67: Bromeliaceae 2 (IV, 17) (escala 1:1000). 


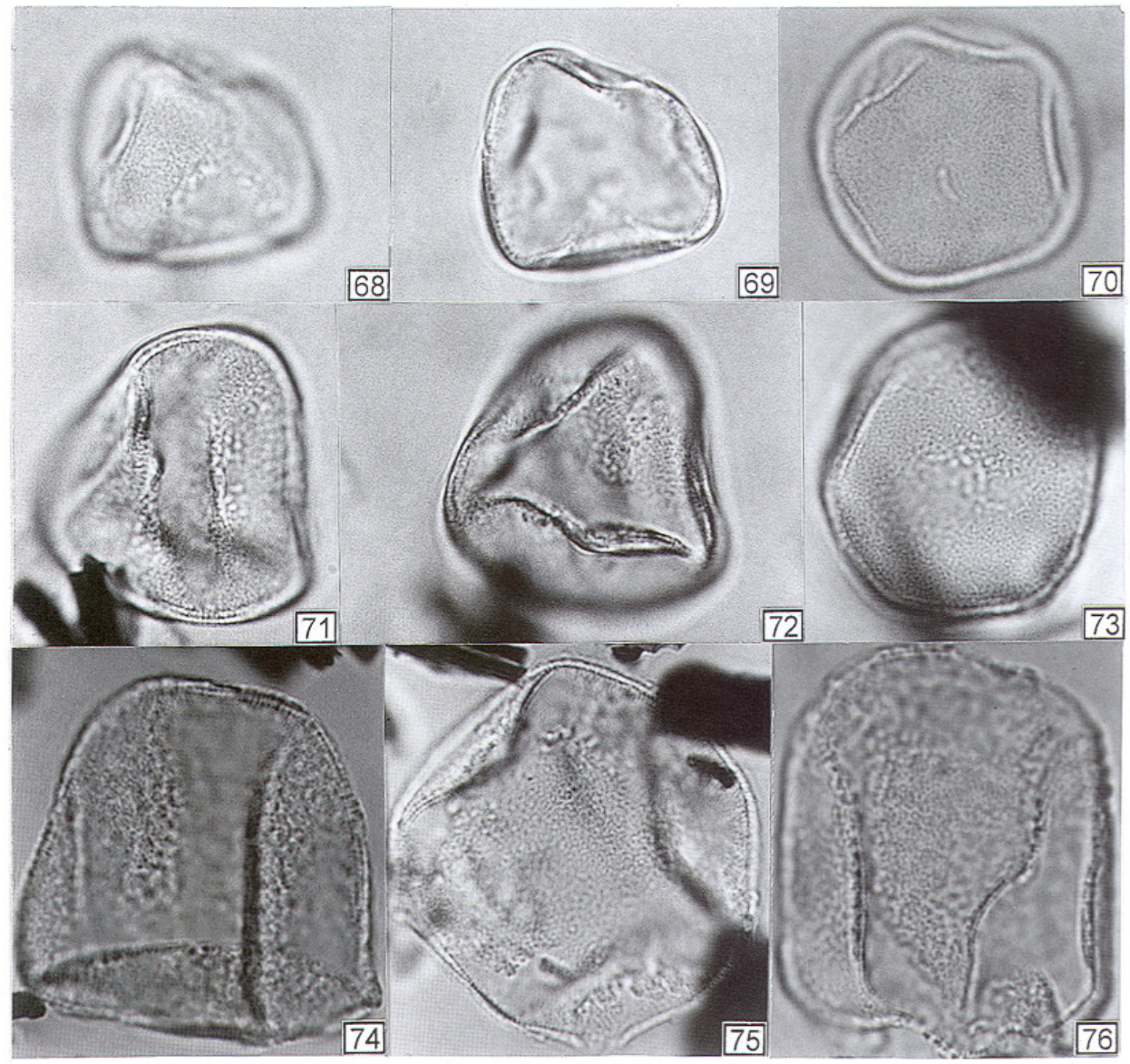

Lámina IX. CYPERACEAE. Figuras 68, 69 y 70: Cyperus 1 (IV, 47; VI, 42) (escala 1:900). Figuras 71, 72, 73 y 74: Cyperus 2 (II, 2; VII, 19) (escala 1:900). Figuras 75 y 76: Schoenoplectus 1 (VII, 19 y 21) (escala 1:900). 


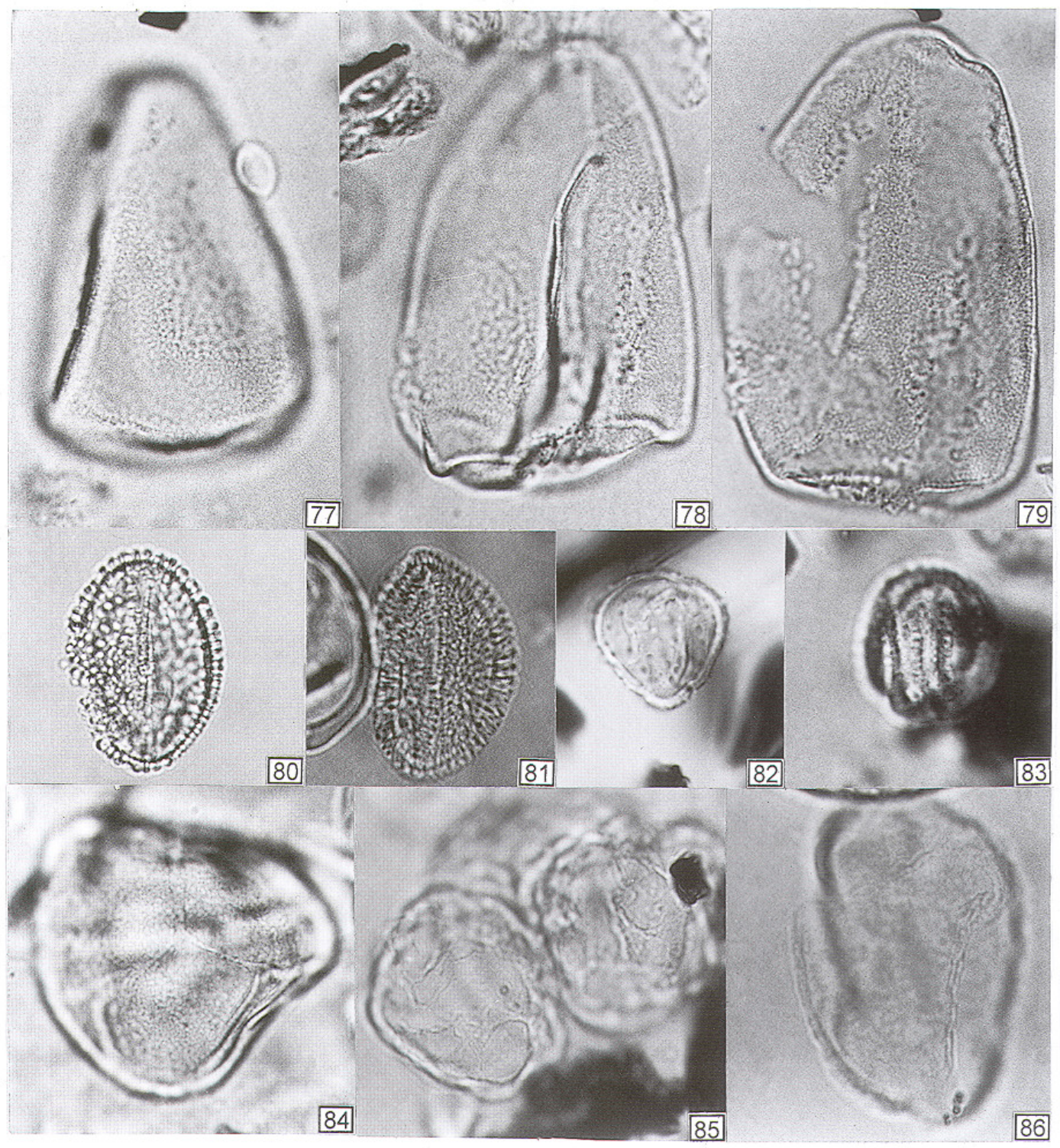

Lámina X. Figuras 77, 78 y 79: Schoenoplectus 2 (VII, 22; II, 2) (escala 1:900). COMMELINACEAE. Figuras 80 y 81: Commelinaceae (IV, 20 y 22) (escala 1:1000). ERIOCAULACEAE. Figuras 82 y 83: Eriocaulon sp. (VII, 17 y 18) (escala 1:1000). JUNCACEAE. Figura 84: aff. Luzula sp. (VII, 16) (escala 1:1000). Figura 85: aff. Juncaceae 1 (VII, 17) (escala 1:1000). Figura 86: aff. Juncaceae 2 (VI, 24) (escala 1:1000). 


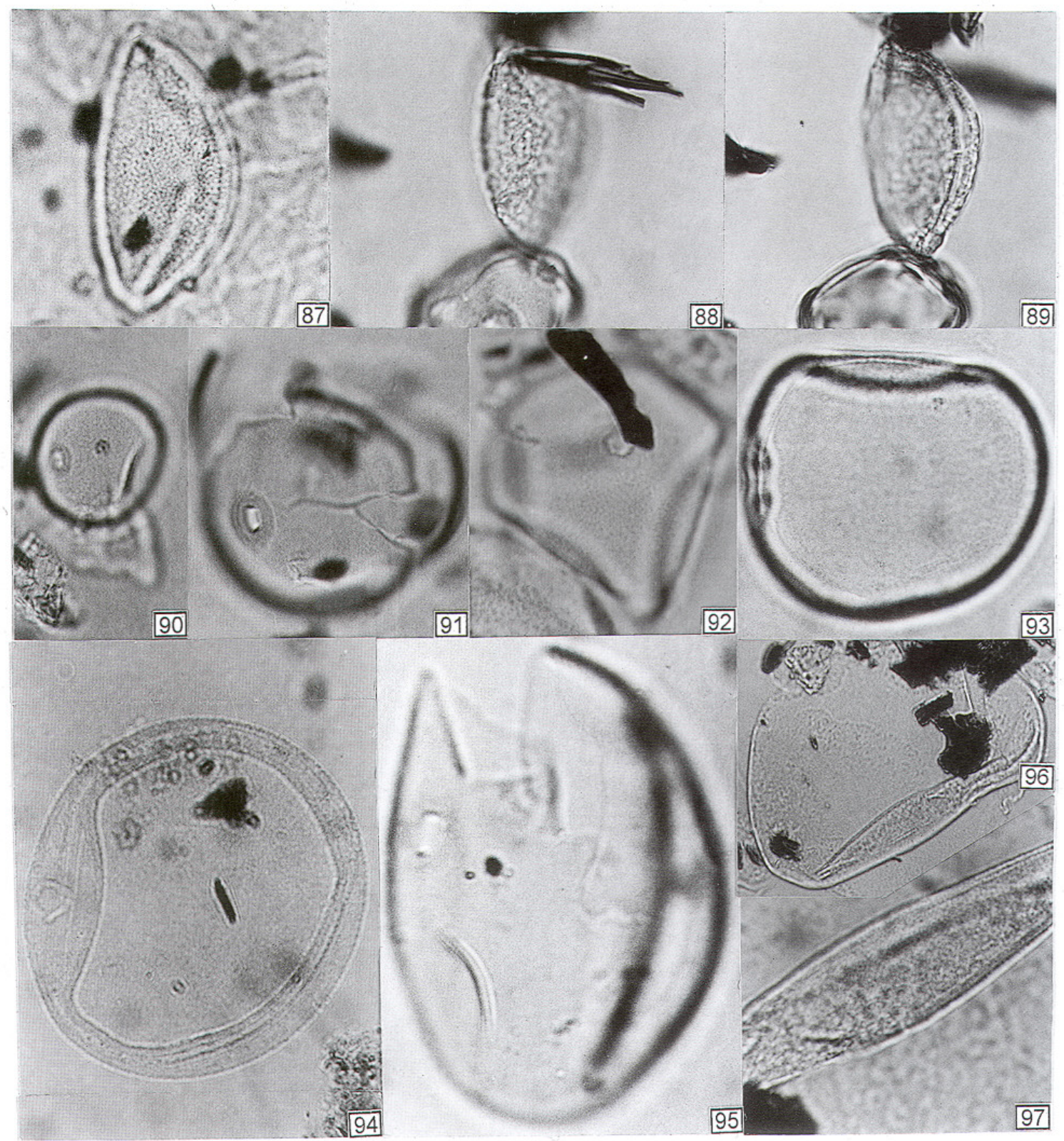

Lámina XI. LILIACEAE. Figura 87: Liliaceae 1 (VII, 27) (escala 1:1000). Figuras 88 y 89: Liliaceae 2 (VII, 14) (escala 1:1000). POACEAE. Figura 90: Poaceae 1 (VI, 46) (escala 1:1000). Figura 91: Poaceae 2 (VII, 18) (escala 1:1000). Figura 92: Poaceae 3 (VII, 32 ) (escala 1:1000). Figura 93: Poaceae 4 (VII, 18) (escala 1:900). Figura 94: Poaceae 5 (VII, 17) (escala 1:1000). Figura 95: Poaceae 6 (VII, 7) (escala 1:1000). Figuras 96 y 97: Zea mays (II, 3) (96, escala 1:500; 97, escala 1:1000). 


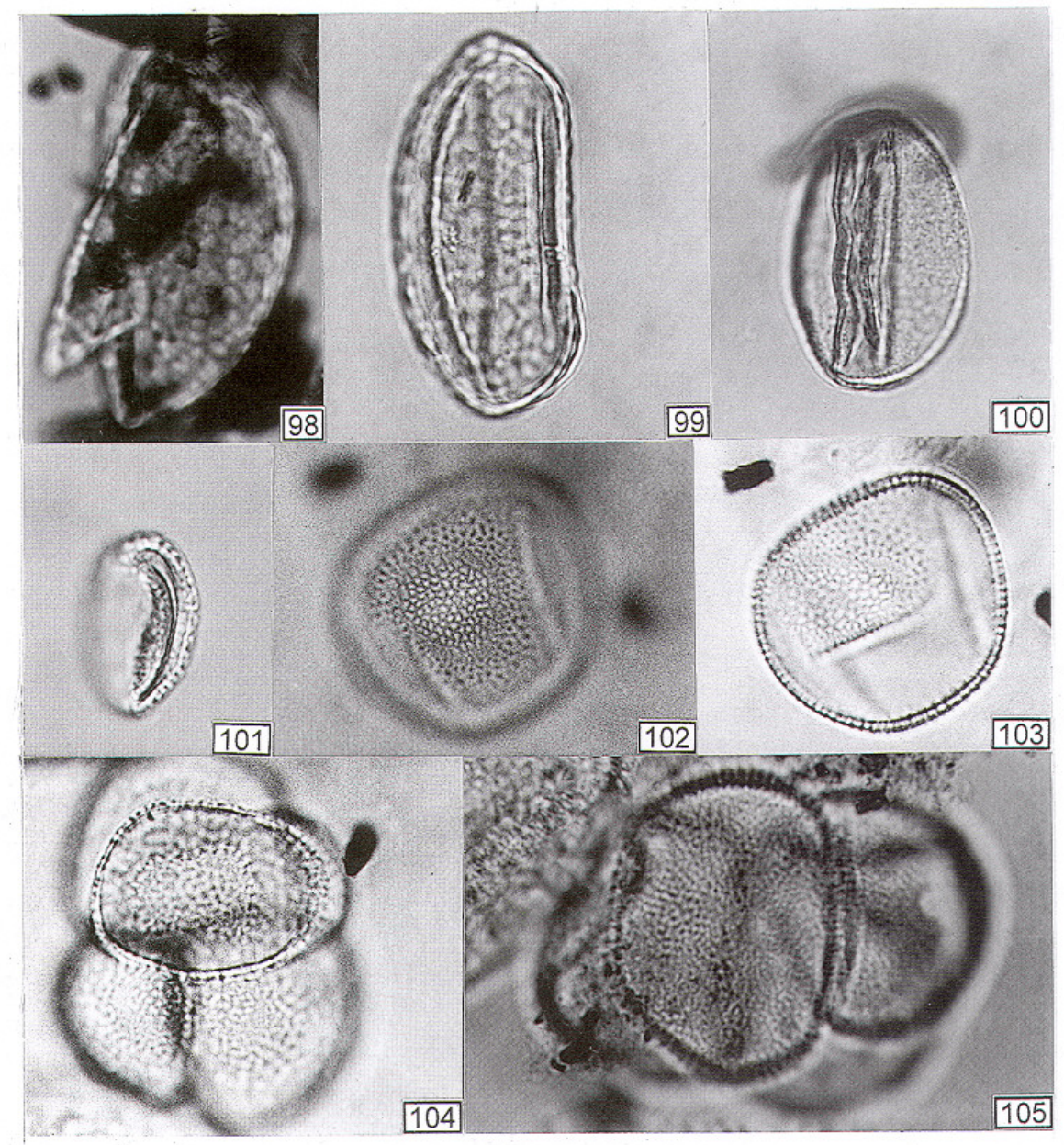

Lámina XII. PONTEDERIACEAE. Figura 98: Heteranthera 1 (VII, 18) (escala 1:450). Figura 99: Heteranthera 2 (VI, 38) (escala 1:900). Figura 100: Heteranthera 3 (IV, 19) (escala 1:1000). Figura 101: Heteranthera 4 (VI, 42) (escala 1:1000). POTAMOGETONACEAE. Figuras 102 y 103: Potamogeton sp. (VII, 26) (escala 1:1000). THYPHACEAE. Figuras 104 y 105: Thypha sp. (VII, 23 y 32) (104, escala $1: 1000 ; 105$, escala $1: 700)$. 


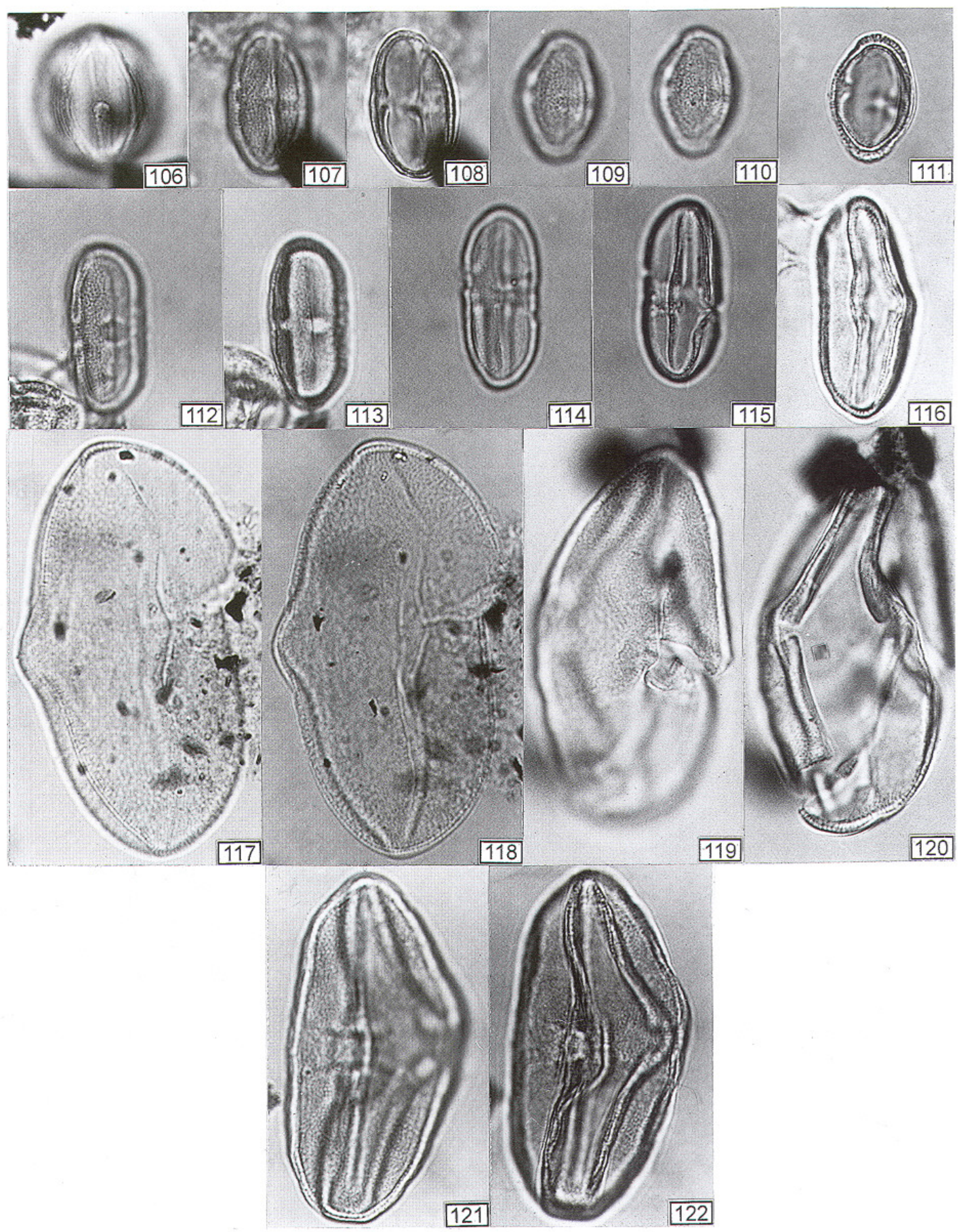

Lámina XIII. MAGNOLIOPSIDA. ACANTHACEAE. Figura 106: Acanthaceae (VII, 19) (escala 1:700). APIACEAE. Figuras 107 y 108: Berula erecta (IV, 17) (107, escala 1:1000; 108, escala 1:750). Figuras 109, 110 y 111: Hydrocotyle sp. (IV, 20) (escala 1:1000). Figuras 112 y 113: Apiaceae 1 (IV, 17) (escala 1:1000). Figuras 114 y 115: Apiaceae 2 (IV, 20). Figura 116: Apiaceae 3 (VII, 26) (escala 1:1000). Figuras 117 y 118: Apiaceae 4 (VII, 32) (escala 1:1000). Figuras 119 y 120: Apiaceae 5 (II, 2) (escala 1:1000). Figuras 121 y 122: Apiaceae $6(\mathrm{IV}, 17)$ (escala 1:1200). 


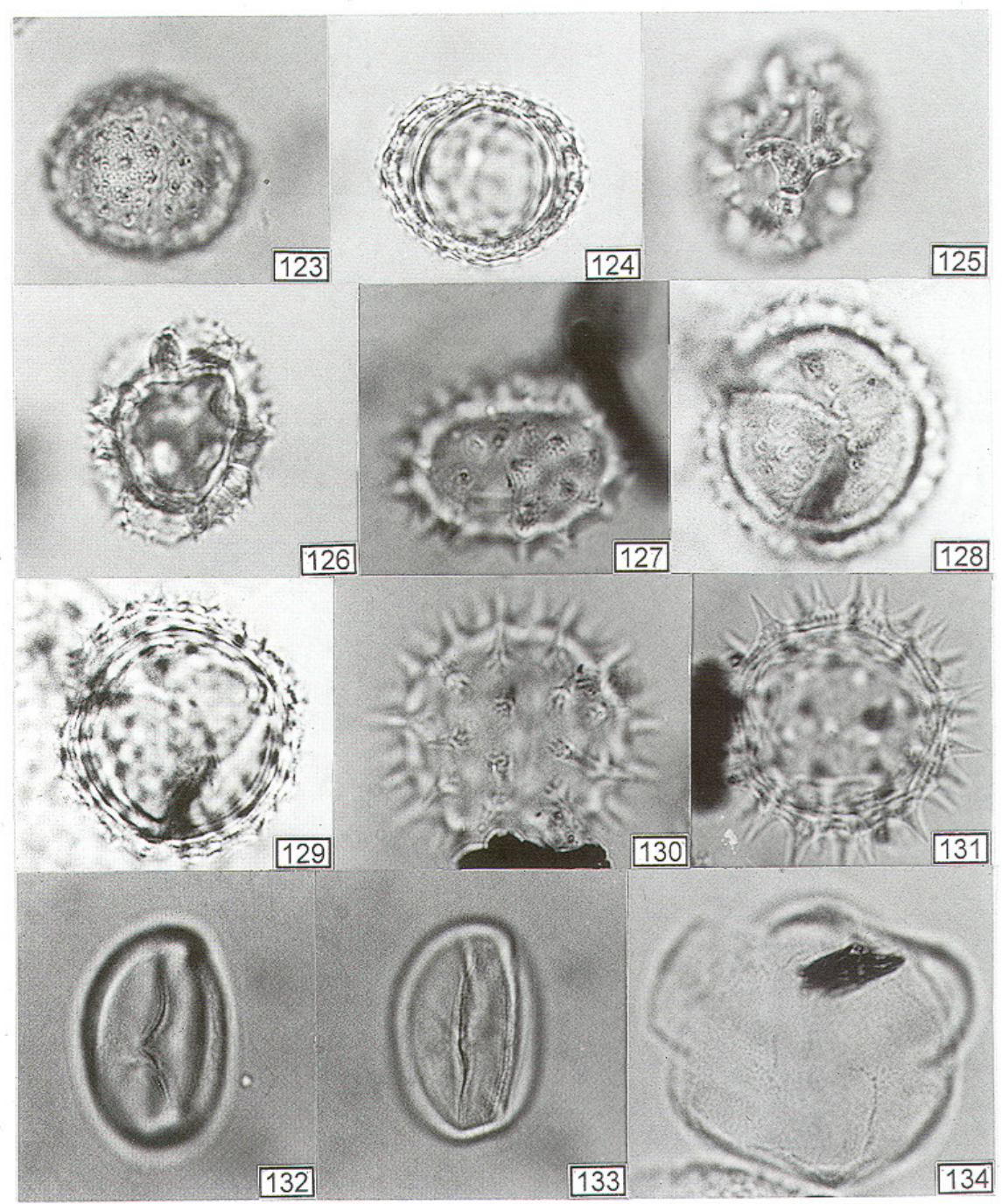

Lámina XIV. ASTERACEAE. Figuras 123 y 124: Ambrosia sp. (II, 6; III, 19) (escala 1:1000). Figuras 125 y 126: Lactuceae (II, 5) (escala 1:1000). Figura 127: Asteraceae 1 (VII, 18) (escala 1:1000). Figuras 128 y 129: Asteraceae 2 (VII, 27) (escala 1:1000). Figuras 130 y 131: Asteraceae 3 (VII, 30) (escala 1:1000). aff. BATIDACEAE. Figuras 132 y 133: aff. Batis maritima (VII,17) (escala 1:1000). BERBERIDACEAE. Figura 134: Berberis sp. (IV, 22). 
Beatriz Ludlow-Wiechers, Lucía Almeida-Leñero y YoKo Sugiura

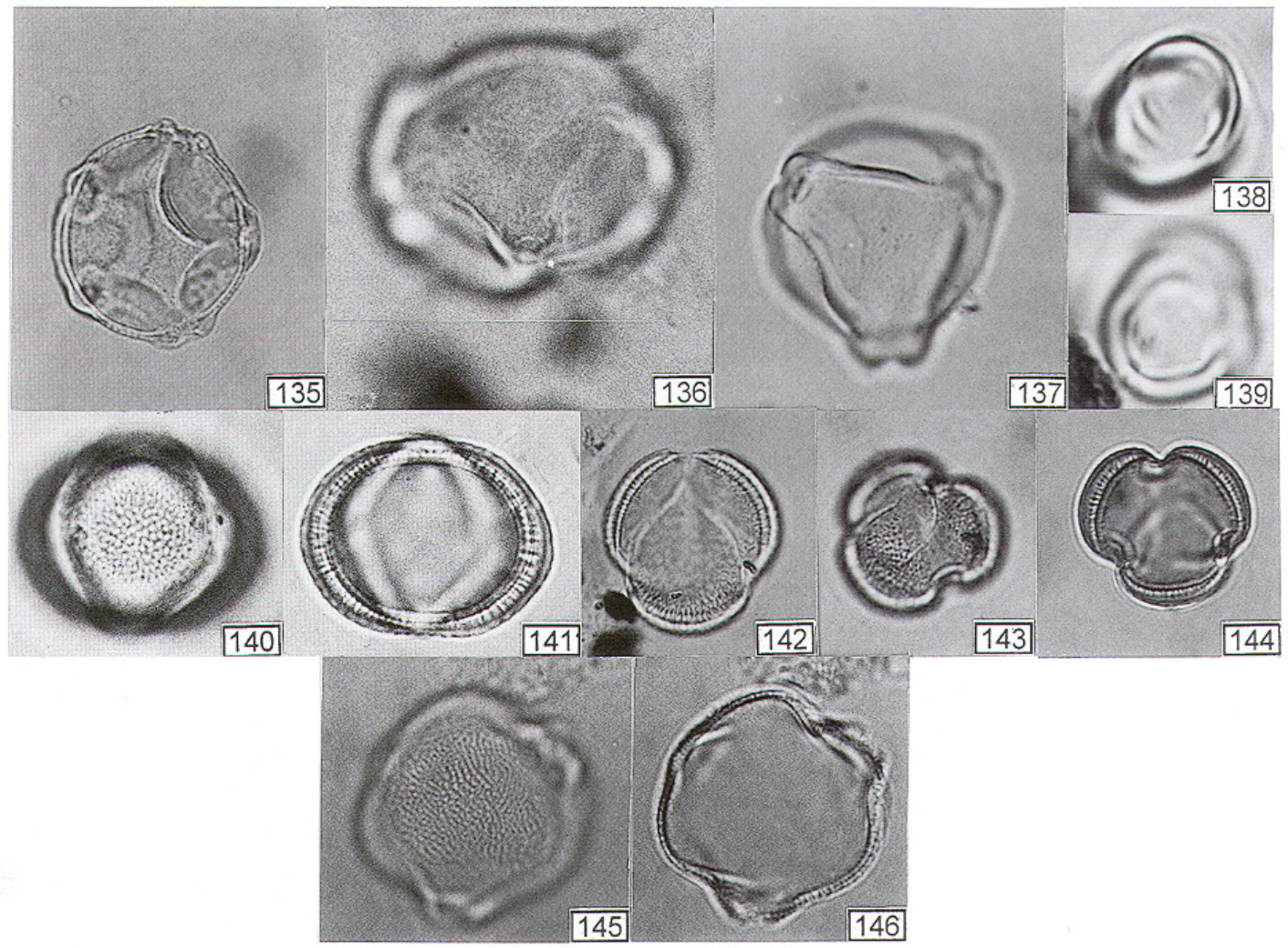

Lámina XV. BETULACEAE. Figura 135: Alnus 1 (V, 46) (escala 1:1000). Figura 136: Alnus 2 (VII, 17) (escala 1:1000). Figura 137: Alnus 3 (VII, 32) (escala 1:1000). BORAGINACEAE. Figuras 138 y 139: Lithospermum sp. (VII, 17) (escala 1:1000). BRASSICACEAE. Figuras 140, 141, 142, 143 y 144: Rorippa sp. (VII, 26 y 30) (escala 1:1000). BURSERACEAE. Figuras 145 y 146: Bursera sp. (VI, 24) (escala 1:1000). 
Palinomorfos del Holoceno de la cuenca alta del río Lerma

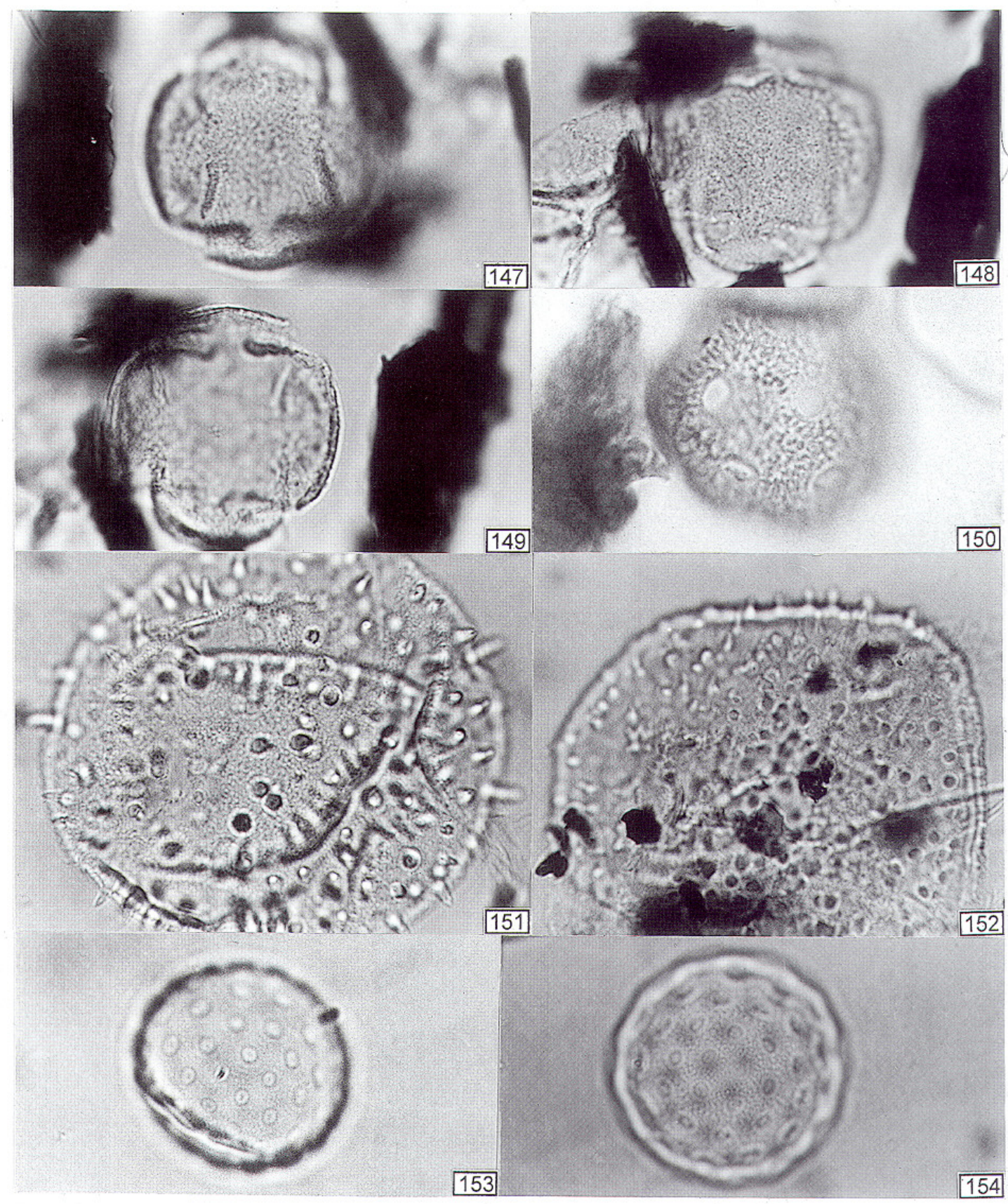

Lámina XVI. CACTACEAE. Figuras 147, 148 y 149: Heliocereus sp. (VII, 19) (escala 1:1000). CARYOPHYLLACEAE. Figura 150: Arenaria sp. (VII, 29) (escala 1:1000). CUCURBITACEAE. Figura 151: Cucurbita 1 (II, 4) (escala 1:1000). Figura 152: Cucurbita 2 (II, 3) (escala 1:1000). CHENOPODIACEAE-AMARANTHACEAE. Figura 153: Cheno-Am 1 (VII, 30) (escala 1:1200). Figura 154: ChenoAm 2 (VII, 32) (escala 1:1000). 


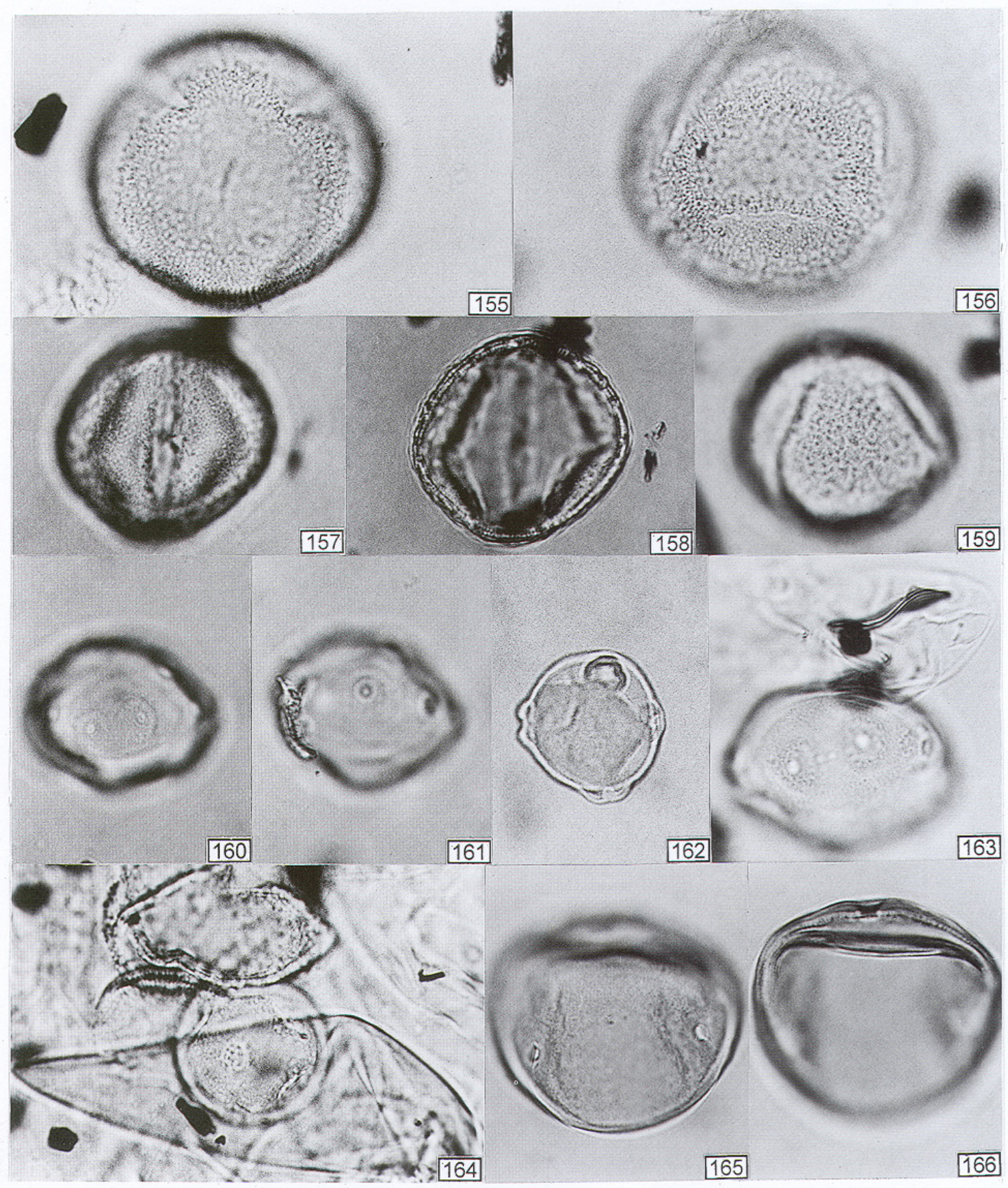

Lámina XVII. CONVOLVULACEAE. Figuras 155 y 156: Convolvulaceae (VII, 23) (escala 1:9000). FAGACEAE. Figuras 157, 158 y 159: Quercus sp. (VII, 17) (escala 1:1000). HALORAGACEAE. Figuras 160, 161 y 162: Myriophyllum 1 (VII, 24) (escala 1:1000). Figura 163: Myriophyllum 2 (VII, 16) (escala 1:1000). HAMAMELIDACEAE. Figura 164: Liquidambar sp. (VII, 27) (escala 1:1000). JUGLANDACEAE. Figuras 165 y 166: aff. Carya sp. (IV, 25) (escala 1:1000). 


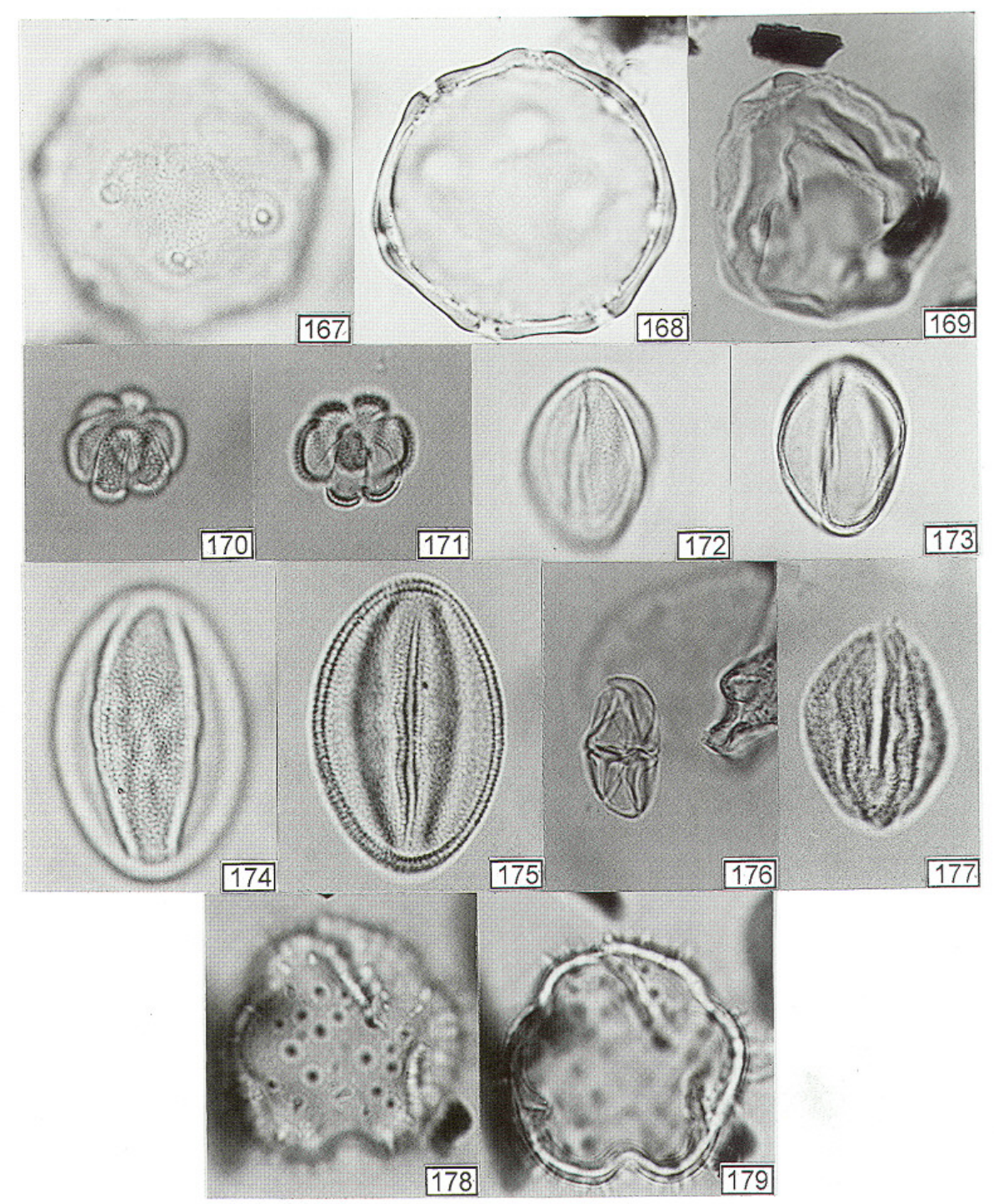

Lámina XVIII. Figuras 167, 168 y 169: Juglans sp. (VII, 15) (escala 1:1000). LAMIACEAE. Figuras 170 y 171: Lamiaceae (IV,19) (escala 1:1000). LEGUMINOSAE. Figuras 172 y 173: Cassia 1 (IV, 20) (escala 1:1000). Figuras 174 y 175: Cassia 2 (IV, 20) (escala 1:900). Figura 176: Mimosa sp. (IV, 19) (escala 1:1000). LENTIBULARIACEAE. Figura 177: aff. Utricularia 1 (II, 2) (escala 1:1000). LORANTHACEAE. Figuras 178 y 179: Arceuthobium sp. (VII, 24) (escala 1:1000). 
Beatriz Ludlow-Wiechers, Lucía Almeida-Leñero y Yoko Sugiura

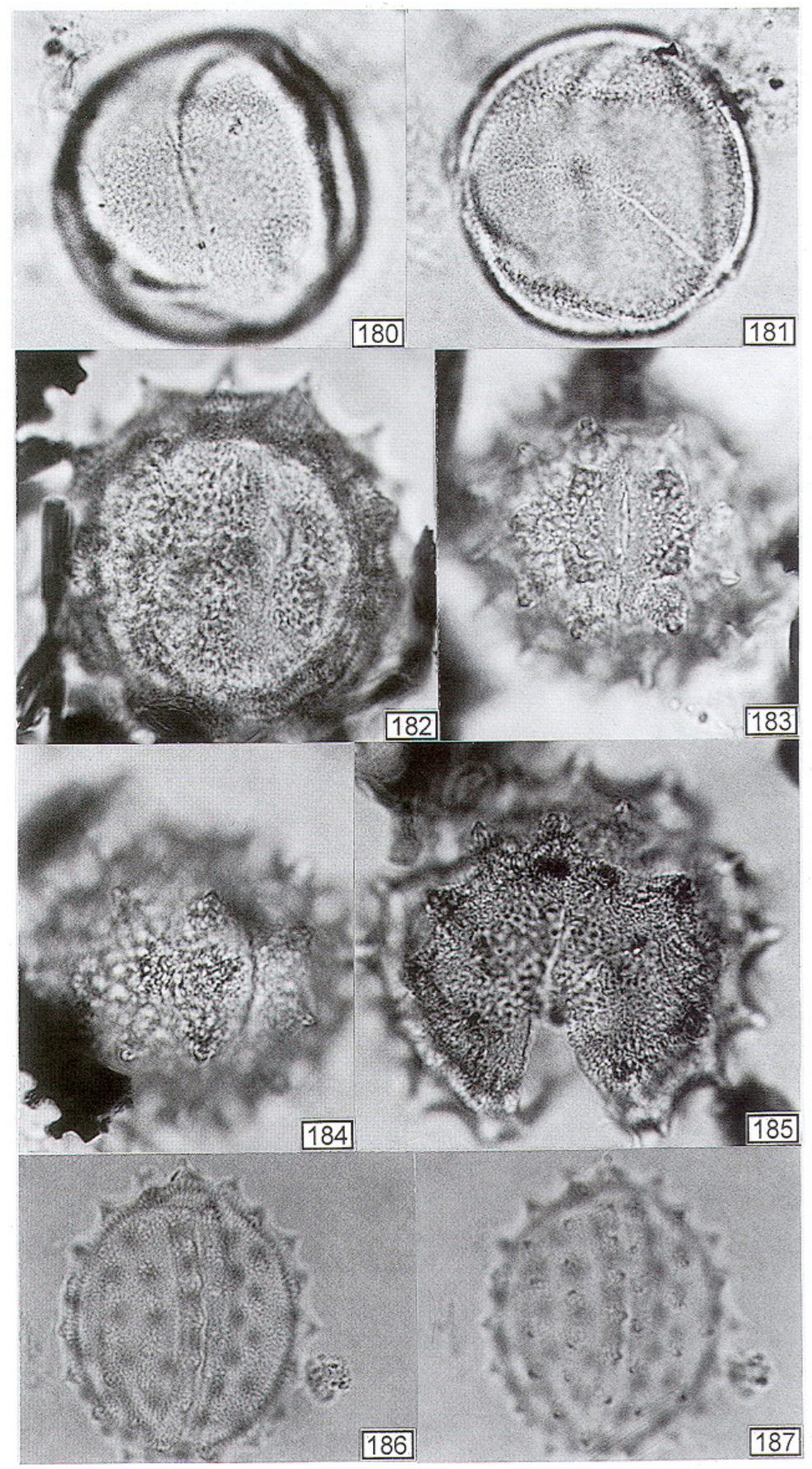

Lámina XIX. MALPIGHIACEAE. Figuras 180 y 181: Malpighiaceae (VII, 26) (escala 1:1000). MALVACEAE, Figura 182, 183,184 y 185: Malvaceae 1 (VII, 16 y 26) (escala 1:1000). Figuras 186 y 187: Malvaceae 2 (IV, 23) (escala 1:1000). MENYANTHACEAE. Figura 188: Nymphoides fallax (VII, 26) (escala 1:1000). MYRICACEAE. Figura 189: Myrica sp. (VI, 46) (escala 1:1000). 


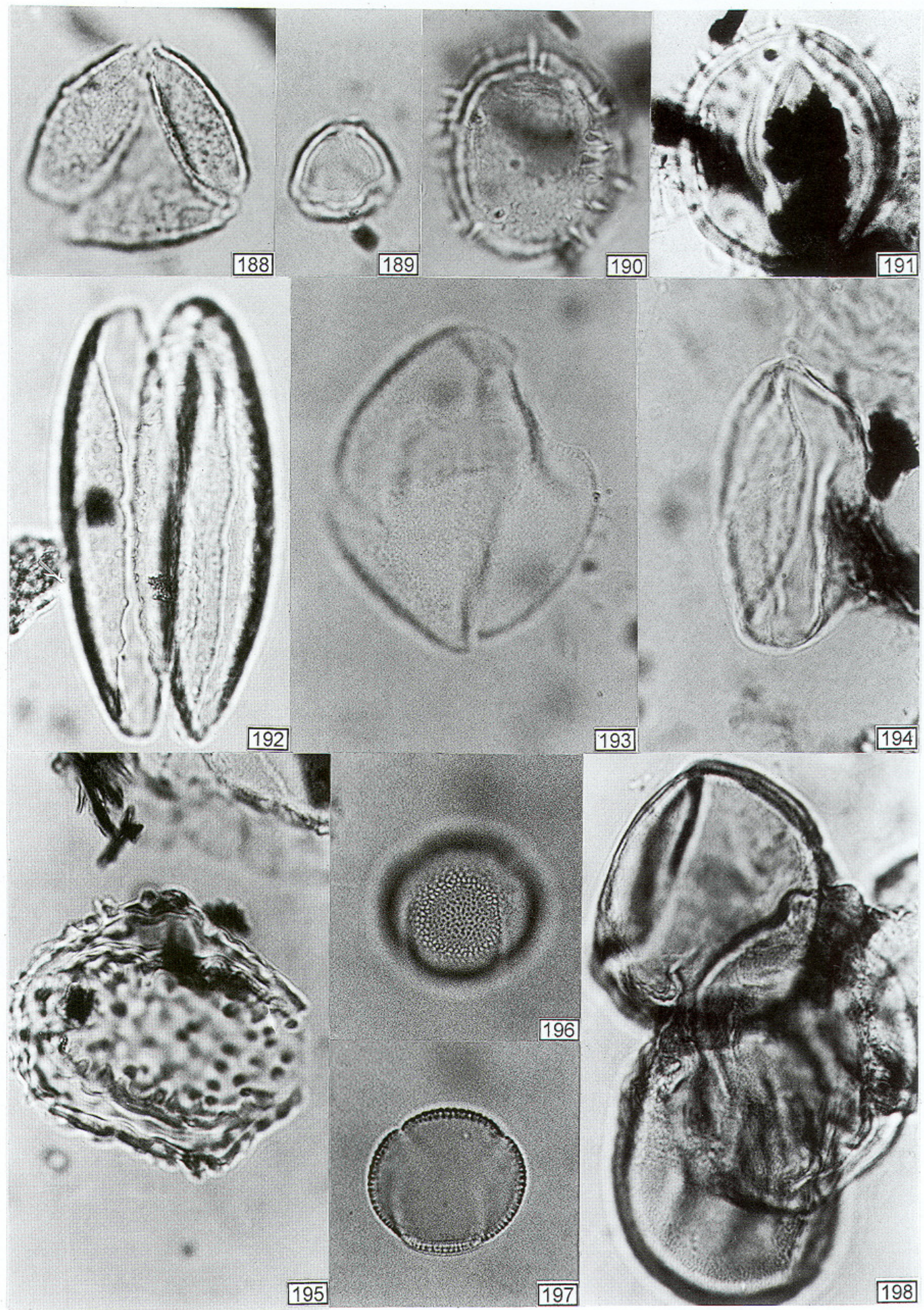

Lámina XX. NYMPHACEAE. Figuras 190 y 191: Nuphar sp. (VII, 17 y 29) (escala 1:1000). Figuras 192, 193 y 194: Nymphaea ampla (VI, 46; VII, 23) (192, escala 1:1200; 193, 194, escala 1:1000). Figura 195: aff. Nymphaea mexicana (II, 5) (escala 1:1000). OLEACEAE. Figuras 196 y 197: Fraxinus sp. (VII, 23) (escala 1:1000). ONAGRACEAE. Figura 198: Ludwigia sp. (VI, 24) (escala 1:1000). 


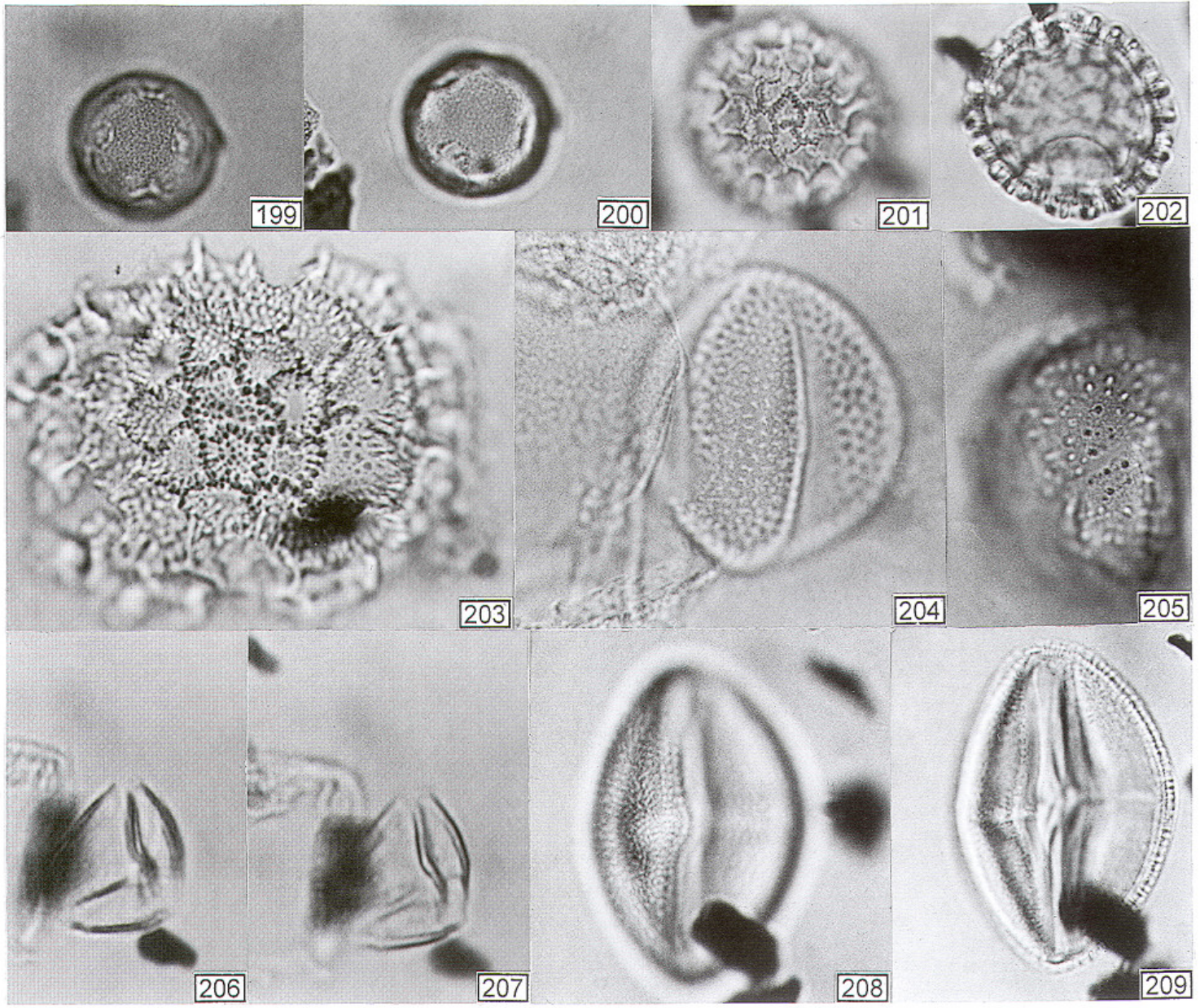

Lámina XXI. PLANTAGINACEAE. Figuras 199 y 200: Plantago sp. (IV, 17) (escala 1:1000). POLYGONACEAE. Figuras 201 y 202 : Polygonum 1 (VII, 17) (escala 1:1000). Figura 203: Polygonum 2 (VII, 32) (escala 1:1000). Figura 204: Polygonaceae (IV, 21) (escala 1:1000). RANUNCULACEAE. Figura 205: Ranunculus sp. (VII, 14) (escala 1:1000). RHAMNACEAE. Figuras 206 y 207: Rhamnus sp. (VII, 18) (escala 1:800). ROSACEAE. Figuras 208 y 209: Prunus sp. (VII, 17) (escala 1:1000). 


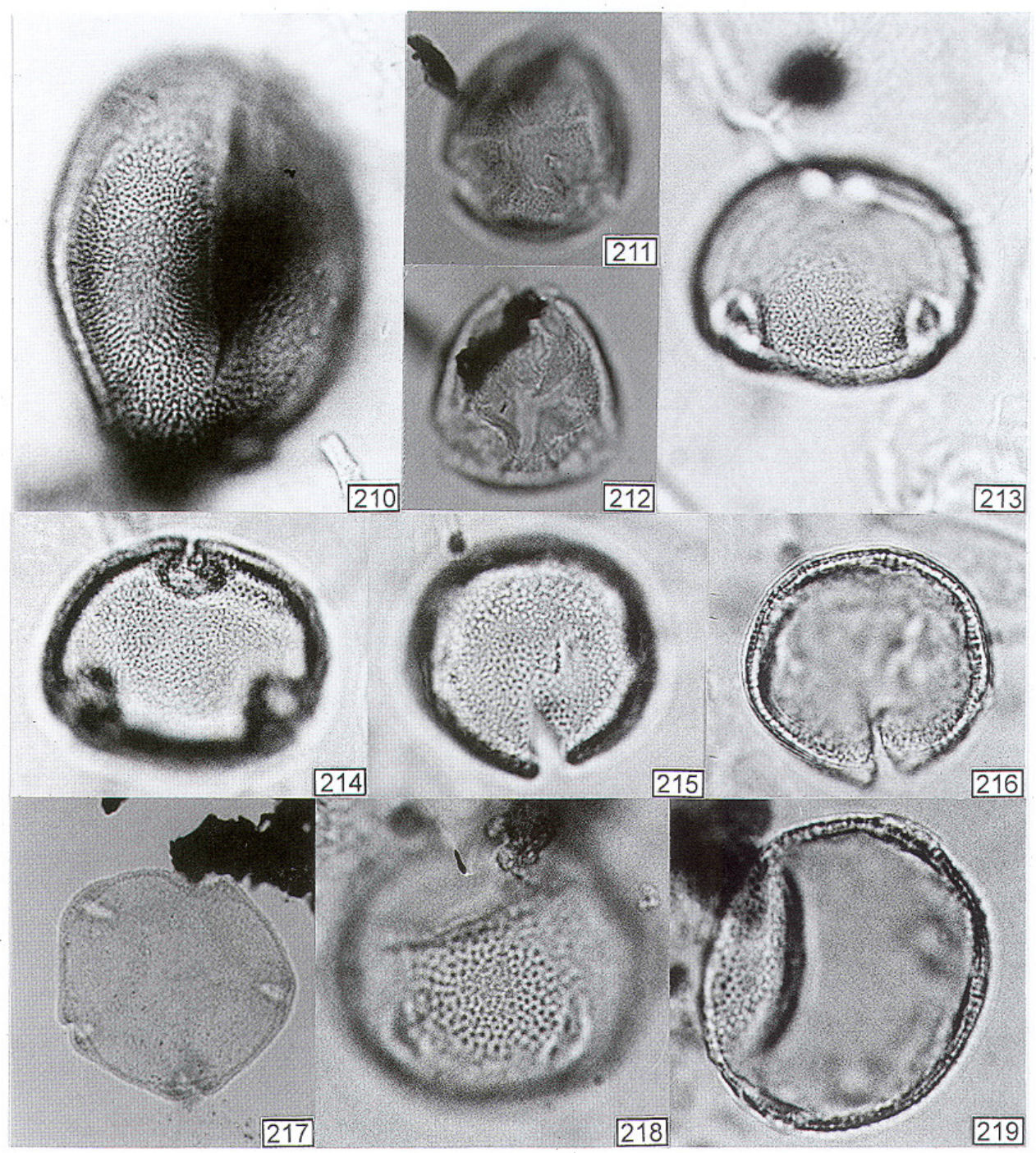

Lámina XXII. Figura 210: Rosaceae (VII, 23) (escala 1:1000). RUBIACEAE. Figuras 211 y 212: aff. Asemnantha sp. (VII, 19) (escala 1:1000). Figuras 213 y 214: Rubiaceae 1 (VII, 27) (escala 1:1000). Figuras 215 y 216: Rubiaceae 2 (VII, 27) (escala 1:1000). Figura 217: Rubiaceae 3 (VII, 31) (escala 1:1000). Figuras 218 y 219: Rubiaceae 4 (VII, 23) (escala 1:1000). 


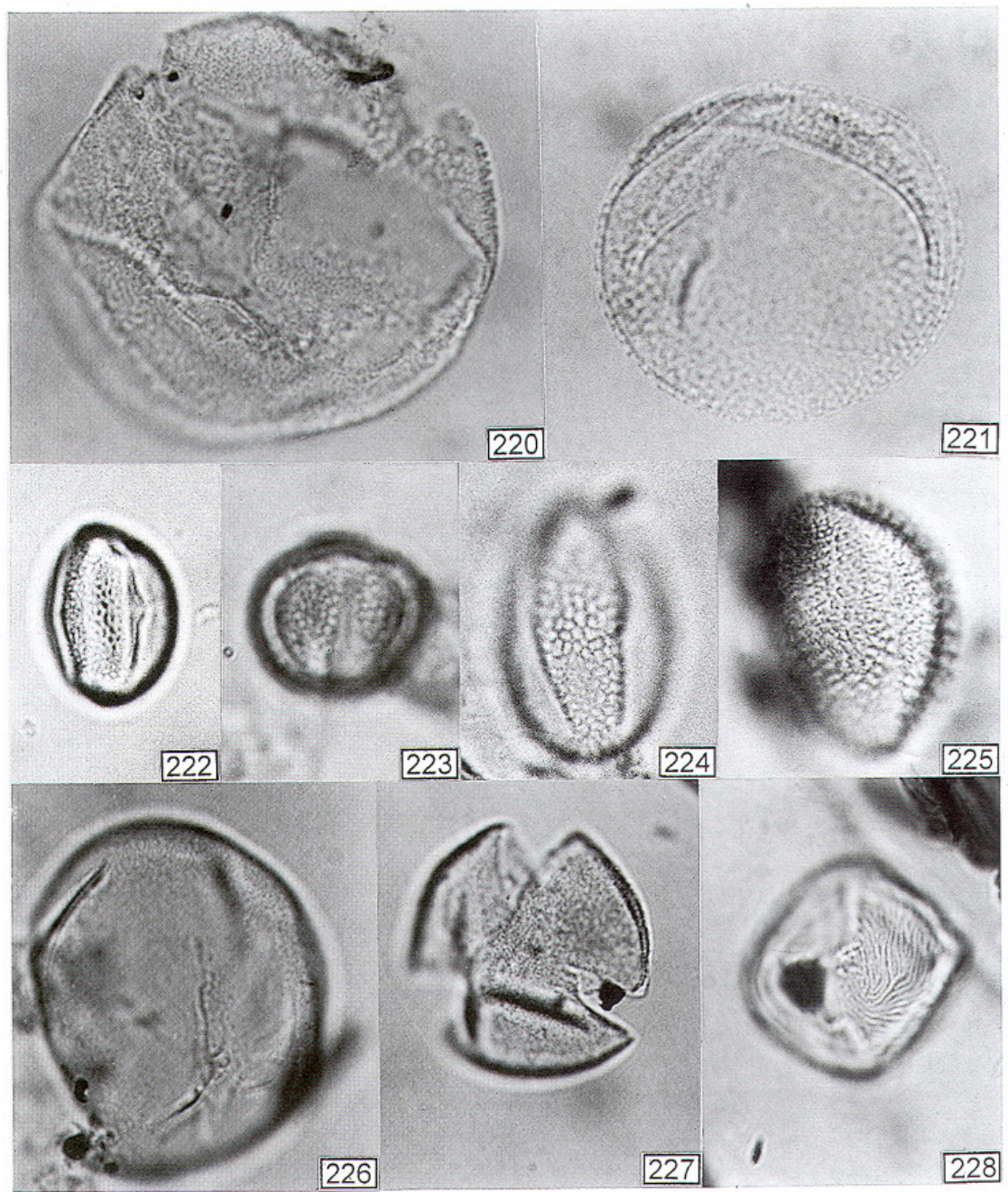

Lámina XXIII. SALICACEAE. Figura 220: Populus 1 (VII, 32) (escala 1:1000). Figura 221: Populus 3 (IV, 22) (escala 1:800). Figura 222: Salix 1 (VII, 26) (escala 1:1000). Figura 223: Salix 2 (IV, 17) (escala 1:1000). Figura 224: Salix 3 (VII, 24) (escala 1:1000). Figura 225: Salix 4 (II, 2) (escala 1:1000). SCROPHULARIACEAE. Figura 226: aff. Scrophulariaceae 1 (VII, 32) (escala 1:1000). Figura 227: aff. Scrophulariaceae 2 (VII, 30) (escala 1:1000). SOLANACEAE. Figuras 228: Datura sp. (VII, 17) (escala 1:1000). 


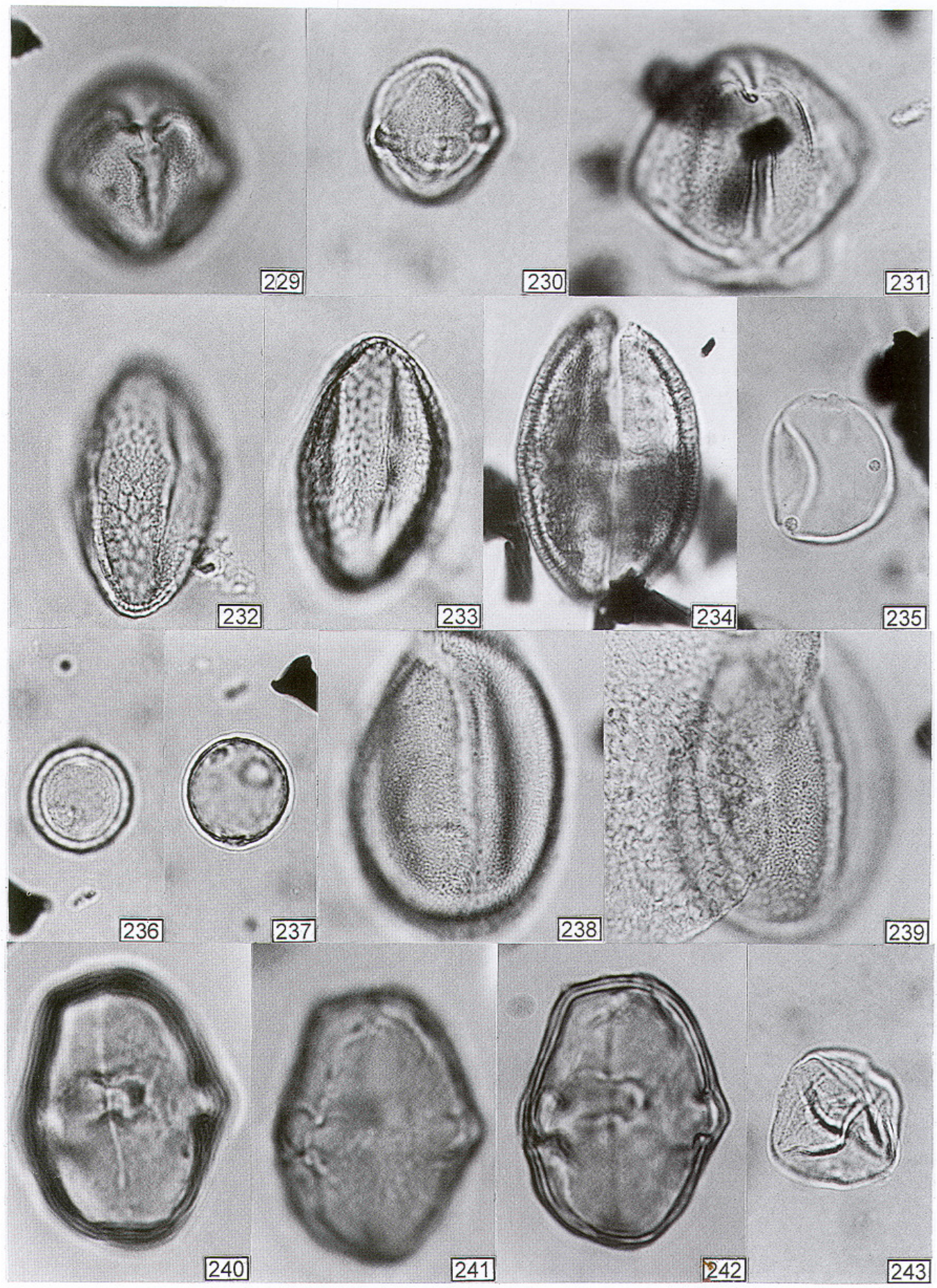

Lámina XXIV. Figura 229: Solanum sp. (IV, 19) (escala 1:1000). Figura 230: Solanaceae 1 (IV, 20) (escala 1:1000). Figura 231: Solanaceae 2 (VII, 17) (escala 1:1000). TILIACEAE. Figuras 232 y 233: Heliocarpus sp. (II, 2) (escala 1:800). Figura 234: Tiliaceae 1 (IV, 18) (escala 1:900). ULMACEAE, Figura 235: aff. Celtis (VI, 46) (escala 1:1000). URTICACEAE. Figuras 236 y 237: Urtica sp. (VII, 14) (escala 1:900). VALERIANACEAE. Figuras 238 y 239: Valeriana $\mathrm{sp}$. (IV, 16) (escala 1:700). VERBENACEAE. Figuras 240, 241 y 242: Lantana sp. (IV, 17) (escala 1:1000). Figura 243: Lippia sp. (VII, 14) (escala 1:800). 


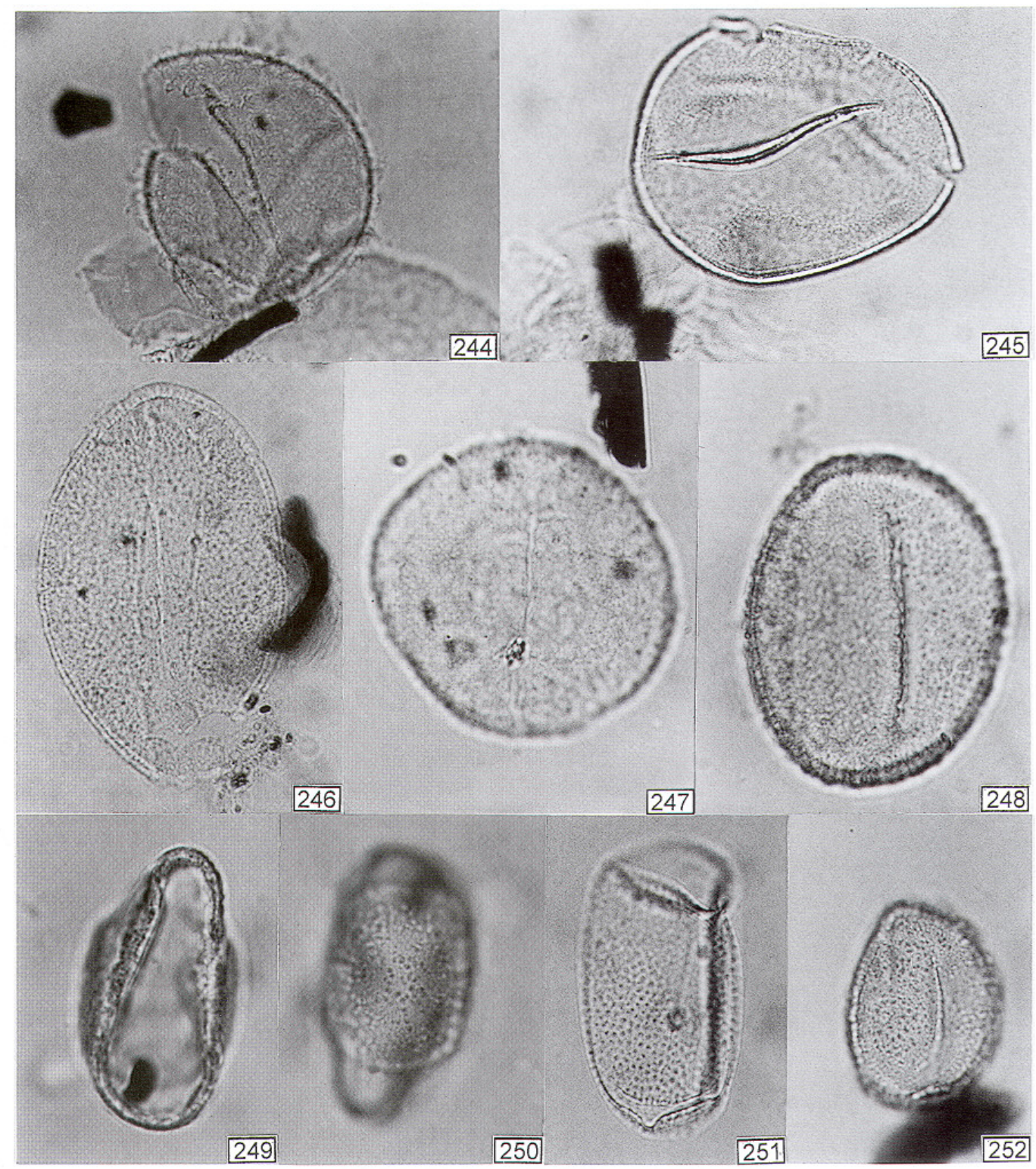

Lámina XXV. INDETERMINADAS. Figura 244: Inaperturado 1 (VII, 30) (escala 1:1000). Figura 245: Inaperturado 2 (VII, 3). Figura 246: Monosulcado 1 (VII, 32) (escala 1:1000). Figura 247: Monosulcado 2 (VII, 17) (escala 1:1000). Figura 248: Monosulcado 3 (probablemente Bromeliaceae), (VII, 19) (escala 1:1000). Figuras 249 y 250: Monosulcado 4 (VII, 24) (escala 1:1000). Figura 251: Monosulcado 5 (IV, 14) (escala 1:1000). Figura 252: Monosulcado 6 (IV, 19) (escala 1:1000). 


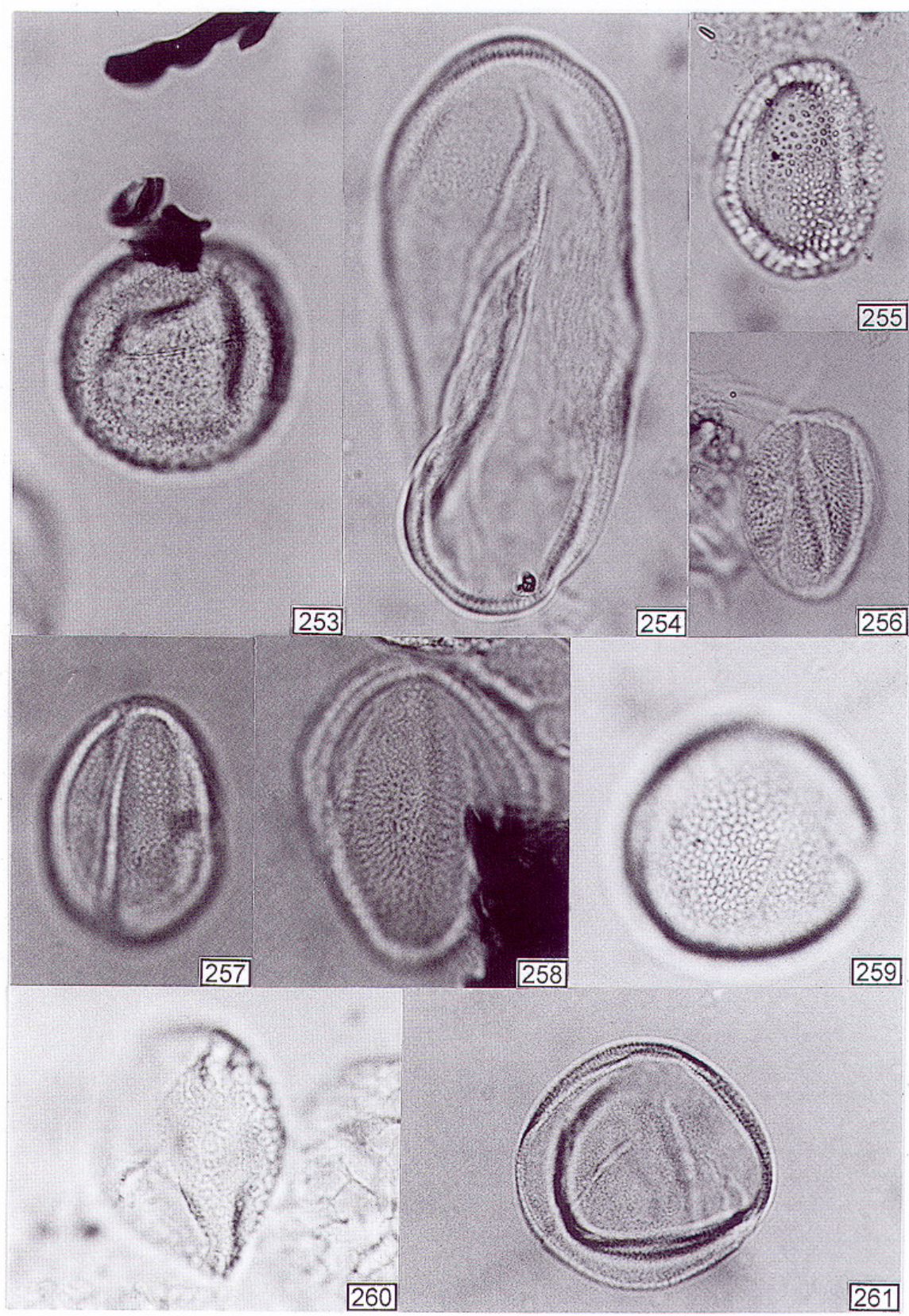

Lámina XXVI. Figura 253: Monosulcado 7 (IV, 19) (escala 1:1000). Figura 254: Monosulcado 8 (IV, 22) (escala 1:900). Figura 255: Tricolpado 1 (probablemente Rubiaceae) (VI, 46) (escala 1:1000). Figura 256: Tricolpado 2 (IV, 20) (escala 1:1000). Figura 257: Tricolpado 3 (VI, 46) (escala 1:1000). Figura 258: Tricolpado 4 (IV, 22) (escala 1:1000). Figura 259: Tricolpado 5 (VII, 24) (escala 1:900). Figura 260: Tricolpado 6 (VII, 24) (escala 1:800). Figura 261: Tricolpado 7 (IV, 24) (escala 1:1000). 


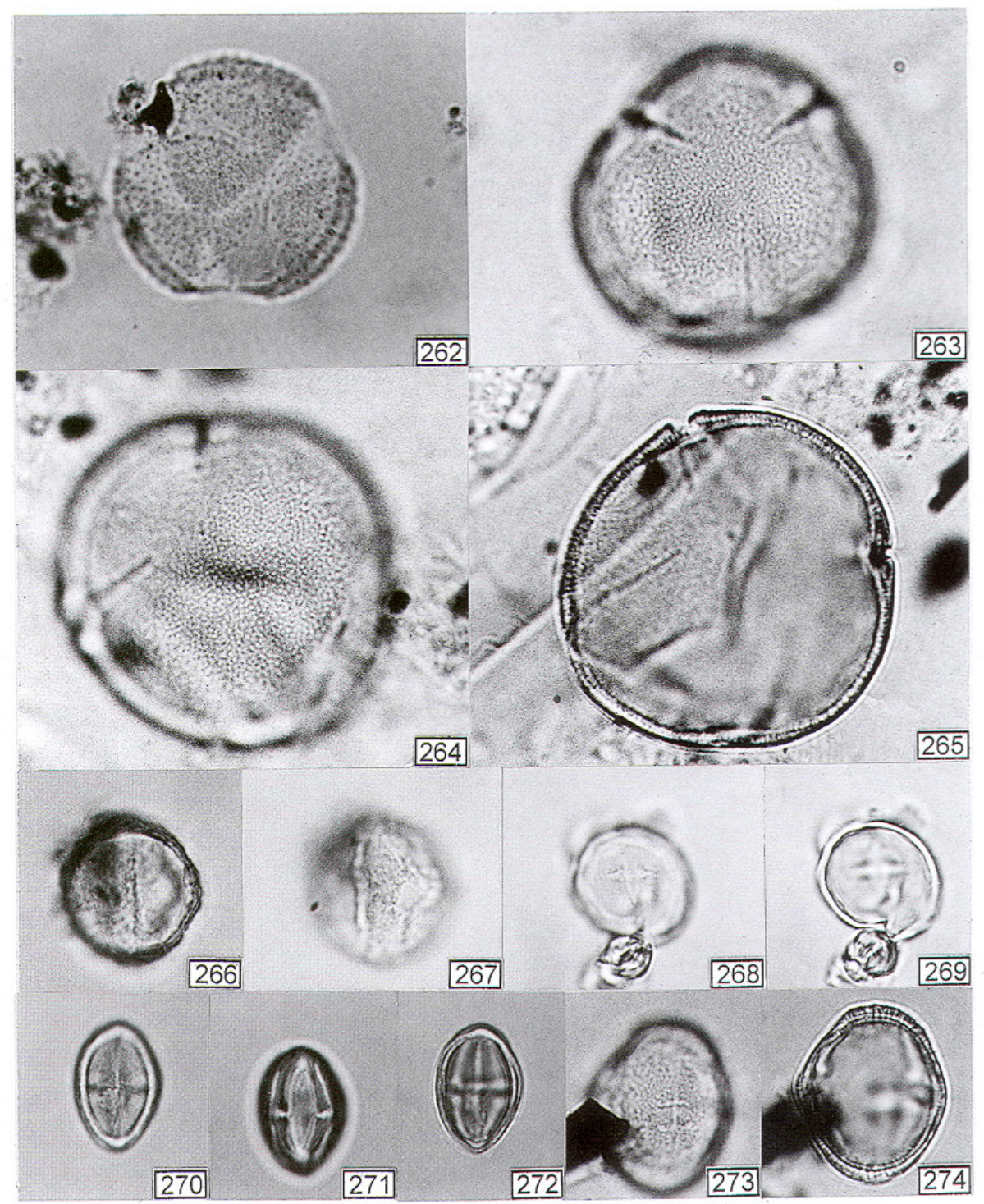

Lámina XXVII. Figura 262: Tricolpado 8 (VII, 32) (escala 1:1000). Figura 263: Tricolpado 9 (probablemente Leguminosae) (VII, 26) (escala 1:900). Figuras 264 y 265: Tetracolpado (VII, 24) (escala 1:1000). Figuras 266 y 267: Tricolpado/tricolporoidado (VII, 38) (escala 1:1000). Figuras 268 y 269: Tricolporado 1 (IV, 20) (escala 1:1000). Figuras 270, 271 y 272: Tricolporado 2 (IV, 19) (escala 1:1000). Figuras 273 y 274: Tricolporado 3 (probablemente Apiaceae) (IV, 22) (escala 1:1000). 


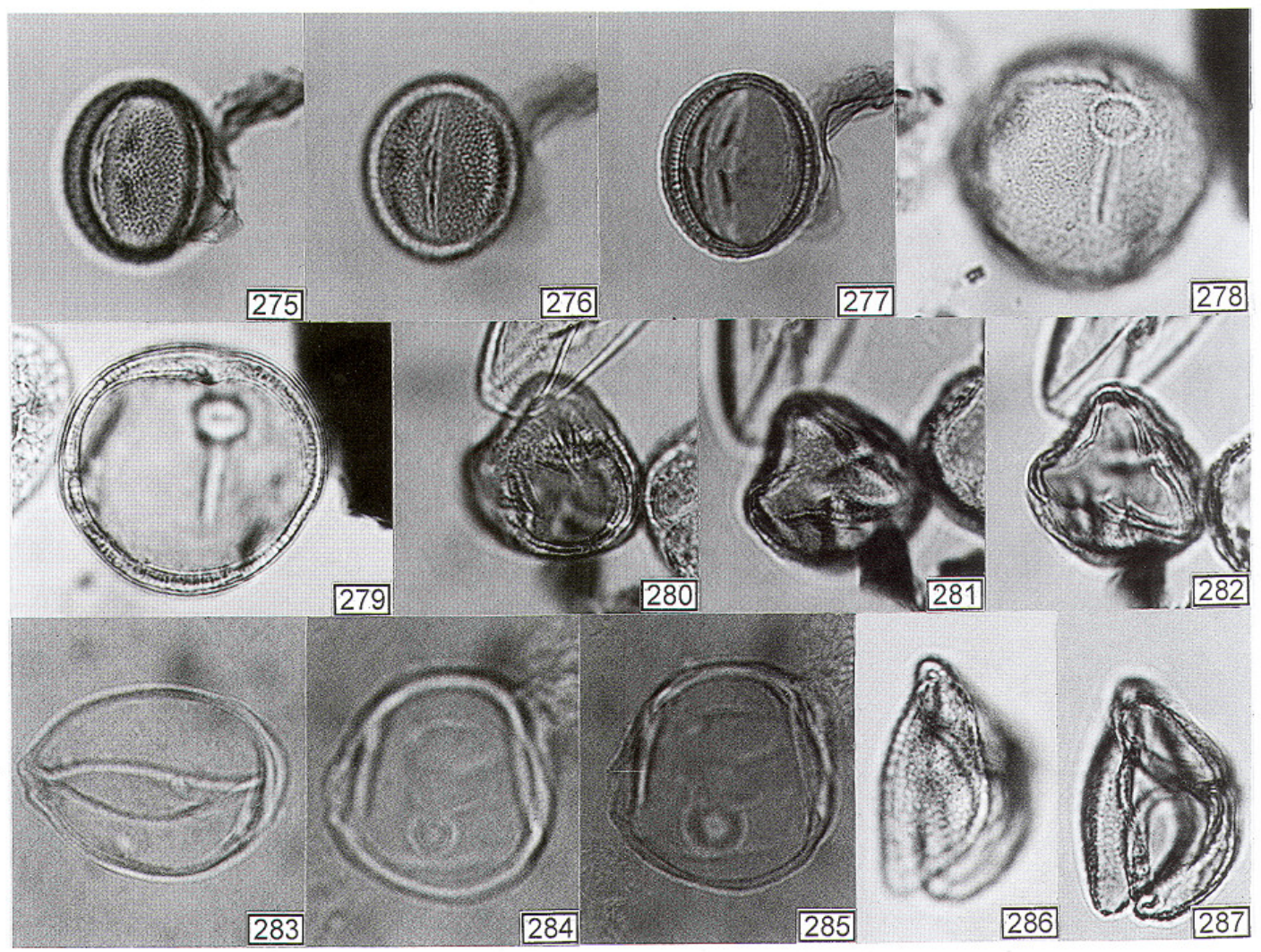

Lámina XXVIII. Figuras 275, 276 y 277: Tricolporado 4 (IV, 19) (escala 1:1000). Figuras 278 y 279: Tricolporado 5 (IV, 18) (escala 1:1000). Figuras 280, 281 y 282: Pentacolporado (IV, 17) (escala 1:1000). Figura 283: Pentaporado (IV, 23) (escala 1:1000). Figura 284 y 285: Tetraporado/pentaporado (IV, 23) (escala 1:1000). Figuras 286 y 287: Tétrada (II, 8) (escala 1:1000). 